DIEGO DE QUEIROZ MACEDO

\title{
Experimentos em simulações paralelas do Dilema do Prisioneiro com $\boldsymbol{n}$ jogadores
}


DIEGO DE QUEIROZ MACEDO

\title{
Experimentos em simulações paralelas do Dilema do Prisioneiro com $\boldsymbol{n}$ jogadores
}

\author{
Dissertação apresentada à Escola \\ Politécnica da Universidade de São \\ Paulo para obtenção do título de Mestre \\ em Engenharia Elétrica. \\ Área de Concentração: \\ Sistemas Digitais \\ Orientador: \\ Prof. Dr. Jaime Simão Sichman
}

São Paulo 
Este exemplar foi revisado e alterado em relação à versão original, sob responsabilidade única do autor e com a anuência de seu orientador.

São Paulo, 24 de outubro de 2011.

Assinatura do autor:

Assinatura do orientador:

Ficha Catalográfica

Macedo, Diego de Queiroz

Experimentos em simulações paralelas do Dilema do Prisioneiro com $n$ jogadores / D. Q. Macedo. — ed. rev. - São Paulo, 2011. $84 \mathrm{p}$.

Dissertação (Mestrado) - Escola Politécnica da Universidade de São Paulo. Departamento de Engenharia de Computação e Sistemas Digitais.

1. Inteligência artificial. 2. Sistemas multiagentes. 3. Teoria dos jogos. 4. Computação evolutiva. 5. Simulação distribuída. I. Universidade de São Paulo. Escola Politécnica. Departamento de Engenharia de Computação e Sistemas Digitais. II. t. 
Dedico este trabalho ao meu irmão, Maickon. 


\section{AGRADECIMENTOS}

Primeiramente, agradeço a Escola Politécnica da Universidade de São Paulo pela oportunidade e ao Conselho Nacional de Desenvolvimento Científico e Tecnológico pelo apoio financeiro. Agradeço também ao Laboratório de Computação Científica Avançada da Universidade de São Paulo pela disponibilização dos recursos computacionais necessários para a elaboração dessa pesquisa.

Ao professor Jaime Simão Sichman, pela orientação, dedicação, paciência, compreensão e estímulo transmitidos durante todo o trabalho.

Ao Inácio Guerberoff Lanari Bó, pelos comentários, dicas e por toda ajuda e atenção fornecida que foram essenciais para o desenvolvimento deste projeto.

A todos os membros do Laboratório de Técnicas Inteligentes, alunos, funcionário e docentes, em especial ao Alan Cleber Borim, Luis Gustavo Nardin, Nicolau Werneck, Tiago Matos e Yannick Plaino Bergamo, não apenas pelo companheirismo, mas pela ajuda e apoio despendidos diariamente.

Aos professores Ricardo Luis de Azevedo da Rocha e João José Neto pelos poucos, porém importantes, momentos de estudo e reflexão que desenvolveram minha mais profunda admiração pela pesquisa e pelo trabalho acadêmico e científico.

Aos professores Sidnei Alves de Araújo, Fabio Henrique Pereira, Cleber Gustavo Dias, Marcos Alberto Bussab e Gregorio Perez Peiro por terem acreditado no meu trabalho e terem me guiado à pesquisa acadêmica.

Ao primo, Adriano, e amigos, pelos momentos de distração.

A minha mãe, Valdemira, pela educação, compreensão e apoio que foram indispensáveis para a execução deste trabalho.

Ao meu pai, Juarez, que descansa em paz, por todos ensinamentos, orientações, apoio e carinho que somente um pai poderia dar e que formaram a pessoa que sou hoje. A ele deixo não apenas um agradecimento, mas minha eterna gratidão.

A todos que não couberam aqui, mas que colaboraram, direta ou indiretamente, para a execução deste trabalho. 
Nem tudo que se enfrenta pode ser modificado, mas nada pode ser modificado sem que seja enfrentado.

(James Baldwin) 


\section{RESUMO}

O Dilema do Prisioneiro com $n$ jogadores é um problema que ilustra a dificuldade na formação da cooperação em sociedades de indivíduos racionais. Diversos trabalhos foram feitos no sentido de compreender melhor os fatores que influenciam o surgimento e a evolução da cooperação nessas sociedades, sendo que muitos desses mostraram que a simulação deste tipo de problema carece de escalabilidade, o que impede a realização de experimentos que envolvam uma grande quantidade de agentes ou de parâmetros de teste. Este trabalho tem o intuito de aplicar conceitos de computação paralela para tratar este problema. Para tal, foi desenvolvido um sistema denominado $\mathrm{PS}_{2} \mathrm{E}_{2}$, evolução de um trabalho anterior, cuja utilização em alguns cenários possibilitou a verificação da influência de alguns parâmetros - tais como o tamanho da população e a expressividade do modelo de representação de estratégias - na utilidade global de um conjunto de agentes que jogam o Dilema do Prisioneiro com $n$ jogadores.

Palavras-chave: Autômatos adaptativos. Autômatos finitos. Computação evolutiva. Dilema do prisioneiro. Inteligência artificial. Simulação de jogos. Simulação distribuída. Sistemas multiagentes. Teoria dos jogos. 


\begin{abstract}
The $n$-Player Prisoner's Dilemma is a problem that illustrates the difficulty of cooperation formation in societies composed of rational individuals. Several studies were made to better understand the factors that influence the emergence and evolution of cooperation in these societies. Many of these showed that the simulation of this type of problem lacks scalability, which hinders the achievement of experiments involving a large number of agents or test parameters. This work intends to apply parallel computing concepts to treat this problem. To this end, it was developed a system called $\mathrm{PS}_{\mathbf{2}} \mathrm{E}_{2}$, an evolution of a previous work, whose utilization in some scenarios allowed the verification of the influence of some parameters - such as the population size and the expressiveness of the strategy representation model - in the global utility of a society of agents that play the $n$-Player Prisoner Dilemma.
\end{abstract}

Keywords: Adaptive automata. Artificial intelligence. Distributed simulation. Evolutionary computation. Finite automata. Game simulation. Game theory. Multi-agent systems. Prisoner's dilemma. 


\section{LISTA DE ILUSTRAÇÕES}

Figura 1.1 - Relação entre os modelos de simulação . . . . . . . . . . 22

Figura 2.1 - Exemplo de Autômato Finito . . . . . . . . . . . 31

Figura 2.2 - Exemplo de uma estratégia representada por um Autômato Finito . . . . . . . . . . . . . . . . . 34

Figura 2.3 - Execução de uma função adaptativa $\ldots \ldots \ldots \ldots$. . . . 35

Figura 2.4 - Exemplo de paralelização utilizando população global . . . . 40

Figura 2.5 - Exemplo de paralelização utilizando populações em ilhas . . 40

Figura 3.1 - Representação gráfica de um toro . . . . . . . . . . 41

Figura 3.2 - Exemplo de reticulado e vizinhança no limite do toro . . . . . 42

Figura 3.3 - Exemplos de vizinhança estendida . . . . . . . . . . . . 42

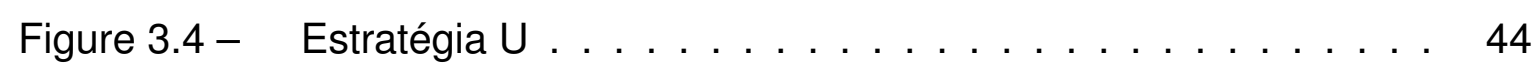

Figura $3.5-$ Estratégia TT5 . . . . . . . . . . . . . . . . . . 44

Figura $3.6-$ Estratégia CCD . . . . . . . . . . . . . . . . 45

Figura $3.7-$ Diagrama de execução do $\mathrm{S}_{2} \mathrm{E}_{2} \ldots \ldots \ldots$

Figura 4.1 - Exemplo de divisão do reticulado . . . . . . . . . . 50

Figura 4.2 - llustração dos agentes que devem ser clonados . . . . . . . 50

Figura 4.3 - Exemplo de um grupo não ótimo e ótimo em um reticulado. . 54

Figura 4.4 - llustração do menor grupo ótimo . . . . . . . . . . . . . 54

Figura 4.5 - Demonstração da função de sucessão e de otimização. . . . 55

Figura $4.6-$ Arquitetura do sistema $\mathrm{PS}_{2} \mathrm{E}_{2} \ldots \ldots \ldots \ldots$

Figura 4.7 - Associação do mecanismo de simulação evolutiva com o de mutação do sistema $\mathrm{PS}_{2} \mathrm{E}_{2} . \ldots \ldots \ldots \ldots$

Figura $4.8-$ Arquitetura mestre/escravo . . . . . . . . . . . . . 59

Figura 4.9 - Associação do mecanismo de simulação com o paralelizador

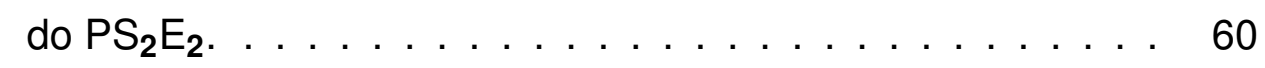




\section{LISTA DE ALGORITMOS}

Algoritmo 4.1 - Busca no espaço de grupos ótimos. . . . . . . . . . 56

Algoritmo 4.2 - Função de sucessão para vizinhanças de von Neumann de ordem $1 \ldots \ldots \ldots \ldots$. . . . . . . . . 57 


\section{LISTA DE GRÁFICOS}

Gráfico 2.1 - Utilidade em função dos jogadores que cooperam no NPPD . 29

Gráfico 5.1 - Baterias 01-06: Tempo médio de execução dos modelos B.AF

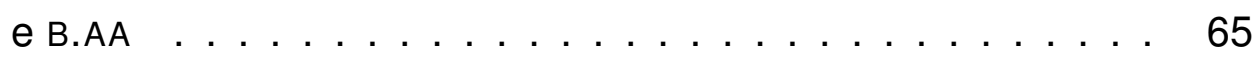

Gráfico 5.2 - Baterias 01-06: Eficiência da execução dos modelos B.AF e B.AA 65

Gráfico 5.3 - Baterias 01-06: Estimativa do tempo de execução de uma bateria dos modelos B.AF e B.AA . . . . . . . . . . . . 66

Gráfico 5.4 - Bateria 07: Utilidade média do conjunto de agentes . . . . . 68

Gráfico 5.5 - Baterias 08-09: Utilidade média do conjunto de agentes . . . 70

Gráfico 5.6 - Baterias 10-12: Utilidade média do conjunto de agentes . . . 72

Gráfico 5.7 - Bateria 13-17: Utilidade média do conjunto de agentes nos modelos B.AF e B.AA . . . . . . . . . . . . . . . 73

Gráfico 5.8 - Baterias 18-22: Utilidade média do conjunto de agentes nos modelos B.AF e B.AA . . . . . . . . . . . . . . 75 


\section{LISTA DE TABELAS}

Tabela 2.1 - Matriz de ganho do PD . . . . . . . . . . . . . . 24

Tabela 2.2 - Possíveis resultados do PD . . . . . . . . . . . . . . 25

Tabela 2.3 - Ganho dos jogadores em um NPPD com cinco jogadores . . . 28

Tabela 3.1 - Experimentos realizados por Bó . . . . . . . . . . . . . 45

Tabela 3.2 - Tempos médios de execução do $\mathrm{S}_{2} \mathrm{E}_{2} \ldots \ldots \ldots \ldots$

Tabela 3.3 - Tempos médios de execução das operações do modelo JE+AF 47

Tabela 3.4 - Tempos médios de execução das operações do modelo JE+AA 47

Tabela 5.1 - Baterias 01-06: Descrição dos experimentos realizados . . . . 63

Tabela 5.2 - Baterias 01-06: Tempos médios de execução dos experimentos para o modelo B.AF . . . . . . . . . . . . . 64

Tabela 5.3 - Baterias 01-06: Tempos médios de execução dos experimentos para o modelo B.AA . . . . . . . . . . . . . . 64

Tabela 5.4 - Bateria 07: Descrição dos experimentos . . . . . . . . 67

Tabela 5.5 - Bateria 07: Resultados dos testes para a hipótese A . . . . 69

Tabela 5.6 - Baterias 08-09: Descrição dos experimentos . . . . . . . . 69

Tabela 5.7 - Baterias 08-09: Resultados dos testes para a hipótese B . . 70

Tabela 5.8 - Baterias 10-12: Descrição dos experimentos . . . . . . . 71

Tabela 5.9 - Baterias 10-12: Resultados dos testes para a hipótese C . . 72

Tabela 5.10 - Baterias 13-14: Descrição dos experimentos realizados . . . . 73

Tabela 5.11 - Baterias 13-17: Resultados dos testes para a hipótese D . . . 74

Tabela 5.12 - Baterias 18-22: Descrição dos experimentos realizados . . . . 74

Tabela 5.13-Baterias 18-22: Resultados dos testes para a hipótese E . . 75

Tabela 5.14- Baterias 07-22: Resultados dos testes para a hipótese F . . 76

Tabela A.1 - Baterias 07-22: Resultados do teste de normalidade. . . . . . 84 


\section{LISTA DE ABREVIATURAS E SIGLAS}

AF - Autômato Finito.

AFA - Autômato Finito Adaptativo.

CCD - Estratégia Custo Crescente para voltar a cooperar.

INPPD - Dilema do Prisioneiro com $n$ jogadores iterado (acrônimo de Iterated n-Player Prisoner's Dilemma).

IPD - Dilema do Prisioneiro Iterado (acrônimo de Iterated Prisoner's Dilemma).

JE+AA - Modelo de simulação proposto por Bó (2008) que utiliza AFAs para a representação das estratégias dos agentes.

JE+AF - Modelo de simulação proposto por Bó (2008) que utiliza AFs para a representação das estratégias agentes.

NPPD - Dilema do Prisioneiro com $n$ jogadores (acrônimo de $n$-Player Prisoner's Dilemma).

PD - Dilema do Prisioneiro (acrônimo de Prisoner's Dilemma).

$\mathrm{PS}_{2} \mathrm{E}_{2}$ - Sistema Paralelo de Simulação Evolutiva Espacial.

$\mathrm{S}_{2} \mathrm{E}_{2}-$ Sistema de Simulação Evolutiva Espacial.

TT5 - Estratégia tit-for-tat para 5 jogadores.

U - Estratégia sempre delatar. 


\title{
LISTA DE SÍMBOLOS
}

\author{
D - conjunto de todas as alocações possíveis sobre o reticulado $\mathbb{U}$. \\ $\alpha \quad-\quad$ valor de significância estatística. \\ $\delta \quad-\quad$ função de transição do AF. \\ $\delta_{t} \quad-\quad$ função de transição do AFA no instante $t$. \\ $\pi \quad-$ ação adaptativa de um AFA. \\ $\Pi \quad$ - conjunto de ações adaptativas de um AFA. \\ $\Sigma \quad-$ conjunto de símbolos (alfabeto) de um AF/AFA. \\ $\tau \quad-$ quantidade de iterações do INPPD. \\ $\omega \quad-\quad$ sequência de ações adaptativas (função adaptativa) de um AFA. \\ $a_{i j} \quad-$ agente disposto na linha $i$ e na coluna $j$ do reticulado $\mathbb{U}$. \\ $A_{p} \quad-$ um subconjunto do reticulado $\mathbb{U}$. \\ C $\quad$ - jogada cooperar no NPPD. \\ d $\quad$ - dimensão do reticulado $\mathbb{U}$. \\ D $\quad$ - jogada delatar no NPPD. \\ I - ação adaptativa de inserção. \\ $F \quad-\quad$ conjunto de estados terminais do AF /AFA. \\ $g \quad$ - número de gerações do jogo evolutivo. \\ $G \quad$ - alocação de conjuntos de um reticulado $\mathbb{U}$. \\ $H_{0} \quad-$ hipótese nula do teste estatístico. \\ $H_{A} \quad-$ hipótese alternativa do teste estatístico. \\ $k \quad-$ quantidade de processos. \\ $k_{\max }$ - quantidade máxima de processos que podem ser alocados \\ simultaneamente com os recursos disponíveis, sem que haja \\ concorrência.
}


$n \quad-$ quantidade de jogadores do NPPD.

$n_{\mathbf{C}} \quad$ - quantidade de jogadores que cooperaram em uma determinada partida do NPPD.

$\mathbb{N} \quad$ - conjuntos dos números naturais.

O - conjunto de todos os grupos ótimos.

$p \quad$ - estatística utilizada para sintetizar o resultado de testes de hipóteses (valor $p$ ).

$\mathbb{P}$ - utilidade dos agentes quando não há cooperação mútua (punição).

$P($ e) - probabilidade de erro de entendimento da estratégia.

$P(\mathrm{~m})$ - probabilidade de mutação da estratégia.

$q_{0} \quad-$ estado inicial de um AF/AFA.

$Q \quad-\quad$ conjunto finito de estados de um AF.

$Q_{t} \quad-\quad$ conjunto finito de estados de um AFA no instante $t$.

$\mathbb{R} \quad$ - utilidade dos agentes quando há cooperação mútua (recompensa).

$R \quad$ - ação adaptativa de remoção.

$\mathbb{S} \quad-\quad$ utilidade do agente que coopera enquanto o oponente delata (inocência).

$\mathbb{T} \quad$ - utilidade do agente delator quando o outro coopera (tentação).

$\mathbb{U} \quad-$ conjunto dos $n \times m$ jogadores dispostos sobre o toro.

$V \quad$ - função de utilidade do NPPD. 


\section{SUMÁRIO}

$\begin{array}{llr}1 & \text { Introdução } & 18\end{array}$

1.1 Motivação . . . . . . . . . . . . . . . . . . . . . . . . . . . 18

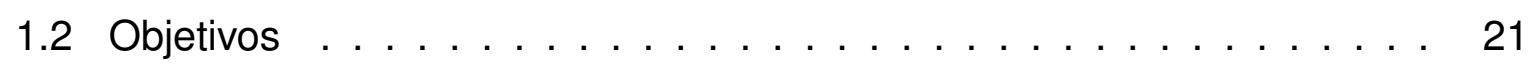

1.3 Organização do documento . . . . . . . . . . . . . . . . . . . . . . . . . 22

2 Conceitos básicos 23

2.1 Teoria dos jogos . . . . . . . . . . . . . . . . . . . 23

2.1 .1 Jogos de soma zero e de soma diferente de zero . . . . . . . . . 23

2.1 .2 Dilema do Prisioneiro . . . . . . . . . . . . . . . . . . 24

2.1 .3 Dilema do Prisioneiro Iterado . . . . . . . . . . . . . . . . . . . 25

2.1 .4 Dilema do Prisioneiro com $n$ Jogadores . . . . . . . . . . . . . 26

2.1 .5 Dilema do Prisioneiro com $n$ Jogadores Iterado . . . . . . . . . . 28

2.2 Autômatos Finitos e Autômatos Finitos Adaptativos . . . . . . . . . . . . . 29

2.2 .1 Autômatos Finitos . . . . . . . . . . . . . . . . . . . . . . . . . . 29

2.2 .2 Autômatos Finitos Adaptativos . . . . . . . . . . . . . . . . . . 31

2.2 .3 Representação das estratégias no INPPD . . . . . . . . . . . . . 33

2.3 Algoritmos evolutivos $\ldots \ldots \ldots \ldots$. . . . . . . . . . . . . . . . . 36

2.4 Computação paralela . . . . . . . . . . . . . . . . . . . . 36

2.5 Algoritmos evolutivos paralelos . . . . . . . . . . . . . . . . . 39

$\begin{array}{lll}3 & \mathrm{~S}_{2} \mathrm{E}_{2} \text { : Abordagem sequencial } & 41\end{array}$

3.1 Modelo de Lindgren \& Johansson . . . . . . . . . . . . . . . . . . . 41

3.2 Extensão do modelo de Lindgren \& Johansson . . . . . . . . . . . . . . 43

3.2.1 Experimentos com os modelos JE+AF e JE+AA . . . . . . . . 43

3.2 .2 Análise de desempenho do sistema . . . . . . . . . . . . . . . . 45 
$\begin{array}{lll}4 & \mathrm{PS}_{2} \mathrm{E}_{2} \text { : Abordagem paralela } & 49\end{array}$

4.1 Paralelização do $\mathrm{S}_{2} \mathrm{E}_{2} \ldots \ldots \ldots \ldots \ldots$

4.2 Divisão do ambiente . . . . . . . . . . . . . . . . . . . . . . . . . . 49

4.2 .1 Problema da divisão . . . . . . . . . . . . . . . . . . . . . . 50

4.2 .2 Grupos ótimos . . . . . . . . . . . . . . . . . . 53

$4.2 .3 \quad$ Busca no espaço de grupos ótimos . . . . . . . . . . . . . . . . . 54

4.3 Projeto do $\mathrm{PS}_{2} \mathrm{E}_{2} \ldots \ldots \ldots \ldots \ldots$

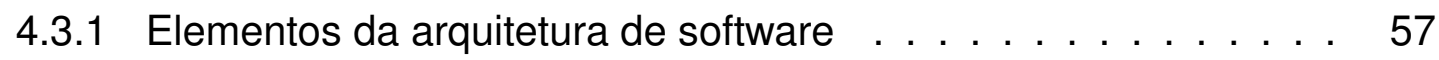

4.3 .2 Plataforma de execução . . . . . . . . . . . . . . . . . . . . 59

4.3 .3 Mecanismo de paralelização . . . . . . . . . . . . . . . 59

$\begin{array}{lll}5 & \text { Experimentação e testes } & 61\end{array}$

5.1 Descrição dos experimentos . . . . . . . . . . . . . . . . . . . . 61

5.2 Ambiente de testes . . . . . . . . . . . . . . . . . . . . . . . 62

5.3 Experimentos: Fase $1 \ldots \ldots \ldots$. . . . . . . . . . . . . 63

$5.3 .1 \quad$ Efeito do número de processadores . . . . . . . . . . . . . . 63

5.4 Experimentos: Fase 2 . . . . . . . . . . . . . . 66

5.4 .1 Efeito do número de gerações . . . . . . . . . . . . . . . . . . 67

5.4 .2 Efeito do tamanho do reticulado . . . . . . . . . . . . . . . . 69

$5.4 .3 \quad$ Efeito da estratégia inicial . . . . . . . . . . . . . . . . . . . . 71

5.4 .4 Efeito da probabilidade de mutação . . . . . . . . . . . . . . . . 72

5.4 .5 Efeito da probabilidade de erro de entendimento . . . . . . . . . 74

5.4 .6 Efeito da expressividade do modelo . . . . . . . . . . . . . 76

\begin{tabular}{lll}
\hline & Conclusões & 77
\end{tabular}

\begin{tabular}{ll}
\hline Referências Bibliográficas & 79
\end{tabular} 
Glossário

82

Apêndice A - Teste de normalidade

84 


\section{INTRODUÇÃO}

\subsection{Motivação}

Suponha que você e um comparsa foram presos após cometerem uma série de delitos. Embora ambos sejam evidentemente culpados, a polícia não coletou provas nem encontrou testemunhas que pudessem denunciar tais crimes. Entretanto, foram encontradas provas que incriminam vocês pela execução de alguns pequenos delitos. Para a sorte (ou azar) de vocês, a polícia precisa que vocês confessem para garantir que ambos sejam condenados.

Sabendo disso, o delegado faz a seguinte proposta: se você concordar em testemunhar contra o seu companheiro, ele retira todas as acusações sobre você e o coloca em liberdade. Em outra sala, essa mesma proposta é feita ao seu comparsa de modo que um não possa saber a decisão do outro antes de tomar a sua própria decisão, que é irrevogável. Além disso, é do conhecimento de todos que, caso ambos os suspeitos resolvam delatar seu comparsa, não haverá artifícios que os auxiliem a escapar das acusações, fazendo com que a pena seja igualmente dividida entre ambos; por outro lado, caso ambos optem pelo silêncio, não haverá outra opção à polícia senão acusá-los apenas pela autoria dos delitos menores.

Agora a decisão é sua: testemunhar ou manter-se omisso? Pleitear a liberdade ou aceitar a condenação?

Com certeza esta não é uma decisão fácil, ainda mais se considerarmos as implicações que as escolhas dos suspeitos teriam em um cenário real. Mas toda esta situação descreve um problema clássico da teoria dos jogos: o Dilema do Prisioneiro (POUNDSTONE, 1992). Trata-se de um jogo onde seus participantes são desafiados a tomar uma decisão que, em conjunto com a decisão do outro prisioneiro, determinará sua sentença. A dificuldade na tomada dessa decisão torna este um tópico amplamente estudado em diversas áreas como economia e ciências sociais, pois representa a dificuldade na formação da cooperação em sociedades de indivíduos racionais.

Outras situações também podem ser citadas para descrever o Dilema do Prisioneiro. Shy (1995) cita um jogo chamado Paz e Guerra, onde dois países devem decidir entre permanecer em paz ou declarar guerra. Caso ambos permaneçam em paz, ambos lucram com os recursos naturais de suas terras. Caso apenas um dois países 
declare guerra, o que tomou a iniciativa conquista os recursos do país indefeso. Por fim, se os dois decidem guerrear, ninguém vence, mas ambos sofrem com os custos referentes à guerra. Neste jogo, mesmo que os países prefiram permanecer em paz, ambos escolherão a opção mais conservadora que é declarar guerra, com medo de se verem indefesos caso o outro tome esta decisão. O medo de ser dizimado faz com que os países entrem em guerra e sofram com perdas que não existiriam se permanecessem em paz.

Em 2002, o Sistema Brasileiro de Televisão estreou um programa de perguntas e respostas chamado Sete e meio. Na etapa final do programa, duas cartas eram dadas para cada um dos dois finalistas. Essas cartas, rotuladas como 7 e 1/2, representavam a opção do participante em dividir ou não o prêmio com o adversário, com uma ressalva: se ambos optassem por não dividir o prêmio, ambos ficavam sem nada. Desse modo, eles eram dispostos frente a frente para que pudessem conversar e entrar um acordo de interesse mútuo, ou seja, dividir o prêmio. Na situação gerada pelo programa, não era apenas a ambição que dificultava a coordenação das ações dos participantes, mas também o medo de ser enganado pela outra parte.

Glance e Huberman (1994) descrevem outro problema chamado de Dilema do Jantar que representa um exemplo do Dilema do Prisioneiro com $n$ jogadores. Este problema retrata uma situação em que um grupo de amigos resolve dividir a conta do jantar e se depara com a oportunidade de saborear uma refeição mais cara sem ter que pagar o valor total que o restaurante cobraria pela mesma. Neste problema, quanto maior é o número de pessoas que optam pelo prato mais caro, maior é o valor da conta; portanto, a opção de pedir pratos caros está relacionada à esperança do jogador de que os outros optem por pratos baratos.

Evidentemente a coordenação da ação dos jogadores não deve ser esperada sem a inclusão de algum mecanismo que favoreça o seu surgimento. Se os jogadores soubessem a ação dos seus oponentes em situações anteriores, por exemplo, seria possível decidir melhor sobre seu caráter e determinar suas ações fazendo uso de estratégias. Tais estratégias tanto poderiam ser utilizadas para predizer as ações dos demais jogadores e dar boas respostas a elas, como poderiam ser utilizadas para punir jogadores que não colaboraram, na tentativa de fazê-los mudar de atitude. Para a inclusão desses mecanismos diversas generalizações destes e de outros jogos semelhantes podem ser encontradas na literatura (AXELROD, 1984; GLANCE; HUBERMAN, 1994; SHY, 1995) consistindo, em sua maioria, em versões iteradas do jogo 
original, isto é, jogos em que seus participantes são confrontados com a mesma situação em questão diversas vezes.

De um modo geral, acredita-se que o estudo e a melhor compreensão da dinâmica desses jogos auxiliem a compreender melhor o surgimento da cooperação em sociedades de agentes que agem racionalmente para atingir um objetivo comum em grupo. Segundo Axelrod (1984), como diversas situações sociais, econômicas, políticas e biológicas podem ser reduzidas a uma instância do Dilema do Prisioneiro, a melhor compreensão dos mecanismos dinâmicos que podem levar ou não à cooperação nesses casos pode ajudar na formulação de políticas, instituições, mecanismos e intervenções mais eficazes.

Diversos trabalhos estudaram a dinâmica de formação da cooperação em jogos baseados no Dilema do Prisioneiro (BOYD; RICHERSON, 1988; HAUERT; SCHUSTER, 1997; MATSUSHIMA; IKEGAMI, 1998; LINDGREN; JOHANSSON, 2003; ERIKSSON; LINDGREN, 2005; BÓ, 2008; GUERBEROFF; QUEIROZ; SICHMAN, 2011) sendo que alguns deles utilizavam simulação computacional. Geralmente esses trabaIhos eram baseados em sociedades de agentes distribuídos que interagiam utilizando alguma regra de interação pré-definida ou estabelecida durante a simulação.

Em particular, Lindgren e Johansson (2003) fizeram um estudo sobre a evolução das estratégias de cooperação em uma versão iterada do Dilema do Prisioneiro com $n$ jogadores em simulações de modelos de autômatos celulares e de campo médio, isto é, com e sem restrições espaciais. A simulação de tais modelos utilizavam algoritmos evolutivos: os agentes interagiam um determinado número de vezes e apenas os mais aptos sobreviviam e geravam descendentes. Neste trabalho concluiu-se que a obtenção da cooperação se desenvolve mais lentamente quando as interações não possuem restrições espaciais.

Dando prosseguimento a este estudo, Bó (2008) desenvolveu uma análise sobre a evolução das estratégias de cooperação em ambientes espaciais evolutivos comparando os resultados das estratégias quando representadas por Autômatos Finitos (AF) e Autômatos Finitos Adaptativos (AFA). Entre os resultados apresentados pôde ser observado que a utilização de formalismos com maior expressividade para a representação das estratégias contribuiu para a manutenção da cooperação. No entanto, a falta de escalabilidade foi uma das dificuldades enfrentadas por este trabalho, o que impossibilitou uma análise mais elaborada dos fatores que influenciam esse comportamento. 
Geralmente, a escalabilidade é um fator desejável em um sistema computacional, pois determina a sua capacidade de crescimento (BONDI, 2000). Embora desejável, nem sempre os sistemas são projetados prevendo todas as possíveis expansões que possam ser requeridas no futuro. Esta falha de projeto, causada principalmente pela dificuldade de abstrair, segmentar e/ou modularizar as diversas tarefas do sistema, impede que novas funções sejam agregadas ao sistema para a solução de problemas mais complexos.

Além da simples otimização do código, uma das maneiras de contribuir para a escalabilidade de um sistema é através da utilização de computação paralela. Com a computação paralela torna-se possível expandir um sistema para a solução de problemas de complexidade superior, por meio da divisão da tarefa original em tarefas menores a serem processadas por dispositivos independentes que se comunicam.

A dificuldade no desenvolvimento de sistemas paralelos reside na dificuldade que existe em determinar quais as tarefas que devem ser divididas e de que forma seus resultados podem ser reagrupados sem afetar o resultado final. Um sistema não projetado para esta finalidade pode possuir uma quantidade tão alta de dependências que sua paralelização pode requerer desde a reorganização de sua estrutura interna até mesmo a reimplementação completa da aplicação.

\subsection{Objetivos}

Este trabalho tem o objetivo de desenvolver um sistema de simulação paralela, evolutiva e espacial que possibilite a análise do surgimento da cooperação em sociedades de agentes que interagem seguindo as regras do Dilema do Prisioneiro com $\mathrm{n}$ jogadores. Além disso, este trabalho tem o intuito de verificar como a complexidade da representação das estratégias influencia esse processo de cooperação.

Para tanto, este trabalho apresenta uma nova implementação do modelo de simulação do Dilema do Prisioneiro com n jogadores inspirado nos trabalhos de Bó (2008) e Lindgren e Johansson (2003) para a execução da simulação em um ambiente de processamento paralelo. Assim, um segundo objetivo deste trabalho é determinar como as tarefas que compõem a simulação podem ser melhor divididas a fim de garantir a máxima utilização dos recursos disponíveis. A relação entre esses trabalhos encontra-se representada na figura 1.1 .

Assim, com a conclusão desse trabalho, espera-se responder as seguintes per- 


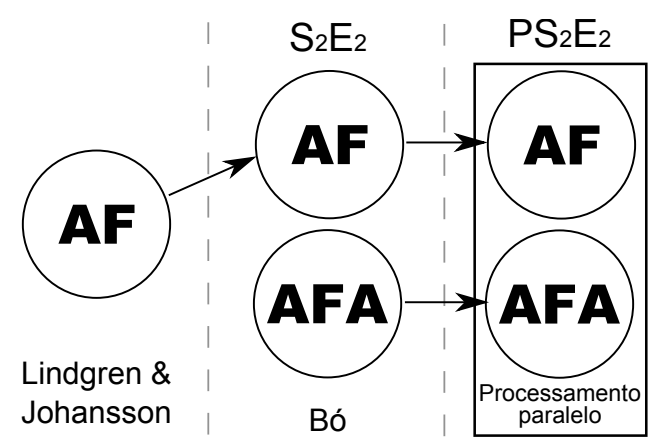

Figura 1.1: Relação entre os modelos de simulação

guntas:

1. Existem vantagens em realizar simulações do Dilema do Prisioneiro com $n$ jogadores em ambientes de processamento paralelo?

2. É possível haver cooperação no longo prazo entre diversos agentes onde há um estímulo individual para a não cooperação? Como este processo é atingido? (BÓ, 2008)

3. Existem vantagens na utilização de modelos mais complexos de representação de estratégias?

4. Quais parâmetros influenciam na utilidade da sociedade? De que forma?

\subsection{Organização do documento}

No capítulo 2, são apresentados alguns conceitos básicos sobre teoria dos jogos, autômatos e computação paralela utilizados para o desenvolvimento deste trabalho. No capítulo 3 é apresentado o $\mathrm{S}_{2} \mathrm{E}_{2}$, que é o sistema proposto por Bó que serviu como base para o sistema paralelo, denominado $\mathrm{PS}_{2} \mathrm{E}_{2}$, que é o objeto de estudo desse trabalho e cujos detalhes são apresentados no capítulo 4 . No capítulo 5 são apresentados os experimentos realizados com uma análise dos resultados obtidos e, por fim, no capítulo 6 são descritas as conclusões obtidas e os trabalhos futuros. 


\section{CONCEITOS BÁSICOS}

\subsection{Teoria dos jogos}

A teoria dos jogos é uma subárea da matemática aplicada que tem como objetivo interpretar o comportamento de indivíduos em situações estratégicas. De uma forma geral, podemos considerá-la como o estudo formal do conflito e da cooperação em sociedades de agentes (TUROCY; STENGEL, 2001).

Esse estudo é realizado por meio do reconhecimento e modelagem matemática desses comportamentos e das características que podem alterá-los. Assim, seus resultados tanto podem ser aplicados a simples jogos de entretenimento como a aspectos significativos do cotidiano. Sua utilização é notável em situações econômicas, sociais e políticas, mas é possível notar a presença da teoria dos jogos em aplicações de diversas áreas.

\subsubsection{Jogos de soma zero e de soma diferente de zero}

Existem diversas formas de classificar um jogo segundo a teoria dos jogos, sendo uma delas através da soma dos ganhos e perdas dos participantes. Quando os ganhos dos participantes equivalem à perda de seus adversários temos configurado um jogo de soma zero. Esse tipo de jogo é encontrado em situações onde as partes se envolvem em uma aposta, assim como acontece no jogo de cara ou coroa: uma vez lançada a moeda, para que um jogador seja declarado vencedor o seu adversário precisa ser o perdedor. Jogos clássicos de tabuleiro, como o Xadrez e Damas também são exemplos de jogos de soma zero.

Quando os ganhos dos participantes não estão relacionados às perdas de seus adversários configura-se um jogo de soma diferente de zero. Essa situação é muito comum na economia, pois qualquer forma de comércio pode ser considerada uma atividade de soma diferente de zero; afinal, quando uma negociação é concretizada, ambas as partes consideram o bem ou serviço adquirido um pouco mais valioso que o bem ou serviço que está sendo ofertado.

De forma semelhante, algumas situações políticas e sociais também nos remontam a estes jogos, pelo menos é isso que demonstra a declaração feita pelo advogado e ex-presidente norte americano Bill Clinton durante uma entrevista para a Wired Mag- 
azine (BRESLAU; HERON, 2000) em referência à Wright (2001):

“(...) quanto mais complexa uma sociedade se torna e mais complexas redes de interdependência se formam dentro e fora da comunidade e nas fronteiras nacionais, mais pessoas são forçadas, dentro de seus próprios interesses, a encontrar soluções de soma diferente de zero. Isto é, soluções ganhar/ganhar ao invés de soluções ganhar/perder."

Tal declaração nos leva a considerar que o estudo desses jogos pode auxiliar a compreender melhor os mecanismos que influenciam e colaboram com as interações positivas de indivíduos em sociedade.

Apesar da importância dos jogos de soma diferente de zero, cabe observar que todo jogo de soma diferente de zero pode ser transformado em um jogo de soma zero através da inclusão de jogadores fictícios (geralmente denominados de "o tabuleiro", "casa", "mesa" etc.) com o intuito de compensar os ganhos e as perdas dos demais jogadores, tornando a soma dos ganhos igual a zero. Portanto, esta definição não determina uma nova classe de jogos, mas apenas um modo diferente de observá-los.

\subsubsection{Dilema do Prisioneiro}

O Dilema do Prisioneiro (PD), mencionado na seção 1.1, é um jogo de soma diferente de zero que descreve uma situação em que cada um dos participantes (os prisioneiros) têm de escolher entre cooperar ou delatar (AXELROD, 1984), sendo que o resultado do jogo depende da combinação das escolhas de ambos os jogadores. Na tabela 2.1 são exibidos os possíveis resultados do dilema do prisioneiro em sua forma clássica.

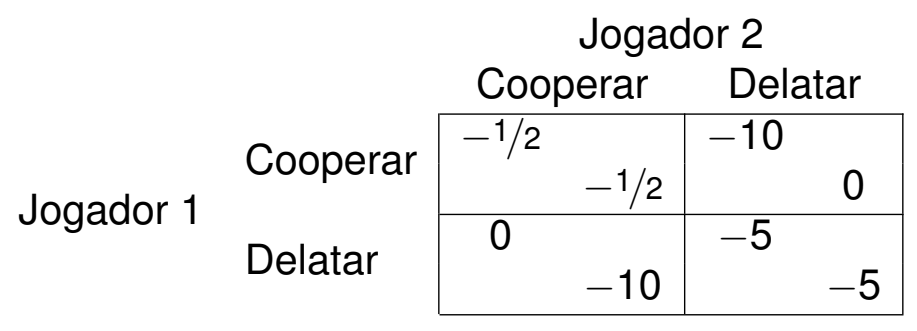

Tabela 2.1: Matriz de ganho do PD. Os valores são negativos pois representam anos de cárcere.

Neste quadro, as linhas representam as possíveis decisões do jogador 1 enquanto as colunas representam as possíveis decisões do jogador 2 . O cruzamento de uma linha com uma coluna representa um possível resultado e cada célula de resultado possui a utilidade obtida pelos jogadores 1 e 2 , respectivamente, em termos da quan- 
tidade de anos de liberdade que o mesmo será privado caso aquela situação se concretize.

De posse desses dados, uma das análises a serem feitas é estabelecer a presença de equilíbrios de Nash. Em um jogo envolvendo dois ou mais jogadores, um equilíbrio de Nash representa uma situação em que nenhum jogador pode melhorar o seu resultado modificando apenas a sua estratégia, dadas as estratégias dos demais jogadores.

No Dilema do Prisioneiro o equilíbrio está na situação em que todos os jogadores optam por delatar, pois independente da jogada do outro jogador, ambos podem diminuir sua pena optando pela delação. Em uma situação real, mesmo que os suspeitos fossem capazes de fazer um acordo prévio de cooperação mútua, ambos teriam uma inclinação pela não cooperação, seja para obter o melhor resultado (a liberdade), seja para fugir do pior resultado (a pena máxima). Essa dificuldade na cooperação faz com que a delação seja a única estratégia esperada, o que obriga os jogadores a produzirem um resultado que não é Pareto eficiente ${ }^{1}$.

Formalmente, são quatro as variáveis que definem o Dilema do Prisioneiro: inocência $(\mathbb{S})$, punição $(\mathbb{P})$, recompensa $(\mathbb{R})$ e tentação $(\mathbb{T})$. Para todos os casos, considerase que $\mathbb{S}<\mathbb{P}<\mathbb{R}<\mathbb{T}$, pois esta condição garante que o equilíbrio de Nash e a estratégia dominante seja a delação, mas que a cooperação seja Pareto eficiente. A tabela 2.2 exibe como estas variáveis são organizadas na matriz de ganho do PD.

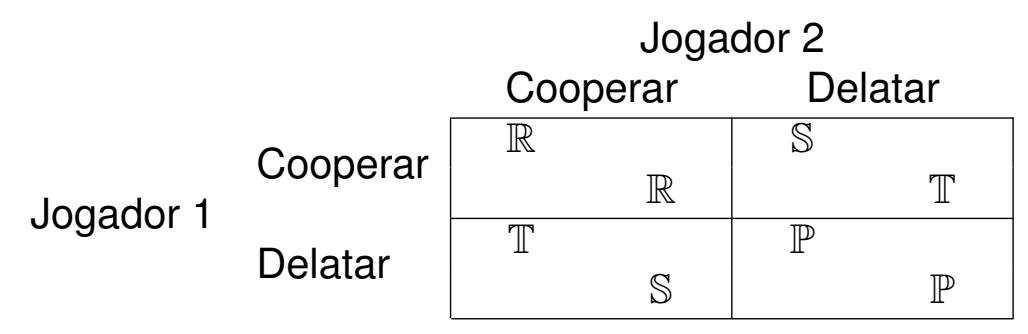

Tabela 2.2: Possíveis resultados do PD.

\subsubsection{Dilema do Prisioneiro Iterado}

Como visto, nenhuma cooperação deve ser esperada em um jogo do Dilema do Prisioneiro com apenas uma iteração. Com base nisso, Axelrod (1984) propôs uma versão chamada de Dilema do Prisioneiro Iterado (IPD) onde supõe-se que os participantes

\footnotetext{
${ }^{1} \mathrm{Um}$ determinado resultado é considerado Pareto eficiente se, e somente se, não existe um meio de um jogador melhorar a sua utilidade sem piorar o resultado dos demais jogadores. No Dilema do Prisioneiro, apenas o resultado em que todos cooperam é Pareto eficiente.
} 
sejam confrontados com a mesma situação do PD sucessivas vezes. Nessa abordagem do jogo, torna-se possível que a cooperação seja estabelecida pelos jogadores, pois sua definição permite que os mesmos respondam às decisões não cooperativas feitas pelo adversário em situações passadas através de retaliação.

A oportunidade de um jogador poder levar em conta as jogadas anteriores de seu adversário permite que estratégias possam ser desenvolvidas. Uma estratégia é um plano de ação que determina o comportamento do jogador para qualquer situação do jogo. Uma das estratégias mais conhecidas para o IPD é denominada Tit-forTat: o jogador inicia cooperando e depois imita a jogada de seu oponente na rodada anterior. Tais estratégias podem ser expressas de diversas maneiras, inclusive através do uso de linguagens formais, como é apresentado na seção 2.2 .

No IPD, o número de iterações é um fator fundamental de decisão para um agente e a posse dessa informação pode determinar a existência de diferentes tipos de estratégias. Se os jogadores souberem o número de rodadas que irão jogar, por exemplo, estes podem estabelecer estratégias baseadas em indução reversa para definir as suas jogadas de modo a maximizar o seu resultado (BÓ, 2008). No entanto, neste trabalho consideramos que o número de iterações não é um parâmetro conhecido pelos jogadores.

Devido às alterações na dinâmica do jogo e, com o intuito de garantir que a cooperação seja Pareto eficiente, Dawkins (1989) estabelece que a seguinte condição seja adicionada à versão iterada do Dilema do Prisioneiro:

$$
2 \mathbb{R}>\mathbb{T}+\mathbb{S}
$$

Caso essa condição não seja garantida, os jogadores poderiam ter um resultado meIhor se ficassem revezando suas jogadas. Em outras palavras, a tentação $(\mathbb{T})$ poderia ser suficientemente maior que a recompensa $(\mathbb{R})$, permitindo que os jogadores estabelecessem acordos para aumentar sua utilidade, sem prejudicar o grupo.

\subsubsection{Dilema do Prisioneiro com $n$ Jogadores}

O Dilema do Prisioneiro com n jogadores (NPPD) é uma generalização do Dilema do Prisioneiro para uma quantidade qualquer de jogadores. Em um jogo com $n$ jogadores determinamos que cada jogador pode optar por jogar $\mathbf{C}$, representando a ação de cooperar; ou $\mathbf{D}$, representando a ação de delatar. 
Neste jogo, a utilidade dos jogadores passa a ser uma função da sua própria jogada, dada a quantidade de jogadores que cooperam. Assim, para que sejam mantidas as características da formulação original do Dilema do Prisioneiro, é necessário que a função de utilidade $V$ possua as seguintes características (LINDGREN; JOHANSSON, 2003):

$$
\begin{gathered}
V\left(\mathbf{D} \mid n_{\mathbf{C}}\right)>V\left(\mathbf{C} \mid n_{\mathbf{C}}\right) \\
V\left(x_{i} \mid n_{\mathbf{C}}\right)>V\left(x_{i} \mid n_{\mathbf{C}}-1\right) \quad x_{i} \in\{\mathbf{C}, \mathbf{D}\} \\
\sum_{i=1}^{n} V\left(x_{i} \mid n_{\mathbf{C}}\right)>\sum_{i=1}^{n} V\left(x_{i} \mid n_{\mathbf{C}}-1\right) \quad x_{i} \in\{\mathbf{C}, \mathbf{D}\}
\end{gathered}
$$

Considerando que $n$ é a quantidade de jogadores e que $n_{\mathbf{C}} \leq n$ é a quantidade de jogadores que estão cooperando, a inequação 2.2 reflete a condição de que, para um mesmo número de jogadores cooperando, um jogador que joga $\mathbf{D}$ obtém uma utilidade maior do que aqueles que jogaram $\mathbf{C}$. A inequação 2.3 indica que a utilidade de um determinado jogador é maior se a quantidade de jogadores que cooperam também for maior, independente da sua jogada. Por fim, a inequação 2.4 mostra que a soma da utilidade obtida por todos os jogadores (utilidade do grupo) é maior se a quantidade de jogadores que cooperam também for maior.

Portanto, a alteração de uma jogada de $\mathbf{D}$ para $\mathbf{C}$ faz com que a utilidade individual do jogador diminua, mas faz com que a utilidade do grupo aumente. De modo análogo, uma alteração de $\mathbf{C}$ para $\mathbf{D}$ faz com que a utilidade individual do jogador aumente, embora faça com que a do grupo diminua. Em outras palavras, o grupo sempre se beneficia se a quantidade de jogadores que cooperam aumenta; no entanto, qualquer jogador pode se beneficiar individualmente, prejudicando o grupo, optando por não cooperar.

Baseando-se nos resultados possíveis da formulação original do Dilema do Prisioneiro, Lindgren e Johansson (2003) adotaram as seguintes funções para calcular a utilidade dos jogadores:

$$
\begin{aligned}
V\left(\mathbf{C} \mid n_{\mathbf{C}}\right)=\frac{n_{\mathbf{C}}}{n-1} \\
V\left(\mathbf{D} \mid n_{\mathbf{C}}\right)=\frac{\mathbb{T} \cdot n_{\mathbf{C}}+\mathbb{P} \cdot\left(n-n_{\mathbf{C}}-1\right)}{n-1} \\
=\frac{n_{\mathbf{C}}}{n-1}(\mathbb{T}-\mathbb{P})+\mathbb{P}
\end{aligned}
$$

Essas funções respeitam as condições do NPPD assumindo que $\mathbb{R}=1$ e $\mathbb{S}=0$, sendo que o valor no final é dividido por $n-1$ para facilitar a comparação dos resultados de 
jogos com diferentes quantidades de jogadores 2 .

$\mathrm{Na}$ tabela 2.3 são exibidas as utilidades de um jogo do NPPD com cinco jogadores $(n=5)$ com $\mathbb{T}=1,5$ e $\mathbb{P}=0,5$. No primeiro exemplo apresentado nessa tabela, todos os jogadores escolhem $\mathbf{C}$ fazendo com que o grupo obtenha a maior utilidade possível $(6,25)$. No segundo exemplo, um dos jogadores escolhe $\mathbf{D}$ enquanto os demais mantém a jogada C; neste caso, observa-se um aumento na utilidade do jogador delator ao mesmo tempo que a utilidade do grupo diminui $(5,50)$. No terceiro exemplo, dois jogadores optam por $\mathbf{D}$ fazendo com que a utilidade do grupo diminua ainda mais em comparação ao exemplo anterior $(4,75)$. No último exemplo, todos os jogadores escolhem $\mathbf{D}$ e o grupo obtém a pior utilidade possível $(2,50)$.

Tabela 2.3: Ganho dos jogadores em um NPPD com cinco jogadores com $\mathbb{T}=1,5 \mathrm{e}$ $\mathbb{P}=0,5$.

\begin{tabular}{ccccccccc}
\hline \multirow{2}{*}{ Jogador } & \multicolumn{2}{c}{ Exemplo 1 } & \multicolumn{2}{c}{ Exemplo 2 } & \multicolumn{2}{c}{ Exemplo 3 } & \multicolumn{2}{c}{ Exemplo 4 } \\
\cline { 2 - 9 } & Jogada & Ganho & Jogada & Ganho & Jogada & Ganho & Jogada & Ganho \\
\hline 01 & C & 1,25 & C & 1,00 & C & 0,75 & D & 0,50 \\
02 & C & 1,25 & C & 1,00 & C & 0,75 & D & 0,50 \\
03 & C & 1,25 & C & 1,00 & C & 0,75 & D & 0,50 \\
04 & C & 1,25 & C & 1,00 & D & 1,25 & D & 0,50 \\
05 & C & 1,25 & D & 1,50 & D & 1,25 & D & 0,50 \\
\hline \hline Total & & 6,25 & & 5,50 & & 4,75 & & 2,50 \\
\hline
\end{tabular}

No NPPD existem, portanto, três resultados a considerar: a utilidade dos jogadores que optaram por C; a utilidade dos que optaram por $\mathbf{D}$ e a utilidade total do grupo. No gráfico 2.1 é apresentada a função $V$ do NPPD com cinco jogadores de modo a comparar esses três valores.

É importante observar que as características fundamentais do PD são mantidas neste jogo e, portanto, o aumento na quantidade de jogadores não altera suas características básicas, mas aumenta a número de resultados possíveis.

\subsubsection{Dilema do Prisioneiro com $\mathbf{n}$ Jogadores Iterado}

O objeto de estudo deste trabalho é o Dilema do Prisioneiro com $\mathrm{n}$ jogadores iterado (INPPD) que, como o próprio nome sugere, é uma generalização do NPPD para múltiplas iterações. Nessa forma do jogo, que se equipara ao IPD, temos reunidas duas

\footnotetext{
${ }^{2}$ Embora este trabalho não pretenda explorar este parâmetro, tal característica foi mantida para garantir a compatibilidade do modelo proposto com modelos já existentes.
} 


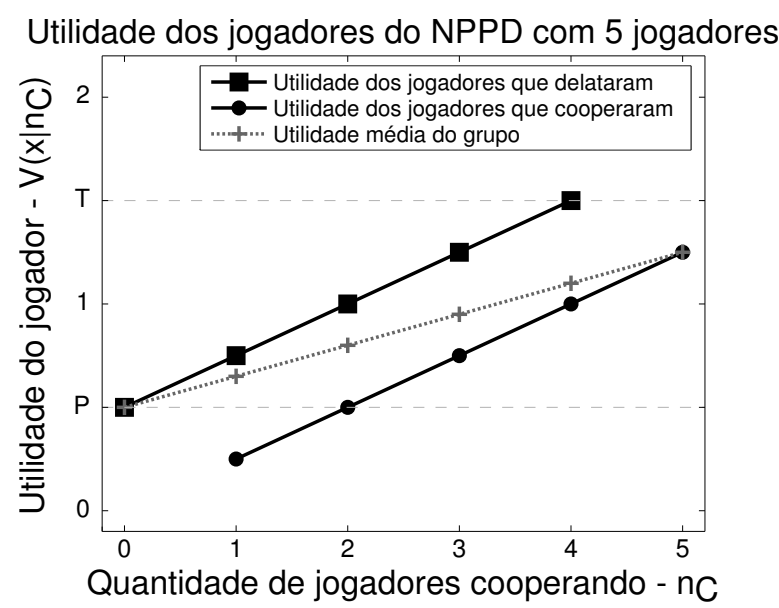

Gráfico 2.1: Utilidade dos jogadores em função da quantidade de jogadores que cooperam com $\mathbb{T}=1,5$ e $\mathbb{P}=0,5$.

características igualmente desejáveis: uma que incentive os jogadores a aumentarem seu ganho individual através da delação; e uma que permita que o grupo crie mecanismos para aumentar o seu ganho, retaliando os jogadores delatores em busca da cooperação.

De modo similar ao IPD, descrito na seção 2.1.3, torna-se necessário o uso de estratégias que determine o comportamento dos jogadores, pois a decisão entre cooperar ou delatar pode levar em consideração não apenas um, mas diversos parâmetros que alteram o resultado do jogo, como a última jogada, a quantidade de participantes que cooperam, tempo de cooperação/delação etc.

Assim, entender o impacto do formalismo utilizado para representar tais estratégias é um dos pontos a serem estudados neste trabalho. Na seção seguinte são apresentados os autômatos finitos e os autômatos finitos adaptativos, e como estes formalismos são utilizados para representar as estratégias do INPPD.

\subsection{Autômatos Finitos e Autômatos Finitos Adaptativos}

\subsubsection{Autômatos Finitos}

Um Autômato Finito (AF) é um caso particular da máquina de estados finitos e consiste na representação formal do modelo mais simples de computação conhecido. Sua estrutura se baseia em três elementos fundamentais: alfabeto, estados e transições. $O$ alfabeto determina a lista de símbolos que compõe a linguagem que o autômato é capaz de reconhecer, os estados são entidades que determinam o comportamento atual 
do autômato e as transições são conexões entre os estados, geralmente definidas através de uma função, que mapeia um novo estado para cada símbolo do alfabeto e estado do autômato.

Na teoria da computação, estes modelos geralmente são utilizados como reconhecedores de linguagens e seus conceitos são largamente utilizados na construção de compiladores. Um reconhecedor de linguagens é um dispositivo que, dada uma cadeia de símbolos sobre um alfabeto (entrada), é capaz de determinar se aquela cadeia pertence ou não à linguagem que o mesmo esteja configurado para reconhecer (saída). Para reconhecer uma cadeia dada como entrada, um Autômato Finito, partindo de um estado denominado estado inicial, transita pelos seus estados consumindo os símbolos da cadeia até que a mesma esteja esgotada. Se, ao término da execução, o AF estiver em qualquer um dos estados denominados estados finais, o autômato aceita a cadeia, caso contrário, o mesmo a rejeita. À classe de linguagens que os autômatos finitos são capazes de reconhecer foi dado o nome de linguagens regulares. Essa classe, de acordo com a Hierarquia de Chomsky (LEWIS; PAPADIMITRIOU, 1998), é a base de todas as outras classes de linguagens e tem uma interpretação muito relevante, pois é a única classe de linguagens cujos formalismos não necessitam de memória auxiliar para o seu reconhecimento.

Autômatos Finitos podem ser determinísticos e não determinísticos. O não determinismo em um autômato permite que o mesmo possa admitir mais do que apenas um caminho para o reconhecimento das cadeias de entrada, permitindo que este explore rotas alternativas para alcançar os estados finais. Desse modo, se ao término da execução algum dos caminhos percorridos fez o autômato atingir um estado final, a cadeia é aceita. AFs determinísticos e não determinísticos são equivalentes em poder computacional (LEWIS; PAPADIMITRIOU, 1998), isto é, a inserção do não determinismo não altera a classe de linguagens que o autômato reconhece e, portanto, para todo $A F$ não determinístico existe uma versão determinística equivalente e vice-versa.

A representação mais comum de um AF é feita através de um grafo orientado, de modo que os vértices são os estados e as arestas são as transições. Nesse tipo de representação, convenciona-se rotular os vértices, indicando o estado que o mesmo representa, sendo que o estado inicial é indicado com uma seta e os estados finais são grafados com um círculo duplo. Os rótulos das arestas representam o símbolo da cadeia de entrada que, ao ser consumido, faz com que o autômato efetue aquela transição. Na figura 2.1 é mostrado um autômato finito determinístico em forma de 
grafo orientado.

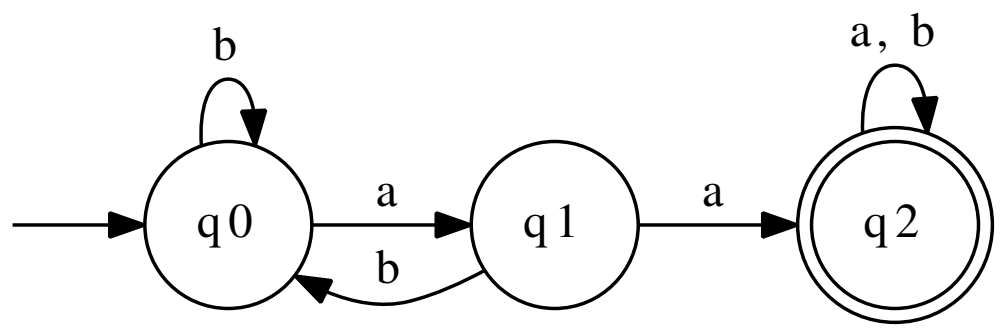

Figura 2.1: Exemplo de Autômato Finito

Formalmente (SIPSER, 2007), um AF é definido pela quíntupla

$$
\left\langle Q, \Sigma, \delta, q_{0}, F\right\rangle
$$

onde:

- $Q$ é um conjunto finito de estados;

- $\Sigma$ é um conjunto finito de símbolos denominado alfabeto;

- $\delta: Q \times \Sigma \rightarrow Q$ é a função de transição;

- $q_{0} \in Q$ é o estado inicial; e

- $F \subseteq Q$ é o conjunto de estados de aceitação ou estados finais.

Em cada instante de execução o autômato admite uma configuração que determina o seu estado atual e o conteúdo da cadeia de entrada que ainda será processado. Desse modo, uma cadeia é considerada reconhecida pelo autômato se não houver mais símbolos a serem processados e o estado atual for um dos estados finais.

\subsubsection{Autômatos Finitos Adaptativos}

A tecnologia adaptativa é o nome dado ao conjunto de técnicas cujo formalismo utiliza os Dispositivos Adaptativos dirigido por Regras propostos por Neto (2002). A ideia central deste formalismo é que dispositivos complexos podem ser obtidos mediante a progressão gradual de dispositivos mais simples através de ações adaptativas, isto é, ações que modificam a sua própria estrutura.

Assim, um Autômato Finito Adaptativo (AFA) é uma reformulação da estrutura representada por um Dispositivo Adaptativo guiado por Regras cujo dispositivo adjacente é um Autômato Finito (PISTORI, 2003). Esse modelo, que consiste em uma 
generalização do AF convencional, contém todos seus os elementos originais, em adição à capacidade de modificar sua própria estrutura. Tal característica, denominada adaptatividade, torna-os equivalentes, em poder computacional, a Máquinas de Turing (ROCHA; NETO, 2001).

Formalmente, um AFA pode ser definido, no instante $t$, pela sêxtupla:

$$
\left\langle Q_{t}, \Sigma, \delta_{t}, q_{0}, F, \Pi\right\rangle
$$

onde:

- $Q_{t}$ é um conjunto finito de estados no instante $t$;

- $\Sigma$ é um conjunto finito de símbolos denominado alfabeto;

- $\delta_{t}: Q_{t} \times \Sigma \rightarrow Q_{t} \times \Pi^{\star}$ é a função de transição no instante $t: 3$

- $q_{0} \in Q_{0}$ é o estado inicial;

- $F \subseteq Q_{0}$ é o conjunto de estados de aceitação;

- $\Pi \subseteq T \times Q_{t} \times \Sigma \times Q_{t+1}$ é um conjunto de ações adaptativas;

- $T=\{I, R\}$ é o tipo de ação adaptativa.

Semelhante à sua versão não adaptativa, em cada instante de execução o AFA admite uma configuração que determina o seu estado atual e o conteúdo da cadeia de entrada que ainda será processado. Desse modo, no AFA uma cadeia é considerada reconhecida pelo autômato se não houver mais símbolos a serem processados e o estado atual for um dos estados de aceitação.

No entanto, a função de transição $\delta_{t}$ de um AFA associa também às suas transições uma função adaptativa $\omega \in \Pi^{\star}$ que consiste em uma sequência de ações adaptativas. Desse modo, se a função de transição $\delta_{t}$ associa uma função adaptativa $\omega$, ou seja, se $\delta_{t}\left(q_{t}, \sigma\right)=\left(q_{t+1}, \omega\right)$, tal função será executada quando o autômato estiver no estado $q_{t}$ e consumir o símbolo $\sigma$. Assim, a medida que o AFA transita por seus estados, ele pode executar uma função adaptativa em resposta a um estímulo e alterar a sua estrutura através de regras preestabelecidas. Observando de uma maneira diferente, o AFA pode assumir a forma de um AF diferente a cada instante de execução, sendo sua forma determinada pelo estímulo fornecido pela cadeia de entrada.

\footnotetext{
${ }^{3} \Pi^{\star}$ representa o fecho reflexivo e transitivo sobre o conjunto $\Pi$, também conhecido como fecho de Kleene.
} 
As alterações admitidas pelo autômato podem ser de vários tipos, de acordo com as especificações e necessidades, podendo ser desde a adição e remoção de estados e de transições, assim como a alteração dos estados de aceitação (BÓ, 2008).

As ações adaptativas $\pi \in \Pi$ aqui utilizadas, podem ser de três tipos elementares (NETO, 2002):

- Ação de Busca (AB): ação que não modifica a estrutura do autômato, mas que possibilita a busca no autômato por alguma característica;

- Ação de Inserção (AI): ação que insere elementos no autômato, como estados e transições;

- Ação de Remoção (AR): ação que remove elementos do autômato que seguem um padrão definido na ação.

\subsubsection{Representação das estratégias no INPPD}

O uso de Autômatos Finitos para a representação das estratégias no INPPD foi proposto inicialmente por Lindgren e Johansson (2003). Embora estes possam representar apenas uma classe bastante simplificada de estratégias, eles possuem características importantes, como a facilidade de uso e a possibilidade de minimização (BÓ, 2008), que facilita o estudo da interação entre os agentes dentro de um ambiente evolutivo.

No modelo de Lindgren e Johansson (2003) que utiliza AFs para representar as estratégias (figura 2.2), cada estado do autômato representa a ação que será tomada pelo agente (C ou D), de modo que estados distintos do mesmo tipo são diferenciados através de identificadores (C1, D1, C2 etc.). Aqui não há estados terminais, porém existe um estado que é definido como sendo o inicial. As transições entre os estados indicam o número de jogadores que devem ter jogado $\mathbf{C}$ para que aquele movimento seja efetuado. Formalmente, o alfabeto $\Sigma$ do AF passa a ser o conjunto $\{x \in \mathbb{N} \mid 0 \leq x \leq n-1\}$ onde $n$ é o número de jogadores do INPPD.

Essa representação é interpretada da seguinte forma: estando um agente em um estado do tipo $\mathbf{C}$ (analogamente do tipo $\mathbf{D}$ ), na próxima iteração do INPPD ele optará por jogar C (analogamente D) e verificará quantos jogadores jogaram $\mathbf{C}$. De acordo com este valor, a transição a ser efetuada pelo agente é estabelecida, fazendo com que a jogada da próxima iteração seja definida pelo estado para o qual ele transitou. 


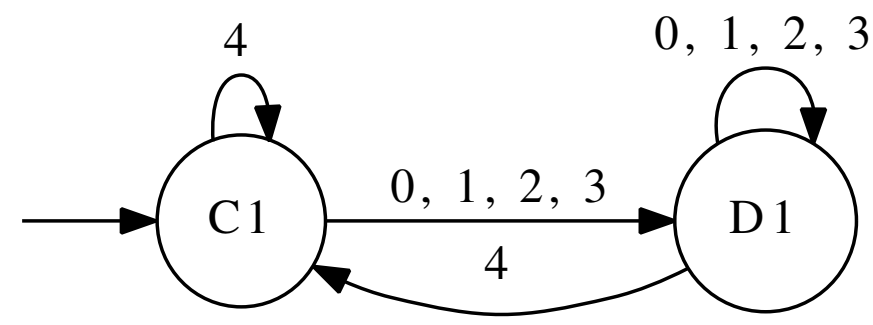

Figura 2.2: Exemplo de uma estratégia representada por um Autômato Finito (BÓ, 2008)

Utilizando o AF da figura 2.2 como referência, o jogador inicia no no estado C1, que indica que sua jogada inicial será $\mathbf{C}$. Se nessa iteração menos de 4 jogadores jogarem $\mathbf{C}$, o jogador transitará para o estado D1 e passará jogar $\mathbf{D}$ indefinidamente nas próximas iterações até que exatamente 4 jogadores joguem $\mathbf{C}$.

Os AFAs funcionam basicamente da mesma maneira, no entanto, estes fazem uso de elementos adicionais para representar as diversas transformações que $o$ autômato pode sofrer como resposta à execução das ações adaptativas, que são feitas de forma dinâmica durante a sua execução.

Um dos elementos utilizados apenas pelos AFAs é a capacidade de fazer referências dinâmicas aos estados. A princípio, determina-se que a ação de busca não é uma ação invocada diretamente pelo autômato, mas indiretamente por outras ações adaptativas. Portanto, estas podem fazer uso das notações C\#x e D\#x para referenciar estados inexistentes ou desconhecidos, onde $\mathbf{x}$ é um identificador secundário. Essas formas de referência possuem interpretações distintas de acordo com o tipo de ação adaptativa que esteja sendo executada.

Se a ação é uma ação de inserção, então a notação especial indica a criação de um novo estado do tipo especificado. Neste caso, o AFA é responsável por determinar internamente um identificador único e válido para o mesmo. Por exemplo, a ação $\pi=I(\mathbf{C} 1,4, \mathbf{C} \# \mathbf{1})$ representa a inserção de uma transição do estado $\mathbf{C} 1$ para um novo estado do tipo $\mathbf{C}$ com o rótulo 4 .

Já se a mesma se trata de uma ação de remoção, então esta indica uma busca por um estado existente com a característica especificada. Assim, a ação $\pi=R(\mathbf{D \# 1 , 3 , C 1 )}$ fará uma busca pelas transições e determinará se existe uma transição que parte de um estado do tipo $\mathbf{D}$ para o estado $\mathbf{C} 1$ com o rótulo 3 . Se este estado existir, ele é removido. Na implementação utilizada neste trabalho, se a busca retornar nenhum ou mais do que um resultado, significa que o estado não pode ser determinado e a ação 
não tem efeito.

Em todos os casos, uma vez atribuído um valor para o identificador secundário, ele se mantém o mesmo até o término da função adaptativa; se uma função adaptativa possui diversas ações que referenciam o estado C\#1, a primeira ação determinará seu valor e as chamadas subsequentes apenas farão referência ao estado já determinado.

Para exemplificar o funcionamento do mecanismo adaptativo do AFA, consideremos a execução de uma função adaptativa $\omega$ que é executada quando uma transição qualquer é feita no autômato ilustrado na figura 2.3a. A descrição das ações adaptativas $\pi_{1}, \pi_{2}, \ldots$ de $\omega$ é dada a seguir:

- $A B$ : Pegue uma referência para um estado do tipo $\mathbf{D}$ que possua uma transição para a entrada "0" apontando para D1. Guarde esta referência em D\#1;

- Al: Crie um novo estado do tipo $\mathbf{C}$ e guarde sua referência em $\mathbf{C \# 1 ;}$

- AR: Remova a transição de D\#1 para D1 para a entrada "0";

- Al: Insira uma transição de D1 para C\#1 para a entrada "0".

Desse modo, o autômato da figura 2.3a após executar a função adaptativa $\omega$, mudará sua estrutura se tornando no autômato representada na figura $2.3 \mathrm{~b}$. Aqui consideramos que a função adaptativa é sempre executada após a transição ser efetuada, portanto, o autômato se mantém no estado D1, podendo transitar para o estado recém criado posteriormente caso receba a entrada apropriada.

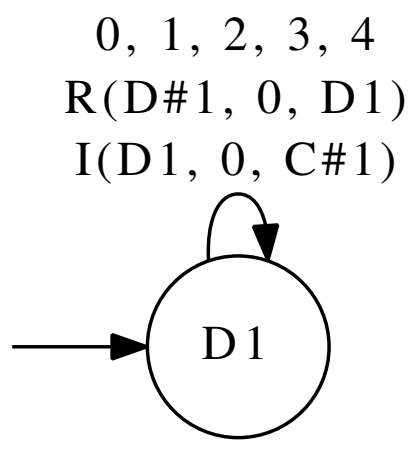

(a) Antes

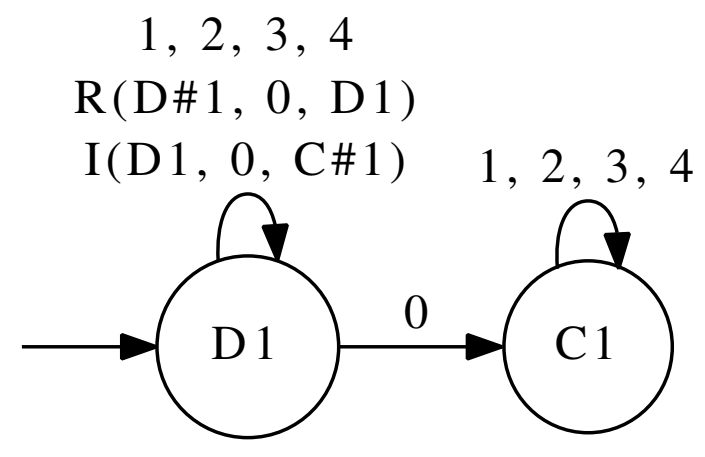

(b) Depois

Figura 2.3: Execução de uma função adaptativa

Uma vez que determinamos o modo como os jogadores irão interagir e o método como estes representam e utilizam suas estratégias, falta determinar o modo como 
será feito o experimento. Sem dúvidas não há interesse aqui em estudar a interação de um grupo isolado de agentes que sempre utilizam a mesma estratégia, mas sim de diversos grupos que interagem de forma organizada e que são capazes de aprender e desenvolver suas próprias estratégias.

\subsection{Algoritmos evolutivos}

Os algoritmos evolutivos são modelos de computação inspirados na teoria da evolução. Nesta forma de computação supõe-se que os agentes são entidades sociais ou biológicas que evoluem para se adaptar ao ambiente em que foram inseridos. A ideia que fundamenta este conceito é que, com o passar do tempo, os seres vivos tiveram que evoluir e se adaptar para sobreviver às alterações e influências exercidas pelo ambiente em que viviam. Em um algoritmo evolutivo, considera-se a presença de três mecanismos essenciais: seleção, reprodução e mutação.

O mecanismo de seleção é o responsável por verificar a aderência de um indivíduo no meio em que este fora inserido, de modo que indivíduos com menor aderência sejam eliminados. O mecanismo de reprodução é o que garante que os indivíduos mais aptos gerem descendentes com características semelhantes às suas. Por fim, 0 mecanismo de mutação é o responsável por permitir que novos indivíduos surjam no sistema, seja para se adaptarem a novas condições que lhe foram impostas, seja para melhorar seu desempenho em uma tarefa já conhecida.

\subsection{Computação paralela}

Para extrair uma maior quantidade de dados, simulações computacionais podem exigir condições extremas de execução, cujo tempo de execução é mensurado em dias ou semanas de execução contínua. Com o intuito de reduzir o tempo de execução dessas simulações, atualmente diversas técnicas são aplicadas para tentar diminuir a complexidade do código e, possivelmente, permitir que a simulação seja executada em um espaço menor de tempo. No entanto, de acordo com o problema que está sendo resolvido, nem sempre é possível conseguir uma grande melhora no tempo de execução do sistema apenas fazendo uso dessas técnicas. Nestes casos em particular, uma boa alternativa é a computação paralela.

A Computação Paralela é uma forma de computação que tem por objetivo possi- 
bilitar a execução de cálculos simultâneos para o cumprimento de tarefas específicas (ALMASI; GOTTLIEB, 1989). Operando sob o princípio que tarefas grandes podem ser segmentadas e divididas em tarefas menores para serem resolvidas, é uma área que vem se expandido com o surgimento e o barateamento dos sistemas multiprocessados.

Sistemas multiprocessados, por sua vez, são arquiteturas especiais providas de diversos processadores ou estações de processamento interconectadas por algum meio e que podem compartilhar recursos como memória, barramento, dispositivos etc. Estas arquiteturas são projetadas para trabalhar em conjunto para a execução de tarefas que necessitam de alta capacidade computacional ou de grande precisão, como simulações, métodos de busca e otimização, previsões etc. No entanto, embora o funcionamento desses sistemas seja semelhante, a usabilidade destes sistemas não é tão trivial como a utilização de sistemas de execução sequencial: eles requerem cuidados especiais para que a aplicação seja capaz de usufruir de todos os recursos que são oferecidos pelo sistema (PATTERSON; HENNESSY, 1998).

Segundo Roosta (2000), o maior problema na utilização dos recursos disponíveis em um sistema multiprocessado é que a maioria das aplicações disponíveis atualmente foram desenvolvidos sem levar em consideração a necessidade de executar tarefas que exijam processamento intenso, pois esta característica do desenvolvimento leva a estrutura interna do sistema a formar diversas dependências que dificilmente podem ser eliminadas com uma simples alteração no código. Portanto, um dos grandes desafios da computação paralela está justamente com a sua proposta: desenvolver sistemas paralelos é mais complexo do que desenvolver sistemas puramente sequenciais, pois a execução do código simultaneamente por diversos computadores introduz uma nova classe de problemas para a computação, como a dependência de dados, a necessidade de comunicação entre os diversos processos e a sincronização das informações entre os mesmos (PATTERSON; HENNESSY, 1998).

\section{Desempenho e escalabilidade de sistemas paralelos}

O desempenho de um algoritmo geralmente é determinado pelo seu tempo de execução, expresso como uma função do tamanho da entrada fornecida (KUMAR et al., 1994). No entanto, o tempo de execução de um algoritmo não depende unicamente do algoritmo em si, mas também da arquitetura do sistema utilizado. Portanto, podemos deve-se sempre considerar que um sistema paralelo é uma combinação do algoritmo 
com a arquitetura para qual este fora projetado.

Torna-se necessário, então, o estabelecimento de métricas para fazer esta avaliação. Uma dessas métricas é o speedup, que é utilizado para determinar o quanto um algoritmo paralelo é melhor do que sua versão sequencial, sendo definido pela razão do tempo de execução de ambos os sistemas (El-Rewini; Abd-El-Barr, 2005).

Supondo que uma tarefa qualquer pode ser dividida em $k$ subtarefas iguais a serem executadas por $k$ processadores distintos, se $T_{1}$ é o tempo de execução do sistema sequencial (com um processador) e $T_{k}$ é o tempo de execução do sistema com $k$ processadores, define-se:

$$
\begin{aligned}
S(k) & =\text { speedup } \\
& =\frac{T_{1}}{T_{k}}
\end{aligned}
$$

Kumar et al. (1994) define em seu livro o que seria um computador paralelo ideal. Este computador, composto de uma quantidade finita de processadores e de memória compartilhada ilimitada e uniformemente acessível por todos os seus processadores, foi idealizado no sentido de permitir que haja interação entre seus processadores sem custo algum. Teoricamente, um algoritmo paralelo projetado para uma máquina como esta deve produzir um speedup igual a quantidade de processadores utilizados $(S(k)=k)$. Este speedup, chamado de ideal ou linear, determina o limite superior para este atributo pois nesta situação quando é dobrada a quantidade de processadores, dobra-se também a velocidade de execução. Portanto, quando projeta-se um sistema paralelo, um dos objetivos é aproximar o speedup do seu valor ideal teórico.

Apesar de a definição indicar o contrário, na prática muitas vezes podem ser observados sistemas com speedup superior à quantidade de processadores. Este fenômeno, conhecido como speedup super linear ocorre geralmente devido a dois fatores (KUMAR et al., 1994):

- o algoritmo sequencial pode ser melhorado ou;

- a arquitetura do hardware deixa o sistema sequencial em desvantagem.

Normalmente a segunda condição é observada com relação ao uso da memória cache do processador. Os dados de um sistema podem ser muito grandes para que um processador os mantenha dentro de sua memória interna, obrigando-o a utilizar a memória principal. Quando este mesmo sistema é dividido em fragmentos, os dados 
podem passar a caber nessa memória interna, privilegiando a execução do sistema.

Através do speedup calcula-se a eficiência computacional de um algoritmo. Esta é uma estimativa do quão bem utilizados os processadores estão sendo para solucionar um determinado problema, em relação à quantidade de esforço cedido para a comunicação e sincronização do algoritmo paralelo. Um algoritmo com speedup linear ou executado sequencialmente têm eficiência igual a 1,0.

$$
\begin{aligned}
E(k) & =\text { eficiência } \\
& =\frac{S(k)}{k}=\frac{T_{1}}{k T_{k}}
\end{aligned}
$$

\subsection{Algoritmos evolutivos paralelos}

Existem duas maneiras básicas para executar algoritmos evolutivos em ambientes paralelos (CAMPOS; YOSHIZAKI; BELFIORE, 2006): trabalhar com apenas uma população, de modo que a avaliação dos indivíduos seja distribuída em diversos processos concorrentemente (população global); ou trabalhar com diversas populações, de modo que cada processo receba a sua própria população (populações em ilhas).

Utilizar uma única população global é um maneira viável de paralelização quando a execução da função de aptidão - responsável por selecionar os indivíduos mais aderentes ao sistema - é demasiadamente impactante para a execução do sistema, em termos de custo computacional. Neste caso entende-se que a ausência de dependência no cálculo dessa função (que é uma premissa razoável em algoritmos evolutivos), pode ser utilizada em benefício do sistema. Nesta forma de implementação, um processo mestre controla a execução do algoritmo, se responsabilizando pela reprodução e mutação da população, mas atribui a processos escravos a responsabilidade de calcular o desempenho dos indivíduos da população.

Por outro lado, utilizar populações em ilhas consiste na execução do algoritmo simultaneamente em processadores independentes, como se cada um objetivasse resolver um problema distinto. Assim, os processadores trocam seus indivíduos de tempos em tempos através de uma topologia pré-determinada. Este método possui como vantagem a capacidade de simular a imigração de indivíduos de uma população para outra, que é uma das características presentes no processo de evolução natural. Esse tipo de método é aplicável quando as populações são demasiadamente grandes 


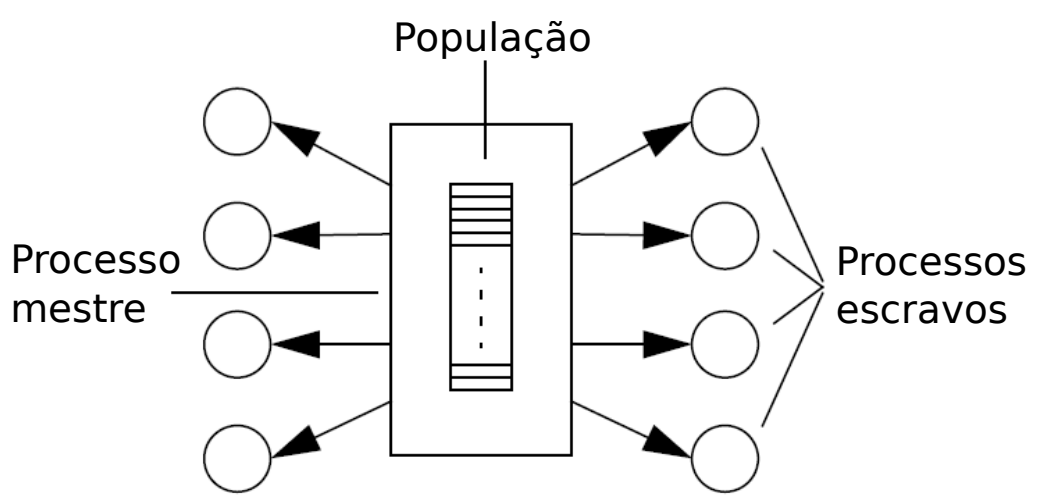

Figura 2.4: Exemplo de paralelização utilizando população global (PIT, 1995)

ou quando o problema é composto de muitos mínimos locais (PIT, 1995).

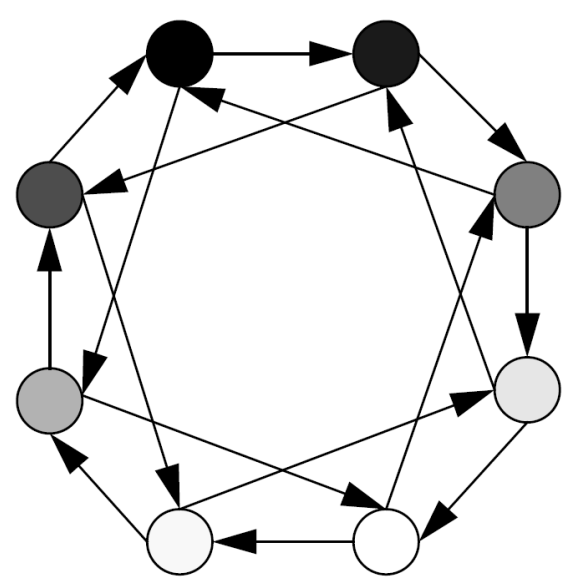

Figura 2.5: Exemplo de paralelização utilizando populações em ilhas (PIT, 1995)

Além das duas implementações citadas, ainda é possível existir uma implementação mista dessas duas técnicas. No entanto, uma técnica mista pode elevar muito a quantidade de processos e, por isso, é preciso observar a granularidade do sistema. Assim, um método misto seria conveniente apenas para a paralelização de sistemas extremamente complexos.

No capítulo seguinte será apresentado o sistema de simulação sequencial do INPPD, bem como suas principais características de funcionamento. 


\section{$3 \quad S_{2} E_{2}$ : ABORDAGEM SEQUENCIAL}

\subsection{Modelo de Lindgren \& Johansson}

Uma das características relevantes no trabalho de Lindgren e Johansson (2003), apresentado originalmente em Lindgren e Nordahl (1994), está relacionada ao ambiente evolutivo proposto. Esse ambiente determina que os agentes que compõem a simulação possuem um ciclo de vida e interagem de acordo com uma dinâmica prédeterminada. Essa dinâmica que coordena as interações dos agentes se baseia na distribuição topológica dos mesmos, ou seja, cada agente ocupa uma posição específica no ambiente e interage apenas com agentes que se encontram acessíveis, dadas algumas restrições.

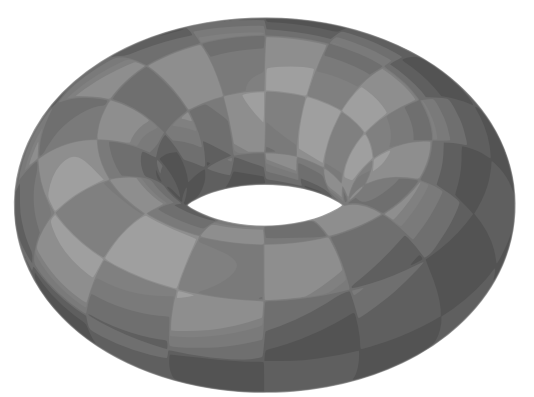

Figura 3.1: Representação gráfica de um toro

No contexto apresentado pelos autores, o ambiente fora definido como um reticulado de tamanho fixo em forma de toro, representado pela figura 3.1. Assim cada célula era ocupada por um agente que interagia com outros agentes conectados seguindo as regras da vizinhança de von Neumann de ordem 1.

Nesta forma de visualização, cada célula é conectada apenas com as quatro células dispostas ortogonalmente ao seu redor, denominadas vizinhas. Essa definição de ambiente, que carece de um ponto central, faz com que todos os agentes presentes interajam com a mesma quantidade de agentes vizinhos e que suas interações não sejam influenciadas, positivamente ou negativamente, pelo posicionamento do mesmo no ambiente.

A projeção bidimensional do toro, assim como a representação de um agente e sua vizinhança pode ser observada nas figuras $3.2 \mathrm{a}$ e $3.2 \mathrm{~b}$. Note que, devido a forma de toro, as células no limite do reticulado se conectam com as células do lado oposto.

Com estas especificações, uma interação ocorre entre os cinco agentes que com- 


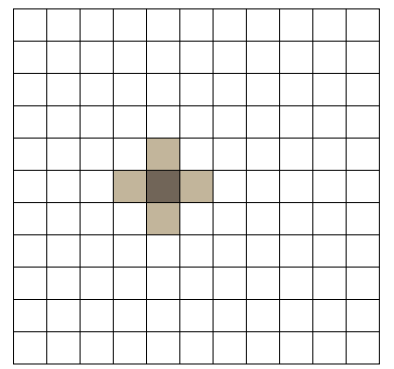

(a)

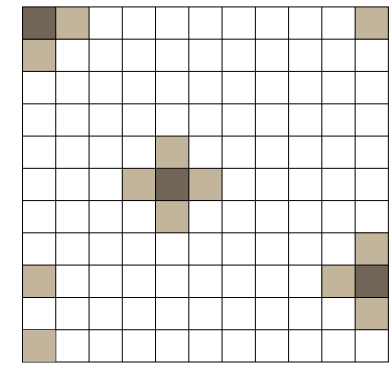

(b)

Figura 3.2: Exemplo de reticulado (a) e vizinhança no limite (b).

põem uma vizinhança, formado pela célula central e suas quatro células vizinhas. Se considerarmos as interações dos agentes e de seus vizinhos, temos que cada um dos agentes participa de cinco interações, que envolvem no total os doze agentes pertencentes à sua vizinhança estendida, representada na figura 3.3. Cada uma dessas interações era constituída por um número fixo $(\tau)$ de iterações do jogo em estudo. Assim, considerando um reticulado com dimensão de $n \times m$, ocorrem exatamente $5 \times \tau \times n \times m$ instâncias do NPPD, por geração.

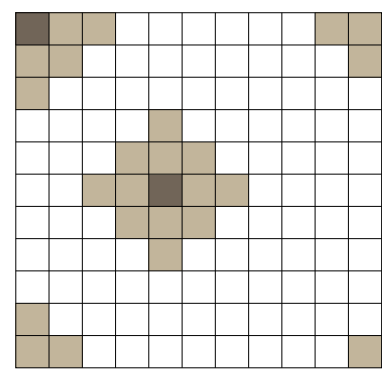

Figura 3.3: Exemplos de vizinhança estendida

Uma geração representa o ciclo de vida da população de agentes, em que ocorrem os processos de seleção, reprodução e mutação de todos agentes do reticulado. Em seu primeiro passo, a seleção, os agentes interagem $\tau$ vezes e recebem uma utilidade que varia de acordo com seu desempenho. Em seguida ocorre a reprodução, onde os agentes com maior utilidade são replicados, substituindo outros com menor utilidade. Por fim, é dado lugar à mutação, que permite que novas estratégias sejam desenvolvidas pelos agentes através de modificações em sua estrutura original.

Lindgren e Johansson compararam os resultados obtidos na simulação deste modelo investigando como a alteração dos parâmetros refletia nos resultados da simulação. Eles executaram simulações em modelos de campo médio, onde as interações individuais são substituídas pela média das interações de todos os jogadores (LASRY; LIONS, 2006a; LASRY; LIONS, 2006b; LASRY; LIONS, 2007; GUÉANT; LASRY; LI- 
ONS, 2011), e em modelos baseados em autômatos celulares, organizando os agentes em um reticulado em forma de toro. Os resultados mostraram que a introdução de limitações espaciais no modelo, ou seja, permitir que os agentes interajam apenas com seus vizinhos, conduziram o desenvolvimento e a manutenção de estratégias mais cooperativas e que a cooperação se estabelece com mais facilidade quando a punição pela não cooperação $(\mathbb{P})$ é suficientemente alta.

\subsection{Extensão do modelo de Lindgren \& Johansson}

Lindgren e Johansson utilizaram diversos formalismos para representar as estratégias dos agentes nos diversos experimentos propostos, sendo que uma delas envolvia a utilização de AFs para a sua representação. O modelo de Bó representou uma extensão dessa representação com o intuito de determinar como a complexidade na representação das estratégias influenciava a obtenção da cooperação. Assim, Bó (2008) desenvolveu o $S_{2} E_{2}$, que comparou o desempenho dos agentes quando suas estratégias eram representadas por AFs e AFAs, dando origem aos modelos JE+AF e $\mathrm{JE}+\mathrm{AA}$.

\subsubsection{Experimentos com os modelos JE+AF e JE+AA}

O modelo JE+AF consistia no jogo evolutivo do INPPD com cinco jogadores utilizando AFs, enquanto o JE+AA consistia no mesmo modelo, porém utilizando AFAs. Em suma foram utilizados parâmetros semelhantes aos utilizados por Lindgren e Johansson, porém, a ideia central do trabalho era determinar se um formalismo capaz de representar estratégias com maior nível de complexidade, que é o caso dos AFAs, obteria um desempenho melhor que um formalismo menos expressivo, os AFs.

Nesse trabalho, que também utiliza o conceito de ambiente evolutivo espacial em forma de toro, todos os agentes eram iniciados com a mesma estratégia e desenvolviam suas próprias estratégias com o passar das gerações através do processo de mutação. As estratégias iniciais utilizadas por Bó são as seguintes:

Sempre delatar (U): $O$ agente inicia jogando $\mathbf{D}$ e mantém essa jogada nas demais iterações independente da ação dos demais jogadores. A figura 3.4 ilustra o AF que representa essa estratégia; 


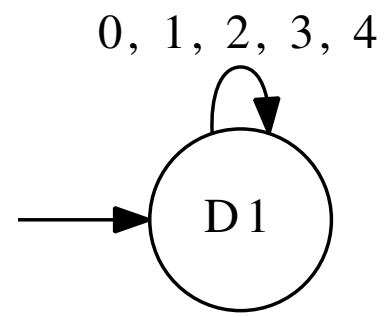

Figura 3.4: Estratégia U

Tit-for-tat para cinco jogadores (TT5): É uma aproximação da estratégia tit-for-tat (AXELROD, 1984) para o INPPD com cinco jogadores. Consiste no agente iniciar jogando $\mathbf{C}$ (voto de confiança), e continuar com a mesma jogada enquanto a maioria também jogar $\mathbf{C}$. Caso a maioria jogue $\mathbf{D}$, então o agente também joga D até que a maioria passe a jogar C. A figura 3.5 ilustra o AF que representa essa estratégia;

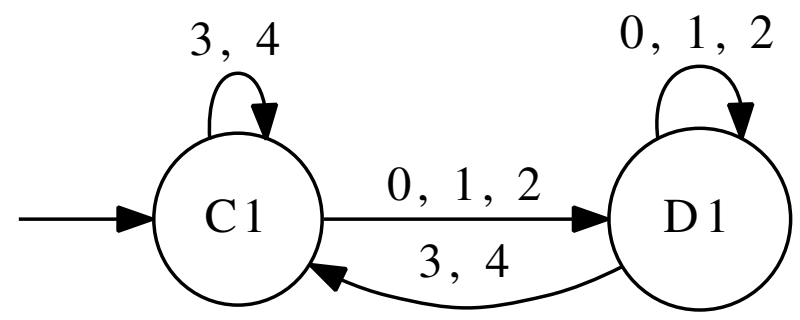

Figura 3.5: Estratégia TT5

Custo Crescente para voltar a cooperar (CCD): Esta estratégia, proposta por Bó e aplicável apenas a AFAs consiste em iniciar jogando $\mathbf{C}$ e manter essa jogada enquanto todos também jogarem $\mathbf{C}$. Além disso, com base neste número de rodadas cooperativas passadas, o jogador determina a quantidade de rodadas que jogará $\mathbf{D}$ a partir do momento em que todos os outros jogadores voltarem a jogar C. A figura 3.6 ilustra essa estratégia.

Bó realizou quatro baterias de testes, duas para cada modelo de modo que eram variadas as quantidades de gerações e as estratégias iniciais dos agentes. Na bateria 01 foram executadas 3 simulações com 8000 gerações onde todos os agentes utilizavam a estratégia $U$. Na bateria 02 foram executadas duas simulações com 5000 gerações em que os agentes iniciavam utilizando tanto a estratégia TT5 (no caso de AFs) quanto a CCD (no caso de AFAs).

Os resultados corroboraram os resultados de Lindgren e Johansson de modo que estratégias de cooperação se tornaram predominantes independente da estratégia 


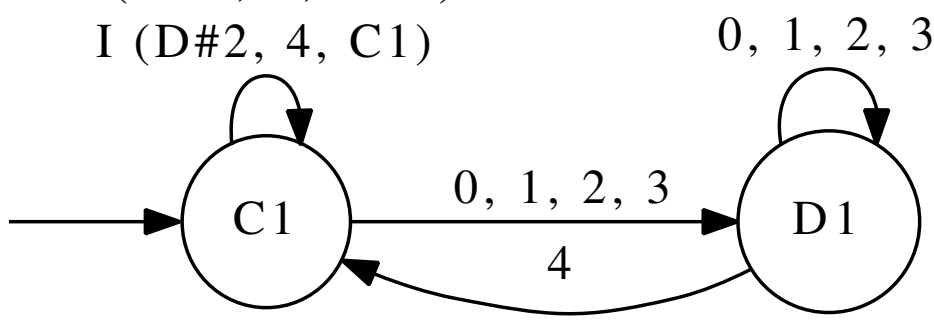

Figura 3.6: Estratégia CCD

Tabela 3.1: Experimentos realizados por Bó (2008)

\begin{tabular}{ccccc}
\hline Modelo & Bateria & Simulações & Gerações & $\begin{array}{c}\text { Estratégia } \\
\text { inicial }\end{array}$ \\
\hline \multirow{2}{*}{$\mathrm{JE}+\mathrm{AF}$} & 01 & 2 & 8000 & $\mathrm{U}$ \\
& 02 & 3 & 5000 & $\mathrm{TT} 5$ \\
$\mathrm{JE}+\mathrm{AA}$ & 01 & 2 & 8000 & $\mathrm{U}$ \\
& 02 & 3 & 5000 & $\mathrm{CCD}$ \\
\hline
\end{tabular}

inicial adotada no modelo JE+AF. Notou-se também que o modelo JE+AA é capaz de desenvolver estratégias de cooperação distintas, mas que não geram uma diferença significativa da utilidade, indicando que os ganhos relacionados à utilização dos AFAs em substituição aos AFs são relativamente baixos. Para endossar estes resultados, o autor sugere o desenvolvimento de simulações com um maior número de gerações para observar o comportamento do sistema ao longo das gerações e reavaliar o ganho com a utilização dos AFAs.

\subsubsection{Análise de desempenho do sistema}

Para a análise de desempenho do $\mathrm{S}_{2} \mathrm{E}_{2}$, foram consideradas as informações fornecidas pelo autor, o ambiente em que fora executado, o modo como o sistema utiliza e gerencia os recursos disponíveis e o tempo de execução de cada etapa do algoritmo, comparando a execução dos modelos JE+AF e JE+AA.

O código utilizado no trabalho de Bó foi cedido para a análise deste trabalho. Os tempos de execução do sistema são apresentados na tabela 3.2 . É importante notar que esses valores são relativos a uma nova execução dos mesmos experimentos utilizando o sistema fornecido e, portanto, diferem dos apresentados pelo autor por terem 
sidos executados em máquinas com configurações distintas.

Tabela 3.2: Tempos médios de execução do $S_{2} E_{2}$

\begin{tabular}{cccccc}
\hline \multirow{2}{*}{ Modelo } & \multirow{2}{*}{ Bateria } & \multicolumn{2}{c}{ Todas as gerações } & \multicolumn{2}{c}{ Uma geração } \\
\cline { 2 - 6 } & & $\mu$ & $\sigma$ & $\mu$ & $\sigma$ \\
\cline { 2 - 6 } JE+AF & 01 & 65 h 48 min. & 38 min. & 29,74 seg. & 1,08 seg. \\
& 02 & 41 h 54 min. & 1 h 53 min. & 30,31 seg. & 1,29 seg. \\
JE+AA & 01 & 89h 47 min. & 6 h 21 min. & 40,57 seg. & 6,97 seg. \\
& 02 & 62 h 1 min. & 1 h 44 min. & 46,24 seg. & 3,07 seg. \\
\hline
\end{tabular}

Nessa tabela é possível observar que os tempos de execução da simulação são elevados e que podem levar dias de execução contínua. Observa-se também que tempo de execução da bateria 01 foi maior que o da bateria 02 em ambos os modelos devido ao fato dela ser constituída por uma quantidade maior de gerações (vide tabela 3.1. No modelo JE+AF, a estratégia inicial não aparenta influenciar significativamente o tempo de execução do algoritmo, causando um aumento de apenas 1,92\% no tempo médio de execução de uma geração, enquanto o modelo JE+AA aparenta influenciar mais no tempo de execução do algoritmo, causando um aumento de 13,98\%, provavelmente devido a maior complexidade das estratégias produzidas.

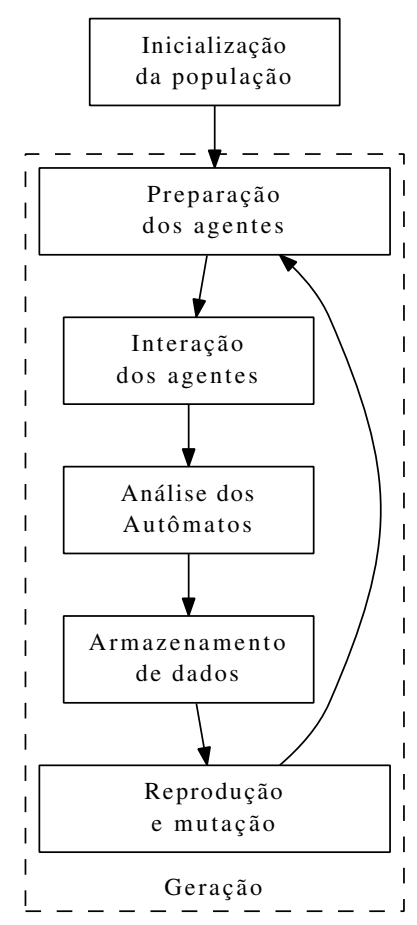

Figura 3.7: Diagrama de execução do $\mathrm{S}_{2} \mathrm{E}_{2}$

Embora estes valores totais nos forneçam uma base para entender a dinâmica do sistema, para realizar uma análise mais apurada do tempo de execução foram 
analisados individualmente os diversos estágios da execução interna do algoritmo, representados pelos itens da figura 3.7. Para a medição dos tempos em cada estágio, o código do $\mathrm{S}_{2} \mathrm{E}_{2}$ foi adaptado neste projeto de modo a apresentar os tempos de execução de cada passo sem afetar seu funcionamento. Os tempos coletados para cada uma das fases de ambos os modelos encontram-se listados nas tabelas $3.3 \mathrm{e}$ 3.4.

Tabela 3.3: Tempos médios de execução das operações do modelo JE+AF(em segundos).

\begin{tabular}{lcccc}
\hline \multirow{2}{*}{ Operação } & \multicolumn{2}{c}{ Bateria 01 } & \multicolumn{2}{c}{ Bateria 02 } \\
\cline { 2 - 5 } & $\mu$ & $\sigma$ & $\mu$ & $\sigma$ \\
\hline Preparação dos agentes & 0,20 & 0,01 & 0,21 & 0,03 \\
Interação dos agentes & 26,95 & 0,21 & 27,32 & 1,02 \\
Análise dos autômatos & 0,40 & 0,05 & 0,50 & 0,19 \\
Armazenamento de dados & 0,02 & $<0,01$ & 0,03 & 0,01 \\
Reprodução e mutação & 2,04 & 0,02 & 2,11 & 0,11 \\
\hline
\end{tabular}

Apesar dos modelos possuírem grandezas distintas, verifica-se que suas características são semelhantes. Em ambos os casos, o passo que requer a maior fatia de tempo para execução é a interação dos agentes, representando 91,02\% e 90,55\% do tempo total de execução das baterias 01 e 02 do modelo JE+AF; e 77,95\% e 81,26\% do tempo total de execução das baterias 01 e 02 do modelo JE+AA.

Portanto, conclui-se que o maior dificuldade dessa simulação, em termos do tempo de execução, é a interação dos agentes, pois é a operação que possui maior relevância durante o processamento de uma geração e, consequentemente, afeta a simulação do sistema como um todo. Tendo isso em vista, entende-se que este é o ponto que merece maior atenção, considerando que o interesse é melhorar o desempenho do sistema.

Tabela 3.4: Tempos médios de execução das operações do modelo JE+AA (em segundos).

\begin{tabular}{lcccc}
\hline \multirow{2}{*}{ Operação } & \multicolumn{2}{c}{ Bateria 01 } & \multicolumn{2}{c}{ Bateria 02 } \\
\cline { 2 - 5 } & $\mu$ & $\sigma$ & $\mu$ & $\sigma$ \\
\hline Preparação dos agentes & 0,66 & 0,13 & 0,79 & 0,06 \\
Interação dos agentes & 31,49 & 1,52 & 36,29 & 0,78 \\
Análise dos autômatos & 3,28 & 0,36 & 1,84 & $<0,01$ \\
Armazenamento de dados & 0,15 & 0,01 & 0,12 & $<0,01$ \\
Reprodução e mutação & 4,82 & 0,86 & 5,62 & 0,42 \\
\hline
\end{tabular}


Neste capítulo, foram apresentados os modelos de simulação de Lindgren e Johansson e Bó, incluindo uma análise de desempenho deste último. Mostrou-se que uma abordagem sequencial para simulação do INPPD pode requerer muito tempo de execução, o que dificulta a coleta de resultados e a avaliação de parâmetros de teste adicionais. Para resolver este problema, neste trabalho propõe-se reimplementar o sistema $\mathrm{S}_{2} \mathrm{E}_{2}$, com o intuito de melhorar seu desempenho através do uso de programação paralela.

Assim, no próximo capítulo é introduzido o sistema $\mathrm{PS}_{2} \mathrm{E}_{2}$ e sua proposta de paralelização. 


\section{$4 \mathrm{PS}_{2} \mathrm{E}_{2}$ : ABORDAGEM PARALELA}

\subsection{Paralelização do $\mathrm{S}_{2} \mathrm{E}_{2}$}

$\mathrm{O} \mathrm{PS}_{2} \mathrm{E}_{2}$ (Sistema Paralelo de Simulação Evolutiva Espacial) é uma reimplementação do $S_{2} E_{2}$ para a execução em ambientes de computação paralela. Embora quaisquer sistemas possam ser executado nesses ambientes; entende-se que um dos grandes objetivos seja garantir a boa utilização dos recursos disponíveis a fim de melhorar o desempenho do sistema. Para tanto, torna-se necessário determinar quais métodos podem e devem ser utilizados para auxiliar nesta tarefa.

Como visto na análise apresentada no capítulo anterior, um dos grandes problemas do $\mathrm{S}_{2} \mathrm{E}_{2}$ está relacionado à interação dos agentes. Dentro do contexto de algoritmos evolutivos, a interação dos agentes pode ser entendida como o momento em que o desempenho da população é avaliado, pois é a partir dos resultados dessa interação que somos capazes apurar o desempenho dos agentes.

Portanto, observa-se um caso em que o cálculo da função de aptidão é muito custoso. Assim, para aumentar a eficiência dessa tarefa, optou-se por utilizar o método global de paralelização dos algoritmos evolutivos, pois ele se demonstra especialmente útil para a solução destes casos. Na implementação desse método é preciso alocar, em cada um dos processos, um ou mais agentes para que a aptidão deles seja calculada simultaneamente, de modo que, quão maior for a quantidade de agentes processados paralelamente, mais rápida será a execução da interação de todo o conjunto.

\subsection{Divisão do ambiente}

Para a paralelização do sistema foi constatada a necessidade de dividir o espaço em que os agentes estavam dispostos de modo a distribuí-los em diversos processos. $\mathrm{Na}$ computação de um modo geral, sempre que uma tarefa é dividida, é preciso observar a sua granularidade com o intuito de não torná-la fina demais, evitando que suas subtarefas sejam demasiadamente pequenas e que o processamento necessário para o gerenciamento das mesmas seja maior do que o tempo de sua execução.

Dado esse problema, observa-se então que é preciso determinar uma boa relação 
entre a quantidade de processos e o tamanho do problema a ser resolvido, de modo que seja garantida a utilização adequada dos recursos. Este problema, inicialmente abordado em Macedo e Sichman (2010), é detalhado a seguir.

\subsubsection{Problema da divisão}

Ao dividir o problema para a execução em processos homogêneos independentes, é desejável que sejam estabelecidas tarefas de tamanhos equivalentes, de modo a distribuir uniformemente a quantidade de dados a serem processados. Desse modo, a figura 4.1 ilustra uma possível maneira de dividir o reticulado em quatro partes de tamanhos compatíveis.

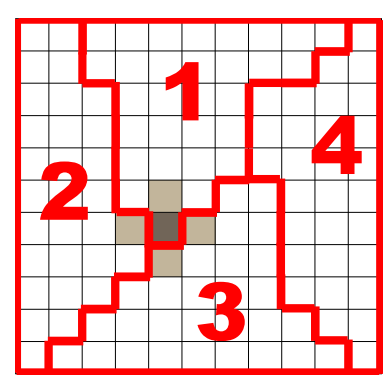

Figura 4.1: Exemplo de divisão do reticulado. Nesta figura observa-se que o agente destacado no grupo 1 precisa de agentes que estão nos grupos 2 e 3.

Observando a figura notamos que o corte sugerido separa alguns dos agentes de seus vizinhos, o que impossibilita a interação entre eles. Isso nos leva a crer que, embora a simulação não gere nenhum tipo de dependência entre as interações dos agentes, a interação deles é dependente da disponibilidade dos vizinhos. Sem sombra de dúvida, qualquer divisão que possa ser sugerida sempre possuirá um ou mais agentes isolados, sem a informação necessária para que possam interagir.

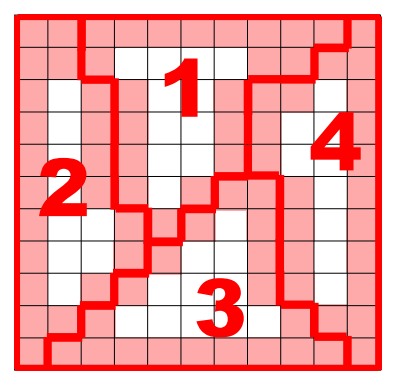

Figura 4.2: Ilustração dos agentes que devem ser clonados (representados em rosa).

Uma maneira de resolver este problema é manter clones dos agentes que estão na fronteira em todos os grupos em que sua presença seja requerida. Baseando-se ainda 
na figura 4.1, os agentes destacados nos grupos 2 e 3 teriam seus clones inseridos nos grupo 1. A figura 4.2 ilustra novamente essa figura, destacando os agentes que necessitam de clones. Nessa figura nota-se, inclusive, que a quantidade de agentes a serem clonados (81) é maior do que a quantidade de agentes cuja clonagem não é necessária (40).

Na prática, a clonagem desses agentes é considerada um excesso ao processamento gerado pela tentativa de paralelização da simulação, isto é, algo que seria desnecessário se a mesma fosse executada em apenas uma máquina. A esse excesso de processamento dá-se aqui o nome de overhead. Assim, uma pergunta a ser respondida é a seguinte: dado um reticulado qualquer, qual a divisão que possui a menor quantidade de agentes cuja clonagem é necessária e com o menor overhead?

Para responder essa pergunta, definiremos o problema formalmente. Seja $\mathbb{U}=$ $\left\{a_{11}, a_{12}, \ldots, a_{1 m}, a_{21}, \ldots, a_{2 m}, \ldots a_{n 1}, \ldots, a_{n m}\right\}$ o conjunto constituído pelos dados dos $n \times$ $m$ agentes dispostos sobre o toro, sendo $a_{i j}$ o agente disposto na linha $i$ da coluna $j$ do reticulado correspondente. Consideramos $G=\left\{A_{1}, A_{2}, \ldots, A_{k}\right\}$ como uma alocação de agentes a serem distribuídos pelos $k$ processos $\left(A_{p} \in 2^{\mathbb{U}}\right)$, que permita que cada jogador jogue com seu respectivos vizinho. Em outras palavras, uma alocação de agentes que interagem utilizando a vizinhança de von Neumann de ordem 1, precisa satisfazer as seguintes expressões:

$$
\begin{aligned}
& \forall a_{i j} \in \mathbb{U}, \exists A_{p} \in G \Longrightarrow\left\{a_{i j}, a_{(i+1) j}, a_{i(j+1)}, a_{(i-1) j}, a_{i(j-1)}\right\} \subseteq A_{p} \\
& \forall A_{p} \in G, \exists a_{i j} \in \mathbb{U} \Longrightarrow\left\{a_{i j}, a_{(i+1) j}, a_{i(j+1)}, a_{(i-1) j}, a_{i(j-1)}\right\} \subseteq A_{p}
\end{aligned}
$$

Devido a disposição dos agentes em forma de toro, considera-se ainda as seguintes regras:

$$
\begin{aligned}
& i=n: \text { se } a_{i j}=a_{n j} \text { então } a_{(i+1) j}=a_{1 j} \\
& i=1: \text { se } a_{i j}=a_{1 j} \quad \text { então } a_{(i-1) j}=a_{n j} \\
& j=m: \text { se } a_{i j}=a_{i m} \text { então } a_{i(j+1)}=a_{i 1} \\
& j=1: \text { se } a_{i j}=a_{i 1} \text { então } a_{i(j-1)}=a_{i m}
\end{aligned}
$$

Deste modo, a equação 4.1 determina que todos os agentes devem estar contidos em algum $A_{p} \in G$ com seus respectivos vizinhos; e a equação 4.2 determina que todo grupo $A_{p}$ deve conter, pelo menos, um agente e seus vizinhos respectivos.

Seja então a seguinte proposição: 
Proposição 1: Dada a dinâmica do jogo, se $k>1$ não existe uma alocação $G$ tal que $A_{p} \in G$ e $A_{p} \cap A_{q}=\emptyset, \forall A_{q} \in G$ com $A_{p} \neq A_{q}$ e que satisfaça as expressões 4.1 e 4.2, isto é, não existe uma forma de dividir o reticulado de modo que existam grupos de agentes formados apenas por elementos distintos daqueles que pertencem aos demais grupos.

Demonstração: Dada uma alocação $G=\left\{A_{1}, A_{2}, \ldots, A_{k}\right\}$ de subconjuntos de $\mathbb{U}$ que satisfaça as condições apresentadas nas expressões 4.1 e 4.2 . Suponha que existe um conjunto $A_{p} \in G$ tal que $A_{p} \cap A_{q}=\emptyset, \forall A_{q} \in G$ e que $|G|=k>1$. Demonstra-se que essa suposição leva a uma contradição.

Seja $a_{i j}$ um elemento qualquer deste conjunto. Como nenhum elemento de $A_{p}$ está em qualquer outro conjunto de $G\left(A_{p} \cap A_{q}=\emptyset\right)$, então $\left\{a_{(i+1) j}, a_{i(j+1)}, a_{(i-1) j}, a_{i(j-1)}\right\}$ deve estar contido em $A_{p}$, de acordo com a condição apresentada na expressão 4.1. Repete-se este passo para cada novo elemento de $A_{p}$, o que implica na inclusão de mais elementos em $A_{p}$.

Por indução, nota-se que a adição de qualquer elemento neste conjunto resulta na inserção de mais elementos, até que sejam inclusos todos os elementos do reticulado $\mathbb{U}$.

Portanto, como $A_{p}=\mathbb{U}$ e $A_{p} \cap A_{q}=\emptyset, \forall A_{p} \in G$, não existem elementos de $\mathbb{U}$ que poderiam ser inseridos nos demais conjuntos de $G$, então $A_{q}=\emptyset$. Contudo, a condição apresentada na expressão 4.2 determina que não podem existir conjuntos em $G$ que não contenham dados suficientes para que haja iteração entre ao menos um jogador, fazendo com que $A_{q} \notin G$. Neste caso, $G=\left\{A_{p}\right\}=\{\mathbb{U}\}$ e $|G|=k=1$, ou seja, uma contradição.

Definimos, portanto, o overhead de um grupo $A_{p}$ como o conjunto de agentes que não podem interagir com seus vizinhos, mas que estão presentes no grupo para que outros agentes possam interagir. Assim, a função overhead : $2^{\mathbb{U}} \rightarrow 2^{\mathbb{U}}$ é descrita como:

$$
\operatorname{overhead}\left(A_{p}\right)=A_{p}-J\left(A_{p}\right)
$$

onde $J\left(A_{p}\right) \subset A_{p}$ é o conjunto de todos os agentes que podem interagir no grupo. Se a vizinhança for uma vizinhança de von Neumann de ordem 1, essa função é:

$$
J\left(A_{p}\right)=\left\{a_{i j} \in A_{p} \mid\left\{a_{(i+1) j}, a_{(i-1) j}, a_{i(j+1)}, a_{i(j-1)}\right\} \subset A_{p}\right\}
$$

Dada uma alocação $G$ sobre o reticulado $\mathbb{U}$, define-se o overhead total através da 
função $L: G \rightarrow \mathbb{N}$ como a soma dos overheads de todos os grupos $A_{p} \in G$ :

$$
L(G)=\sum_{A_{p} \in G} \mid \text { overhead }\left(A_{p}\right) \mid
$$

Portanto, sendo $k_{\max }$ a quantidade máxima de processos que podemos alocar com os recursos disponíveis (de modo que não haja concorrência) e $\partial=\left\{G_{1}, G_{2}, G_{3}, \ldots\right\}$ o conjunto de todas as alocações possíveis sobre o reticulado $\mathbb{U}$ que respeitem às condições expressas nas expressões $4.1 \mathrm{e}$ 4.2, o problema é encontrar o conjunto $G_{r} \in \partial$ de máxima cardinalidade $k$ tal que $L\left(G_{r}\right) \leq L\left(G_{r}^{\prime}\right), \forall G_{r}^{\prime} \in \partial$ e $\left|G_{r}\right|=k \leq k_{\max }$.

\subsubsection{Grupos ótimos}

Para sugerir uma solução ao problema apresentado na seção anterior, definimos o que é um grupo ótimo. Entende-se como um grupo válido como sendo qualquer elemento de uma alocação $G \in \partial$ que satisfaça as expressões 4.1 e 4.2 . Um grupo ótimo, por sua vez, é um grupo válido cuja inserção de qualquer agente implica no aumento do seu overhead.

Definição: Um grupo $A_{p}$ de agentes do reticulado é considerado ótimo - para fins de processamento paralelo - se não existe um grupo $A_{q}$ diferente de $A_{p}$ que contém todos os elementos de $A_{p}$, porém com um overhead menor. Assim, dado um reticulado $\mathbb{U}$ qualquer, o conjunto de grupos ótimos é definido por:

$$
O(\mathbb{U})=\left\{A_{p} \in 2^{\mathbb{U}}|| \text { overhead }\left(A_{p}\right)|\leq| \operatorname{overhead}\left(A_{q}\right) \mid, \forall A_{q} \in 2^{\mathbb{U}} \text { e } A_{p} \subset A_{q}\right\}
$$

De forma análoga, uma alocação ótima, é uma alocação G que contém apenas grupos ótimos, ou seja, para um reticulado $\mathbb{U}$, se $A_{p} \in G$ então $A_{p} \in O(\mathbb{U})$. A figura 4.3 ilustra um grupo não ótimo e um grupo ótimo, respectivamente. É importante notar que justamente a existência do grupo representado na figura $4.3 \mathrm{~b}$ é que faz com que o grupo da figura $4.3 a$ não satisfaça a condição ótima.

A propriedade ótima de um grupo pode ser determinada verificando se a inserção de algum dos agentes que estão na fronteira do grupo faz com que o overhead permaneça inalterado. Caso positivo, o grupo não é ótimo. Assim sendo, para tornar um grupo não ótimo em um grupo ótimo, basta inserir estes agentes ao grupo e repetir o teste até que a inserção de qualquer agente da fronteira do grupo faça o overhead 


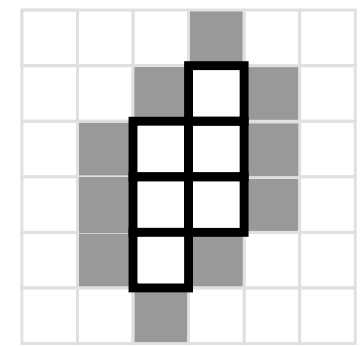

(a) Agentes: 6

Overhead: 10

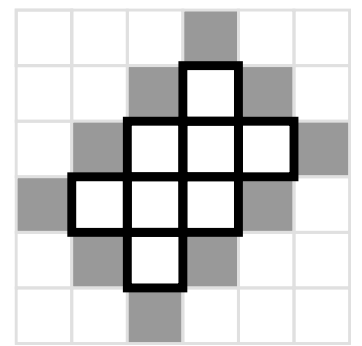

(b) Agentes: 8

Overhead: 10

Figura 4.3: Exemplo de um grupo não ótimo (figura 4.3a) e um grupo ótimo (figura 4.3b em um reticulado $6 \times 6$. As células com bordas escuras representam os agentes contidos no grupo e as células destacadas representam o overhead do mesmo.

aumentar.

\subsubsection{Busca no espaço de grupos ótimos}

Para obter uma alocação ótima para os agentes, definimos uma busca que não se importa com a posição absoluta dos agentes no reticulado, mas na geometria formada pela divisão do reticulado que forma o grupo. Então apresentamos aqui uma busca no espaço de grupos ótimos, que organiza os dados em uma árvore de busca (RUSSELL; NORVIG, 2003), onde cada vértice representa uma forma geométrica que deve ser utilizada para formar a alocação ótimo que resolve o problema.

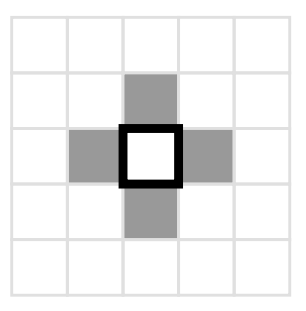

Agentes: 1

Overhead: 4

Figura 4.4: Ilustração do menor grupo ótimo

Intuitivamente, sabemos que o menor grupo válido que pode ser definido é o grupo formado por um único agente (figura 4.4). Este grupo é ótimo pois a adição de qualquer um dos agentes que o cercam implica no aumento do seu overhead. Assim sendo, definimos este grupo como a raiz da nossa árvore de busca.

É possível expandir este grupo aumentando o número de agentes no grupo. Assim, definimos uma função de sucessão que retorna o conjunto como todos os grupos 
que podem ser formados através da inserção de um agente vizinho no grupo. Como declarado anteriormente, esta busca não se interessa no posicionamento dos agentes no reticulado, portanto, dois grupos são considerados equivalentes se for possível rotacioná-los ou espelhá-los para que tenham a mesma forma ${ }^{1}$. Aplicando esta função ao vértice raiz, tem-se como retorno um grupo formado por duas células adjacentes. Este grupo que também é o próximo vértice a ser visitado, representa uma melhor solução em termos de custo computacional do que o vértice precedente, uma vez que possui uma taxa menor de overhead por agente.

Aplicando a função neste novo vértice, obtemos dois novos vértices que representam dois grupos diferentes, no entanto, um deles não é ótimo logo precisamos otimizá-lo antes de visitá-lo. A figura 4.5 ilustra este processo iterativo.

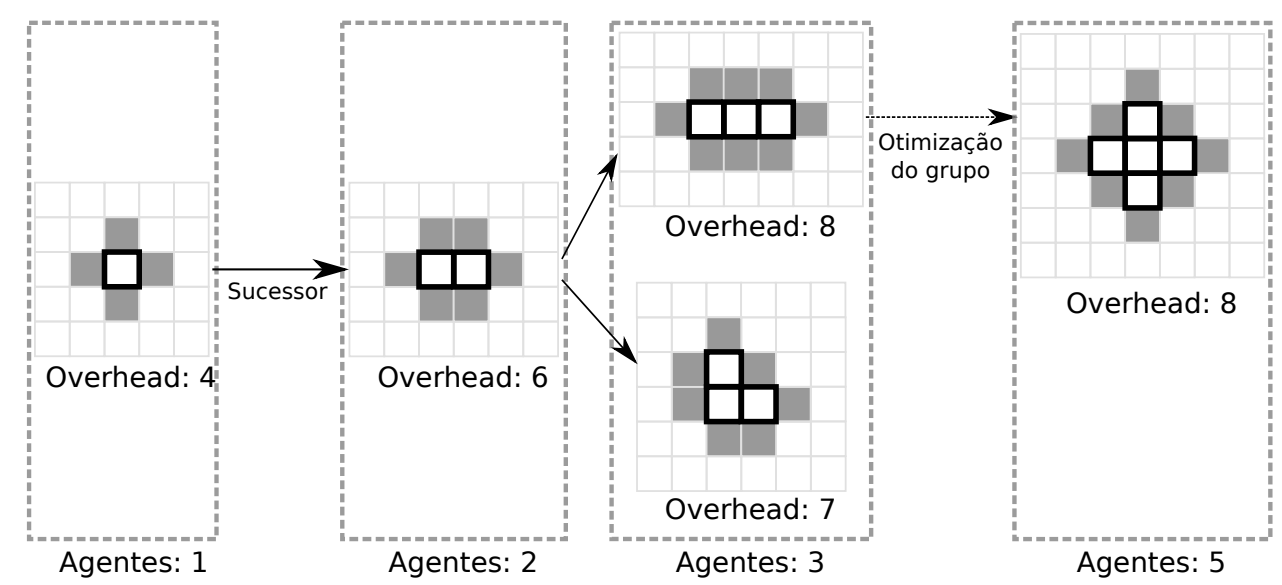

Figura 4.5: Demonstração da função de sucessão e de otimização.

Seria possível continuar expandindo o tamanho do grupo até que não existissem mais vértices sucessores. Nesta situação, teríamos encontrado a folha cujo grupo correspondente contém todos os agentes do reticulado, o que não é exatamente o que procuramos. A princípio, como estamos efetuando uma busca dentro de um espaço de grupos ótimos, entende-se que qualquer vértice encontrado poderia ser utilizado para determinar uma alocação $G_{r}$ válida que minimiza $L$, portanto, é preciso determinar um ponto de parada para esta busca.

Como $k_{\text {max }}$ é a quantidade máxima de processos que podemos alocar com os recursos disponíveis, podemos concluir que não seria interessante se a quantidade de elementos da alocação $G_{r}$ indicada pela busca fosse maior que este valor, pois assim teríamos mais fatias da tarefa do que recursos para processá-la. Assim, partindo da premissa que nosso sistema é homogêneo, ou seja, a mesma quantidade de

\footnotetext{
${ }^{1}$ Este procedimento traz à tona um problema combinatório que não é tratado por este trabalho. As soluções para os problemas combinatórios foram encontradas manualmente por tentativa e erro.
} 
recursos são alocados todos processos, cada grupo da nossa alocação deve possuir $|\mathbb{U}| / k_{\text {max }}$ agentes, pelo menos, para evitar que o número de alocações seja maior que o de recursos. Uma vez que a busca atinge esse limiar, selecionamos o grupo com menor overhead dentre os grupos disponíveis que possuem o tamanho desejado. Os algoritmo 4.1 e 4.2 mostram a implementação dessa busca e da função de sucessão.

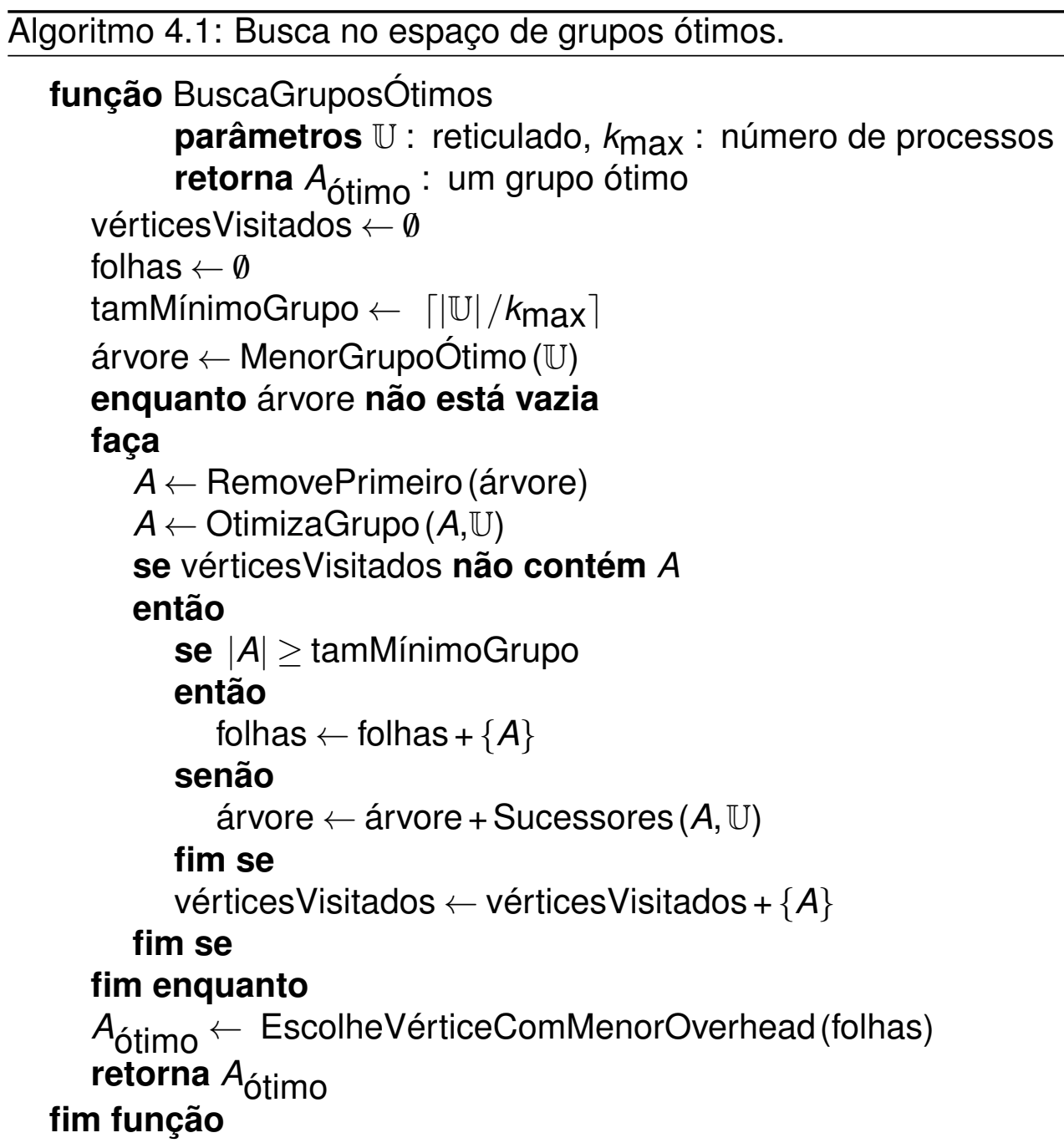

Como resultado desse algoritmo obtém-se um grupo ótimo de tamanho e forma apropriada para ser utilizado pela simulação. Assim, o próximo passo é definir a alocação ótima formada por cópias do grupo obtido com o algoritmo de busca. Em geral, observa-se que o resultado desse algoritmo possui a forma geométrica de um losango ou similar. Esta resposta é evidente pelo fato da vizinhança de von Neumann de ordem 1 se expandir num sentido que colabora essa formação. Baseando-se neste argumento entende-se que o reticulado formado por agentes que interagem seguindo as regras da vizinhança de von Neumann dessa ordem deve ser dividido em formas losangulares com o intuito de diminuir o overhead da simulação. 


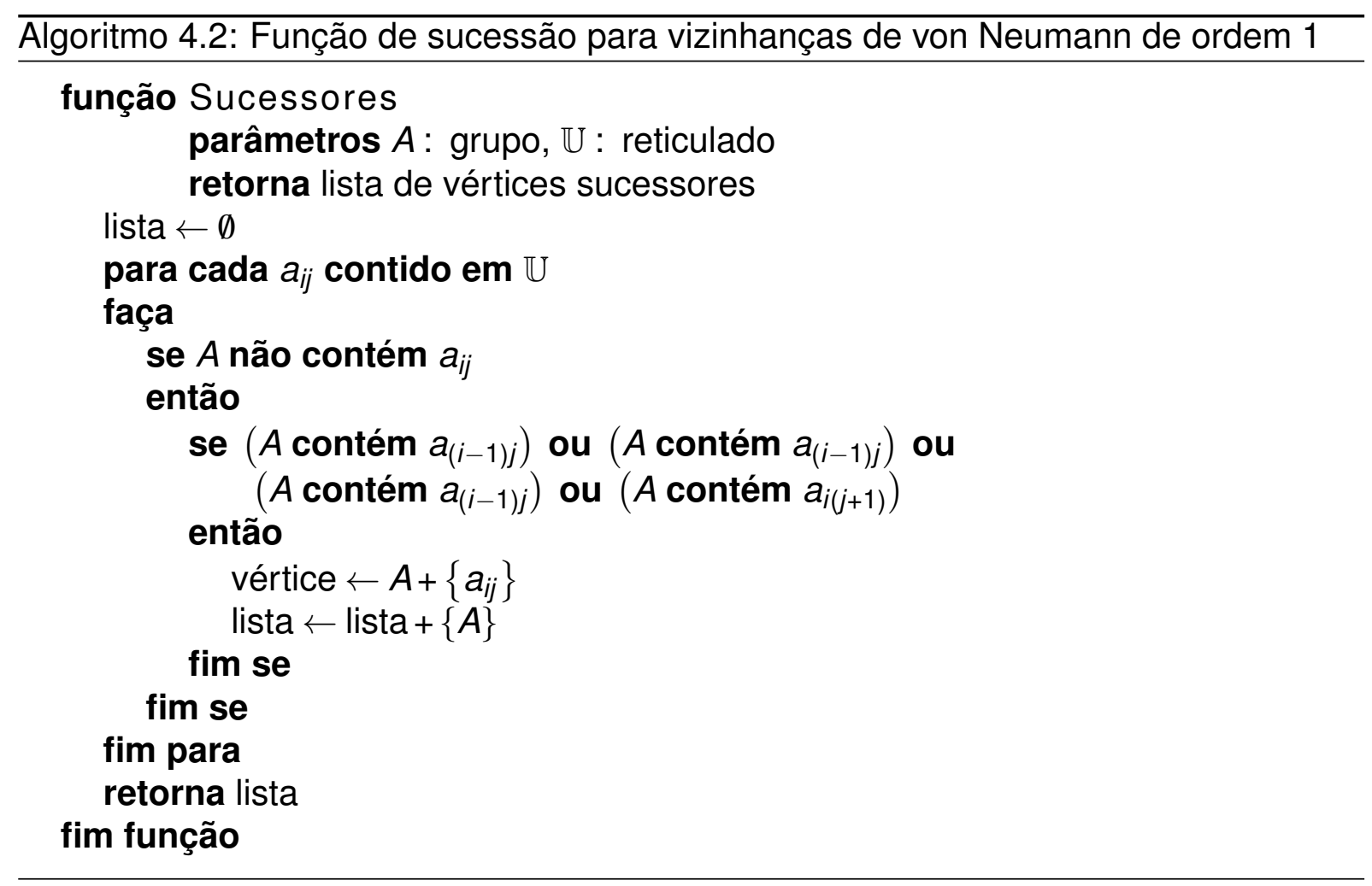

\subsection{Projeto do $\mathrm{PS}_{2} \mathrm{E}_{2}$}

Nas subseções seguintes é apresentado alguns elementos da arquitetura de software, a plataforma de execução e o mecanismo de paralelização do $\mathrm{PS}_{\mathbf{2}} \mathrm{E}_{\mathbf{2}}$.

\subsubsection{Elementos da arquitetura de software}

O sistema foi dividido em seis elementos primários: Simulação, Jogo, Ambiente, Vizinhança, Agente e Estratégia. Cada elemento desta arquitetura é representado por uma entidade na figura 4.6 .

Para inicializar o sistema, primeiramente a estratégia é construída, seja ela representada por um AF ou um AFA, para que depois um agente seja instanciado. O agente é o responsável por determinar suas jogadas e guardar informações, tais como a contabilização de seus ganhos, a última jogada feita etc. Uma vez instanciado o agente e determinada a vizinhança que será utilizada, inicia-se o processo de instanciação do ambiente, que preenche todas as suas posições com clones do agente inicial. $O$ ambiente é o elemento que determina a posição dos agentes no espaço e os interliga através da vizinhança fornecida, formando os grupos de agentes vizinhos.

Determinado o ambiente e o jogo que ditará as regras das interações dos agentes, 
o processo se finaliza com a formação do mecanismo de simulação. Esse mecanismo representa o controle principal do sistema, responsável pela dinâmica evolutiva do ambiente. É ele quem controla as gerações do ambiente e invoca os mecanismos de seleção, reprodução e a mutação dos agentes.

A simulação evolutiva se comunica com um mecanismo que implementa mutações de agentes. Essa forma de abstração permite que novas mutações sejam inclusas no sistema sem a necessidade de alterar a estrutura original do código. $\mathrm{O} \mathrm{PS}_{\mathbf{2}} \mathrm{E}_{\mathbf{2}}$ implementa e utiliza as mesmas mutações propostas por Bó, a saber:

Altera o tipo de estado Escolhe aleatoriamente um estado do autômato e altera seu tipo (de $\mathbf{C}$ para $\mathbf{D}$ ou vice-versa).

Altera uma transição Escolhe dois estados do autômato e um rótulo aleatoriamente. Se a transição já existir, ela é removida, caso contrário é adicionada.

Altera o estado inicial Escolhe aleatoriamente um estado do autômato e o define como estado inicial.

Adiciona um novo estado Escolhe aleatoriamente um tipo de estado o e insere no autômato. Depois escolhe aleatoriamente outro estado do autômato e cria transições partindo deste para o estado recém-criado com todos os rótulos possíveis.

Nova função adaptativa Cria aleatoriamente uma função adaptativa de até 3 ações, bem como todos os seus parâmetros. Depois, uma transição é selecionada aleatoriamente do autômato para receber a função adaptativa recém-criada; se a transição já possuir outra função adaptativa alocada, ela é sobrescrita. Este tipo de mutação ocorre somente nas simulações envolvendo AFAs.

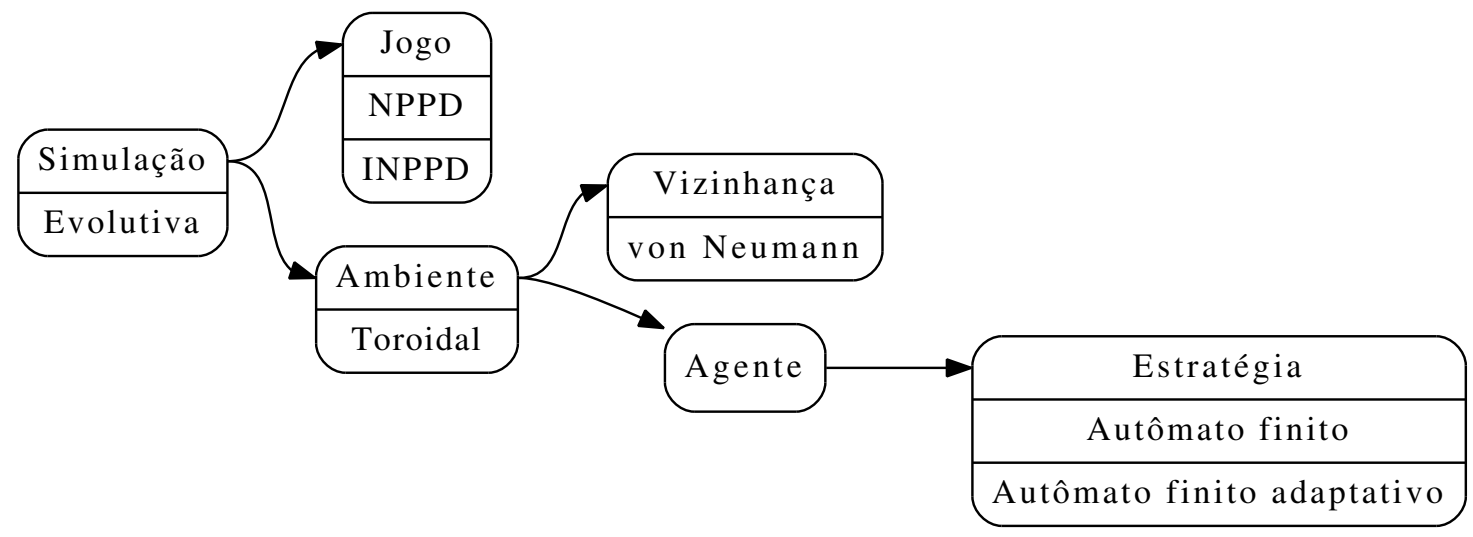

Figura 4.6: Arquitetura do sistema $\mathrm{PS}_{2} \mathrm{E}_{2}$ 


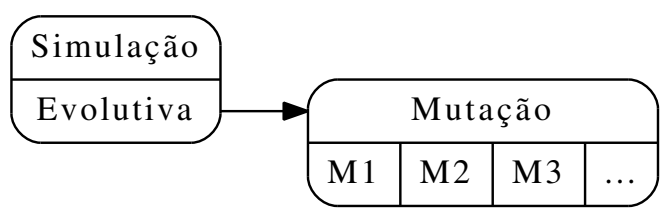

Figura 4.7: Associação do mecanismo de simulação evolutiva com o de mutação do sistema $\mathrm{PS}_{2} \mathrm{E}_{2}$.

\subsubsection{Plataforma de execução}

Para o desenvolvimento do $\mathrm{PS}_{\mathbf{2}} \mathrm{E}_{2}$ optou-se por utilizar a linguagem de programação Python que fora a mesma utilizada pelo $\mathrm{S}_{2} \mathrm{E}_{2}$. Além do intuito de aproveitar o que já havia sido desenvolvido, essa opção foi feita também devido ao Python ser largamente utilizado por uma comunidade ativa e pela velocidade de execução de seu código ser equiparado com códigos compilados, apesar de ser executada através de um interpretador.

\subsubsection{Mecanismo de paralelização}

A paralelização do sistema foi implementada através do módulo Parallel Python (VITALII, 2005). Como foi apresentado na seção 3.2.2, apenas um estágio da simulação será paralelizado, assim, optou-se por uma arquitetura do tipo mestre/escravo, onde um processo mestre controla outros processos, denominados escravos.

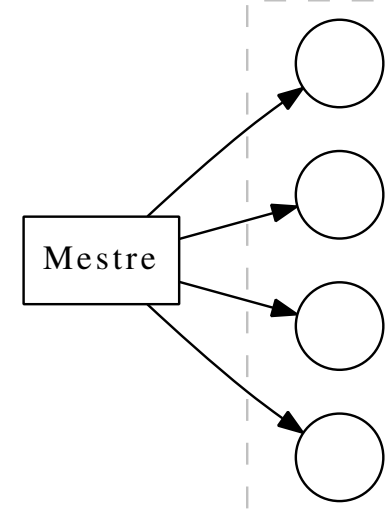

Escravos

Figura 4.8: Arquitetura mestre/escravo

$\mathrm{Na}$ implementação utilizada, a comunicação entre os processos ocorre diretamente através de um protocolo próprio que trafega diretamente via TCP/IP. Ao ser inicializado, o mestre recebe os dados com informações sobre todos os escravos dis- 
poníveis e suas respectivas informações para conexão (endereço e porta). Como o sistema foi projetado para ser executado em um ambiente confiável, nenhuma forma de autenticação foi considerada para o $\mathrm{PS}_{2} \mathrm{E}_{2}$, embora o Parallel Python já implemente a troca de uma chave de segurança por padrão.

No $\mathrm{PS}_{2} \mathrm{E}_{2}$ a execução de todos os passos da simulação é de responsabilidade do processo mestre. Ele centraliza os dados da simulação e requisita os processos escravos apenas durante o processo de interação dos agentes. Assim, com o intuito de diminuir a quantidade de dados transmitidos, o processo mestre transmite apenas as informações sobre os agentes que o escravo deve processar, de acordo com o padrão de divisão preestabelecido.

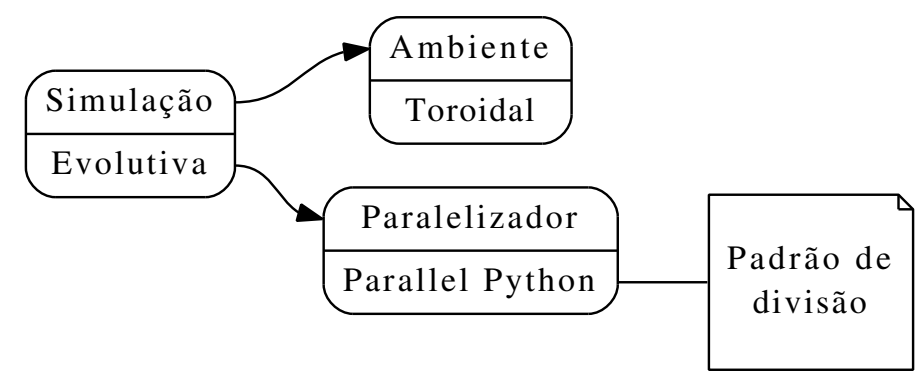

Figura 4.9: Associação do mecanismo de simulação com o paralelizador do $\mathrm{PS}_{\mathbf{2}} \mathrm{E}_{\mathbf{2}}$.

Ao contrário de prever o bloqueio do processo mestre enquanto os escravos trabalham, esta implementação faz com que o mestre indique a si próprio para ajudar no processamento dos dados, transformando-se em um dos escravos. Assim, independente da ordem de finalização das tarefas, o processo mestre aguarda todos os processos finalizarem suas respectivas tarefas, inclusive a si mesmo, antes de prosseguir a simulação. Uma vez que todos indicam a sua conclusão, o mestre solicita os resultados e reúne os fragmentos de informação novamente em um único ambiente.

O próximo capítulo apresenta os experimentos realizados com o sistema $\mathrm{PS}_{2} \mathrm{E}_{2}$ para avaliar a eficácia do método de paralelização proposto, bem como analisar o efeito da variação de alguns parâmetros no resultado da simulação do INPPD. 


\section{EXPERIMENTAÇÃO E TESTES}

\subsection{Descrição dos experimentos}

Para efeito de experimentação e análise dos resultados, foram realizadas diversas simulações utilizando o sistema $\mathrm{PS}_{2} \mathrm{E}_{2}$ apresentado no capítulo 4 . A experimentação foi divida em duas fases, detalhadas nas subseções seguintes. Cada uma delas planeja avaliar o impacto que a alteração dos parâmetros e da quantidade de processadores exerce sobre o sistema.

Para possibilitar a comparação dos resultados com trabalhos anteriores, os parâmetros considerados nos experimentos foram os mesmos utilizados por Bó (2008) e são os seguintes:

- $k$ representa o número de processadores envolvidos para a execução da simulação;

- $d$ representa a dimensão do reticulado;

- $g$ representa a quantidade de gerações;

- $P(\mathrm{~m})$ representa a probabilidade de mutação, ou seja, a probabilidade da estratégia ser alterada após a fase de reprodução;

- $P($ e) representa a probabilidade de erro de entendimento, ou seja, a probabilidade do jogador fazer uma jogada não condizente com a sua estratégia.

Cada bateria consiste na execução de 32 simulações de ambos modelos de representação de estratégias apresentados (AF e AFA). Essa quantidade de simulações foi escolhida arbitrariamente de modo que houvesse uma quantidade suficiente de dados para produzir informações estatísticas passíveis de análise. Após a execução da simulação, foram contabilizados os tempos de execução de cada tarefa, assim como a soma das utilidades dos agentes dispostos no reticulado.

Além destes, existem dois parâmetros que, embora presentes, não foram objetos de estudado neste trabalho: o custo de complexidade da estratégia e a número de iterações por geração. O custo de complexidade, é um peso agregado à estratégia do agente que beneficia aqueles que possuem estratégias com menor número de 
estados. O número de iterações por geração é a quantidade de vezes que os agentes jogam o INPPD para acumular sua utilidade fazendo uso de sua estratégia. Neste trabalho, o custo de complexidade da estratégia e o número de iterações por geração foram fixados em 0,002 e 150, respectivamente, mesmos valores utilizados no trabalho de Bó.

\subsection{Ambiente de testes}

Com o intuito de avaliar o desempenho obtido com a paralelização da simulação, 5 baterias foram executadas em um cluster cedido pelo Laboratório de Computação Científica Avançada da Universidade de São Paulo (LCCA-USP). O cluster utilizado é constituído por 59 servidores DELL ${ }^{\circledR}$ PowerEdge ${ }^{\circledR}$ 1950, com 2 processadores Intel ${ }^{\circledR}$ Xeon ${ }^{\circledR} 5430$ (4 núcleos de 2,66 GHz, 12 MB de cache L2 e barramento frontal de 1333 $\mathrm{MHz}$ ), 16 GB de RAM DDR2-FBDIMM de $667 \mathrm{MHz}$ e HD SAS de 300 GB. O cluster utiliza sistema operacional Scientific Linux SL release 5.4 (Boron), kernel 2.6.18164.11.1.el5_lustre.1.8.3 e utiliza o sistema de filas e escalonador TORQUE/PBS que garante a gerência e reserva dos recursos computacionais para que processos concorrentes não sejam executados simultaneamente no mesmo processador.

Os recursos do cluster foram reservados, de modo que o sistema distribuísse os processadores de forma homogênea entre os servidores de acordo com a sua disponibilidade. Portanto, considerando que cada servidor possui oito núcleos de processamento, as simulações que utilizam 2, 4 ou 8 processadores não foram necessariamente executadas em uma única máquina, embora exista uma probabilidade que isso tenha ocorrido. Em outras palavras, uma simulação que utiliza 8 processadores pode ter sido executada em um único servidor, assim como pode ter sido executada em oito servidores diferentes, utilizando um processador cada. De forma semelhante, as simulações que envolvem 16 ou 32 processadores foram executadas, no mínimo, em 2 ou 4 servidores, respectivamente, pois não existem servidores com essas quantidades de processadores.

O custo operacional gerado pela comunicação dos servidores não foi considerado neste trabalho. 


\subsection{Experimentos: Fase 1}

A Fase 1 teve o objetivo único de avaliar o ganho de desempenho obtido com a distribuição do processamento da interação dos agentes no reticulado nos processadores do cluster, isto é, utilizando-se o sistema $\mathrm{PS}_{2} \mathrm{E}_{2}$. Essa análise foi feita com a coleta dos tempos de execução das simulações realizadas com diferentes quantidades de processadores, com o intuito de calcular a eficiência do algoritmo.

Para tanto, foram executadas cinco baterias de simulações em cada um dos modelos (B.AF e B.AA). Todas as baterias foram compostas por 32 execuções de 5000 gerações do jogo em um reticulado de tamanho $50 \times 50$, onde todos os agentes iniciam com a estratégia TT5, interagem 150 vezes por geração, custo de complexidade de estratégia de 0,002, taxa de mutação e probabilidade de erro de $1 \%$. Tais valores representam o caso base de teste utilizado neste trabalho, idênticos aos utilizados por Bó, o que facilitou a verificação da corretude do algoritmo durante a fase de desenvolvimento.

Neste primeiro experimento, as cinco baterias se diferenciaram apenas na quantidade de processadores utilizados para a sua execução. A quantidade de processadores foi escolhida com base na disponibilidade de recursos no cluster fornecido; assim foram executadas simulações com 1, 2, 4, 8, 16 e 32 processadores. Na tabela 5.1 são descritos os parâmetros das baterias realizadas nesta fase.

Tabela 5.1: Baterias 01-06: Descrição dos experimentos realizados

\begin{tabular}{ccccccc}
\hline Bateria & $k$ & $d$ & $g$ & $P(\mathrm{~m})$ & $P(\mathrm{e})$ & Estratégia \\
\hline 01 & 1 & $50 \times 50$ & 5000 & $1 \%$ & $1 \%$ & TT5 \\
02 & 2 & $50 \times 50$ & 5000 & $1 \%$ & $1 \%$ & TT5 \\
03 & 4 & $50 \times 50$ & 5000 & $1 \%$ & $1 \%$ & TT5 \\
04 & 8 & $50 \times 50$ & 5000 & $1 \%$ & $1 \%$ & TT5 \\
05 & 16 & $50 \times 50$ & 5000 & $1 \%$ & $1 \%$ & TT5 \\
06 & 32 & $50 \times 50$ & 5000 & $1 \%$ & $1 \%$ & TT5 \\
\hline
\end{tabular}

\subsubsection{Efeito do número de processadores}

Os resultados obtidos com a execução das baterias nesta fase encontram-se listados nas tabelas 5.2 e 5.3, para os modelos B.AF e B.AA, respectivamente. O tempo exibido corresponde ao tempo real absoluto de execução da simulação (também chamado de 
tempo real). Com base na execução da Bateria 01 de cada modelo (que corresponde a execução do código em um único processador, isto é, a execução sequencial do código), calculou-se o fator de speedup e a eficiência do código executado.

Tabela 5.2: Baterias 01-06: Tempos médios de execução dos experimentos para o modelo B.AF

\begin{tabular}{|c|c|c|c|c|c|}
\hline \multirow{2}{*}{ Bateria } & \multirow{2}{*}{ k } & \multicolumn{2}{|c|}{ Tempo } & \multirow{2}{*}{ Speedup } & \multirow{2}{*}{ Eficiência } \\
\hline & & $\mu$ & $\sigma$ & & \\
\hline 01 & 1 & $11 \mathrm{~h} 24 \mathrm{~min}$. & $1 \mathrm{~h} 13 \mathrm{~min}$. & 1,0000 & 1,0000 \\
\hline 02 & 2 & 7 h 06 min. & $36 \mathrm{~min}$. & 1,6063 & 0,8032 \\
\hline 03 & 4 & 4 h 03 min. & $15 \mathrm{~min}$. & 2,8124 & 0,7031 \\
\hline 04 & 8 & 2 h 39 min. & $13 \mathrm{~min}$. & 4,3047 & 0,5381 \\
\hline 05 & 16 & 2 h 04 min. & $16 \mathrm{~min}$. & 5,5233 & 0,3452 \\
\hline 06 & 32 & $1 \mathrm{~h} 49 \mathrm{~min}$. & $13 \mathrm{~min}$. & 6,3008 & 0,1969 \\
\hline
\end{tabular}

Tabela 5.3: Baterias 01-06: Tempos médios de execução dos experimentos para o modelo B.AA

\begin{tabular}{|c|c|c|c|c|c|}
\hline \multirow{2}{*}{ Bateria } & \multirow{2}{*}{$k$} & \multicolumn{2}{|c|}{ Tempo } & \multirow{2}{*}{ Speedup } & \multirow{2}{*}{ Eficiência } \\
\hline & & $\mu$ & $\sigma$ & & \\
\hline 01 & 1 & 27 h 49 min. & $1 \mathrm{~h} 57 \mathrm{~min}$. & 1,0000 & 1,0000 \\
\hline 02 & 2 & $13 \mathrm{~h} 22 \mathrm{~min}$. & $2 \mathrm{~h} 20 \mathrm{~min}$. & 2,0816 & 1,0408 \\
\hline 03 & 4 & 7 h 49 min. & $46 \mathrm{~min}$. & 3,5571 & 0,8893 \\
\hline 04 & 8 & $5 \mathrm{~h} 15 \mathrm{~min}$. & $31 \mathrm{~min}$. & 5,2977 & 0,6622 \\
\hline 05 & 16 & 4h $05 \mathrm{~min}$. & $27 \mathrm{~min}$. & 6,8249 & 0,4265 \\
\hline 06 & 32 & $3 \mathrm{~h} 40 \mathrm{~min}$. & $19 \mathrm{~min}$. & 7,5732 & 0,2367 \\
\hline
\end{tabular}

O gráfico 5.1 exibe os tempos médios de execução das simulações. Sendo os valores obtidos comparados com o tempo de execução do código sequencial dividido pela quantidade de processadores nos dois modelos estudados (tempo linear).

No modelo B.AF, pode-se observar que o ganho de tempo obtido com o aumento de único processador foi de cerca de $38 \%$ e que este valor aumentou a medida que mais processadores foram adicionados, chegando a cerca de $84 \%$. O mesmo comportamento também pode ser observado no modelo B.AA, com cerca de $52 \%$ e $87 \%$ de ganho utilizando 2 e 32 processadores, respectivamente. Além disso, nos resultados do modelo B.AA foi observada a ocorrência de um speedup super linear quando 2 processadores foram utilizados.

Considerando que as baterias da fase 2 são compostas de simulações que compartilham características semelhantes, os resultados obtidos nesta fase foram utili- 


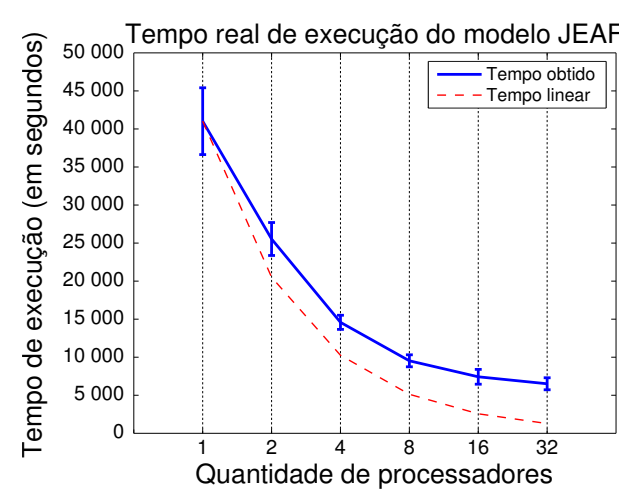

(a) B. AF

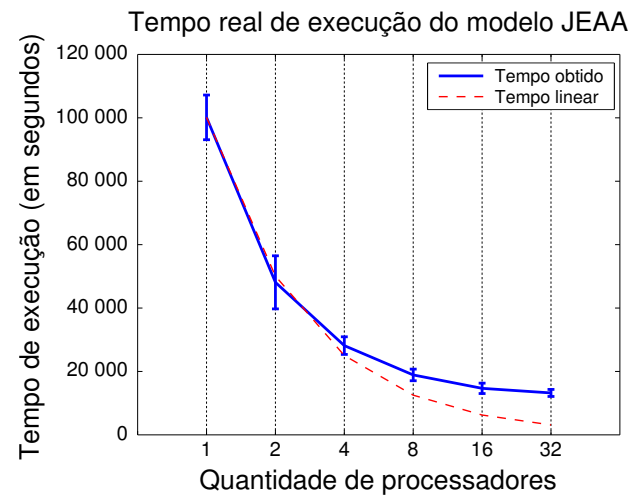

(b) B.AA

Gráfico 5.1: Baterias 01-06: Tempo médio de execução dos modelos B.AF e B.AA

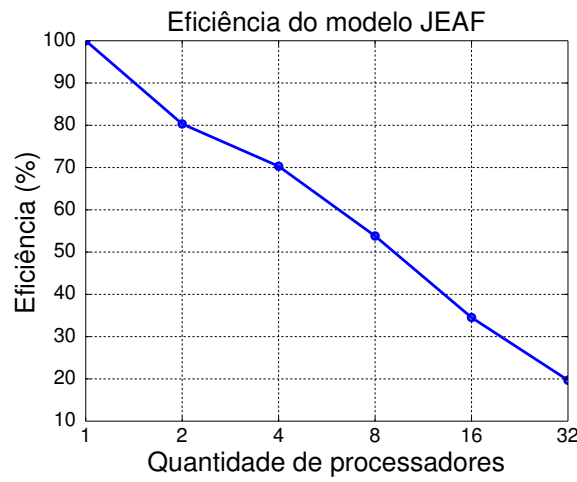

(a) B.AF

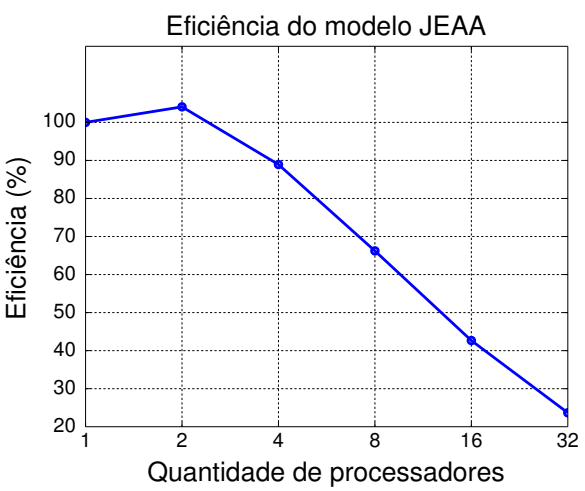

(b) B.AA

Gráfico 5.2: Baterias 01-06: Eficiência da execução dos modelos B.AF e B.AA

zados para determinar a quantidade de servidores a serem utilizados nas baterias subsequentes.

Dos 59 servidores disponíveis no cluster, 22 são dedicados para a execução de tarefas paralelas, totalizando 176 processadores (8 processadores por servidor). Como os recursos do cluster são compartilhados entre diversos usuários que executam tarefas distintas, a alocação dos recursos é feita através de uma estratégia de escalonamento por fração justa (fair-share scheduling) que, dada a demanda do servidor, não permite que um único usuário utilize mais do que 35\% de todos os recursos disponíveis, ou seja, 61 processadores. Além disso, o sistema também não permite que cada usuário mantenha mais do que 13 tarefas em execução simultaneamente, independente da quantidade de recursos alocados.

Considerando essas informações, o gráfico 5.3 exibe a estimativa do tempo de execução de cada um dos modelos em função da quantidade de processadores, dada a alocação de recursos no cluster. Esse gráfico apresenta o tempo total de execução 
de cada bateria, composta pela execução de 32 simulações distintas, considerando a disponibilidade e a forma como os recursos são alocados no servidor. Em ambos os gráficos, pode-se observar que a utilização de 4 processadores representa o menor tempo e, portanto, representa a melhor quantidade de processadores a ser utilizada para a execução das baterias da fase 2 .

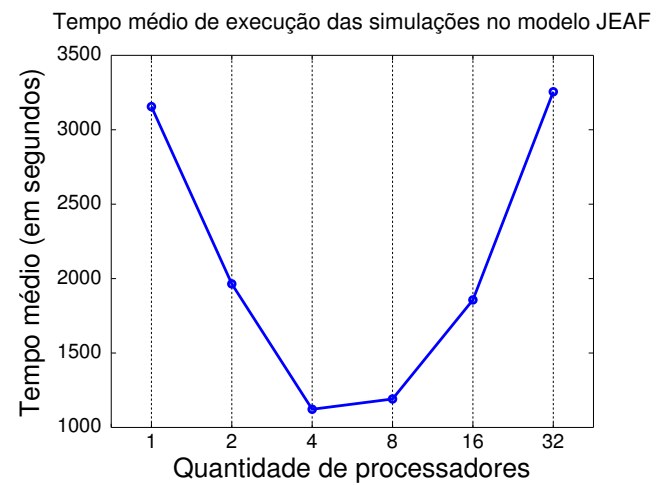

(a) B.AF

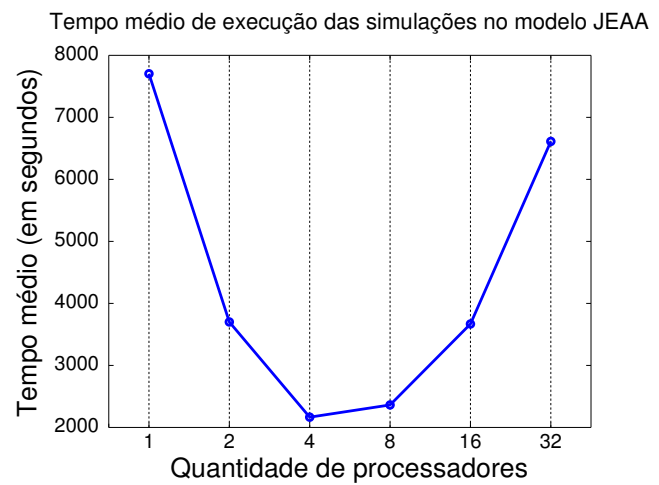

(b) B.AA

Gráfico 5.3: Estimativa do tempo de execução de uma bateria (32 simulações) dos modelos B.AF e B.AA. Este valor foi calculado utilizando o tempo médio de cara uma das simulações ajustado pela quantidade de tarefas que podem ser executadas simultaneamente no cluster.

\subsection{Experimentos: Fase 2}

A Fase 2 teve o objetivo de avaliar como a variação dos parâmetros da simulação influencia no seu resultado e desenvolvimento. Diversos parâmetros foram avaliados, conforme serão descritos nas seções subsequentes. Assim como na Fase 1, todas as baterias foram executadas 32 vezes em cada um dos modelos propostos e todos os valores apresentados representam a média calculada com os dados de todas as execuções.

Para avaliar o ganho obtido com cada parâmetro estudado, a soma da utilidade de todos agentes foi coletada em cada uma das gerações da simulação. Sendo $V_{a_{i j}}$ a utilidade do agente $a_{i j}$ em uma geração, a equação 5.1 descreve a função Utilidade que calcula a soma das utilidades dos agentes em uma geração. O valor final é divido pela quantidade de agentes no reticulado para facilitar a comparação de experimentos 
com diferentes quantidades de agentes.

$$
\text { Utilidade }(\mathbb{U})=\frac{\sum_{a_{i j} \in \mathbb{U}} V_{a_{i j}}}{|\mathbb{U}|}
$$

Neste trabalho optou-se por utilizar o teste da soma dos postos de Wilcoxon para aceitar ou rejeitar hipóteses estatísticas formuladas a partir dos dados obtidos. Essa escolha foi feita com base nos próprios dados que demonstraram não estarem normalmente distribuídos, conforme detalhado no apêndice $\mathrm{A}$.

O teste da soma dos postos de Wilcoxon é um teste de hipótese não paramétrico, isto é, é um teste que não está condicionado a uma distribuição de probabilidades. Trata-se de uma alternativa viável, em relação a outros testes, como o teste $t$ de Student, que condiciona sua eficácia a necessidade dos dados seguirem uma distribuição de probabilidades específica. $\mathrm{O}$ calculo desse teste se resume em determinar o valor $p$ e verificar se este é menor ou igual a um valor de significância estatística $\alpha$ estipulado. $O$ valor $p$ indica a probabilidade de se obter uma estatística igual ou maior àquelas observadas em uma amostra, assumindo verdadeira a hipótese nula.

Em todos os experimentos o valor $\alpha$ estimado é 0,05 , indicando que a hipótese nula é rejeitada sempre que o valor $p$ é inferior a este valor. Quando isso acontece, dizemos que a hipótese alternativa pode ser confirmada estatisticamente com $95 \%$ de certeza.

\subsubsection{Efeito do número de gerações}

O primeiro experimento dessa fase pretende determinar o quanto os resultados variam conforme a evolução natural do sistema. Diferentemente dos demais experimentos, este contém apenas uma bateria e os dados a serem analisados foram coletados a cada 5000 gerações. Os parâmetros desta bateria são detalhados na tabela 5.4 .

Tabela 5.4: Bateria 07: Descrição dos experimentos

\begin{tabular}{ccccccc}
\hline Bateria & $k$ & $d$ & $g$ & $P(\mathrm{~m})$ & $P(\mathrm{e})$ & Estratégia \\
\hline 07 & 4 & $50 \times 50$ & 20.000 & $1 \%$ & $1 \%$ & TT5 \\
\hline
\end{tabular}

O gráfico 5.4 exibe a utilidade média dos agentes com o desenvolvimento das gerações. Nesse gráfico, nota-se que o experimento que envolve autômatos finitos adaptativos garantiu aos agentes uma utilidade média superior em comparação à mesma 
simulação utilizando autômatos finitos, gerando uma utilidade média $22,78 \%, 18,32 \%$, $14,96 \%$ e 15,01\% maior nas gerações 5000, 10000,15000 e 20000, respectivamente.

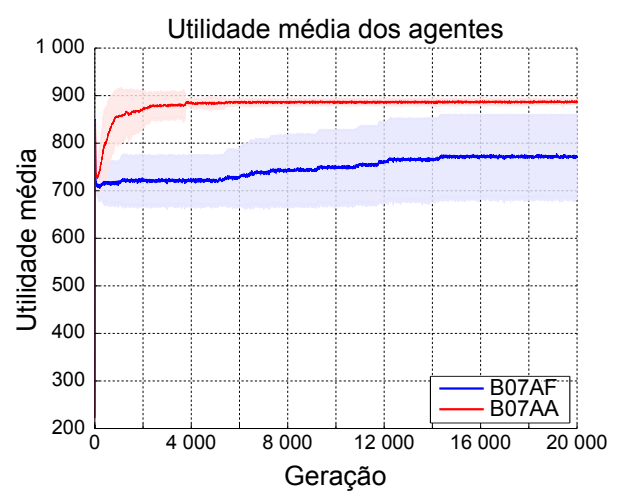

Gráfico 5.4: Bateria 07: Utilidade média do conjunto de agentes

Avaliando os gráficos, observamos que o sistema se estabiliza rapidamente no modelo B.AA de modo que após a geração 4000 já não é possível observar alterações significativas na utilidade média dos agentes. No entanto, o mesmo pode ser observado no modelo B.AF, onde é possível observar um crescimento sutil até a geração 16000 .

Hipótese A: A utilidade dos agentes aumenta com o passar das gerações.

Para validar essa hipótese, a expressamos matematicamente da seguinte forma:

$$
\text { Utilidade }\left(X_{1}\right)<\operatorname{Utilidade}\left(X_{2}\right)
$$

onde $X_{1}$ e $X_{2}$ representam uma amostra dos resultados obtidos em uma determinada geração. Fazemos assim a análise dos dados, dois a dois, a fim de verificar os intervalos onde nossa hipótese é aceita.

$$
\begin{aligned}
& H_{0}=\operatorname{Utilidade}\left(X_{1}\right) \geq \operatorname{Utilidade}\left(X_{2}\right) \\
& H_{A}=\operatorname{Utilidade}\left(X_{1}\right)<\operatorname{Utilidade}\left(X_{2}\right)
\end{aligned}
$$

Os resultados dos testes são exibidos na tabela 5.5 .

Como se pode observar, a hipótese nula não é rejeitada em nenhum experimento do modelo B.AA, mostrando que não há ganhos estatísticos significantes nesse modelo entre as gerações avaliadas. No modelo B.AF, por outro lado, o resultado dos testes mostrou que existe um ganho com o passar das gerações, provavelmente causados pela dificuldade que este modelo possui em se estabilizar. 
Tabela 5.5: Bateria 07: Resultados dos testes para a hipótese A

\begin{tabular}{ccccccc}
\hline \multirow{2}{*}{$X_{1}$} & \multirow{2}{*}{$X_{2}$} & $\alpha$ & \multicolumn{2}{c}{ B.AF } & \multicolumn{2}{c}{ B.AA } \\
\cline { 4 - 7 } & & & $p$ & $H_{0}$ & $p$ & $H_{0}$ \\
\hline 5000 & 10000 & 0,05 & 0,049 & Rejeita & 0,402 & Não rejeita \\
5000 & 15000 & 0,05 & 0,009 & Rejeita & 0,165 & Não rejeita \\
5000 & 20000 & 0,05 & 0,007 & Rejeita & 0,089 & Não rejeita \\
10000 & 15000 & 0,05 & 0,042 & Rejeita & 0,089 & Não rejeita \\
10000 & 20000 & 0,05 & 0,102 & Não rejeita & 0,105 & Não rejeita \\
15000 & 20000 & 0,05 & 0,445 & Não rejeita & 0,452 & Não rejeita \\
\hline
\end{tabular}

Com base nesses testes, optou-se por fixar os próximos experimentos em 5000 gerações pelo fato dos testes estatísticos do modelo B.AA terem indicado que esta é uma quantidade suficiente de gerações a se considerar e por esta ser uma quantidade de gerações ser viável de ser computada, em termos computacionais, dados os recursos disponíveis e a quantidade de experimentos propostos por este trabalho.

\subsubsection{Efeito do tamanho do reticulado}

As baterias seguintes tiveram o intuito de analisar as dimensões do reticulado influencia as estratégias produzidas pelos agentes. Aqui foram consideradas as dimensões de $50 \times 50$ e $128 \times 128$ que correspondem às dimensões utilizadas em Bó (2008) e Lindgren e Johansson (2003), respectivamente ${ }^{1}$. A parâmetros desse experimento são detalhados na tabela 5.6 .

Tabela 5.6: Baterias 08-09: Descrição dos experimentos

\begin{tabular}{ccccccc}
\hline Bateria & $k$ & $d$ & $g$ & $P(\mathrm{~m})$ & $P(\mathrm{e})$ & Estratégia \\
\hline 08 & 4 & $50 \times 50$ & 5000 & $1 \%$ & $1 \%$ & TT5 \\
09 & 8 & $128 \times 128$ & 5000 & $1 \%$ & $1 \%$ & TT5 \\
\hline
\end{tabular}

O gráfico 5.5 exibe as utilidades médias dos agentes obtidos com este experimento.

No modelo B.AA não foi possível observar uma grande diferença na utilidade média dos agentes, no entanto, no modelo B.AF nota-se um acréscimo considerável na utilidade média dos agentes quando o reticulado possui maiores dimensões, o que se

\footnotetext{
${ }^{1}$ sem prejuízo ao experimento, optou-se por aumentar a quantidade de processadores da Bateria 09 para 8 processadores a fim de reduzir o tempo de execução.
} 


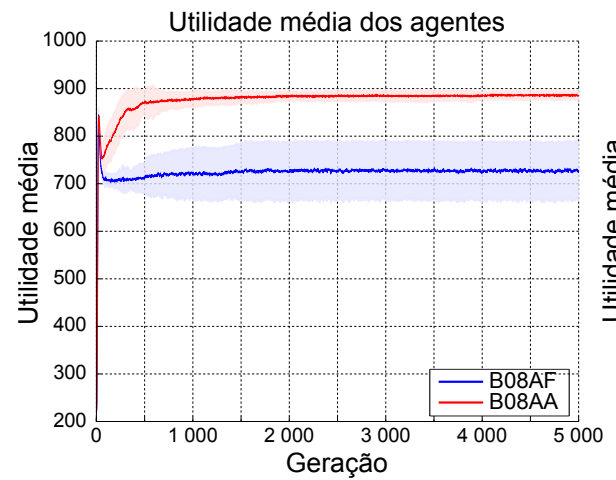

(a) Bateria 08

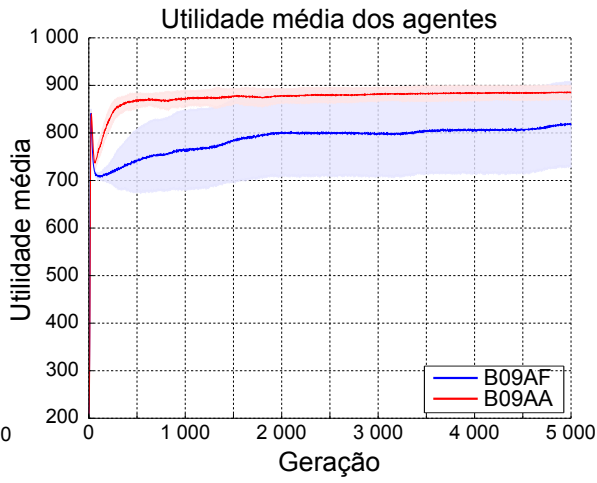

(b) Bateria 09

Gráfico 5.5: Baterias 08-09: Utilidade média do conjunto de agentes

deve à diversidade das estratégias produzidas pelo experimento ter facilitado a sua convergência.

Hipótese B: O aumento do tamanho do reticulado aumenta a utilidade do modelo.

Para validar essa hipótese, formulamos o teste da seguinte maneira:

$$
\begin{aligned}
& H_{0}=\operatorname{Utilidade}\left(X_{1}\right) \geq \operatorname{Utilidade}\left(X_{2}\right) \\
& H_{A}=\operatorname{Utilidade}\left(X_{1}\right)<\operatorname{Utilidade}\left(X_{2}\right)
\end{aligned}
$$

Os dados são são apresentados na tabela 5.7 .

Tabela 5.7: Baterias 08-09: Resultados dos testes para a hipótese B

\begin{tabular}{ccccccc}
\hline \multirow{2}{*}{$X_{1}$} & \multirow{2}{*}{$X_{2}$} & $\alpha$ & \multicolumn{2}{c}{ B.AF } & \multicolumn{2}{c}{ B.AA } \\
\cline { 4 - 7 } & & & $p$ & $H_{0}$ & $p$ & $H_{0}$ \\
\hline B08 & B09 & 0,05 & 0,001 & Rejeita & 0,805 & Não rejeita \\
\hline
\end{tabular}

Neste teste, a hipótese de que a utilidade do experimento do reticulado de menor dimensão (B08) é maior do que no experimento com maiores dimensões foi rejeitada no modelo B.AF mas não foi rejeitada no modelo B.AA.

Entende-se que esse resultado é inconclusivo para determinar um bom tamanho para o reticulado, portanto, nos próximos experimentos optou-se por utilizar a dimensão $50 \times 50$, para equiparar os resultados com o modelo estudado por Bó (2008) e para não inviabilizá-los computacionalmente, devido a sua complexidade. 


\subsubsection{Efeito da estratégia inicial}

Com o objetivo de validar os resultados com os obtidos em Lindgren e Johansson (2003) e Bó (2008), outras baterias foram feitas onde as estratégias iniciais dos agentes são as estratégias U, TT5 e CCD, apresentadas na seção 3.2.1. Em adição aos experimentos apresentados em Bó (2008) citados no capítulo 3, foi inclusa uma bateria do modelo B.AA que investiga a evolução da cooperação numa simulação utilizando a estratégia TT5 como estratégia inicial, além disso, é preciso notar que o experimento envolvendo a estratégia inicial CCD só é aplicável ao modelo B.AA por conter transições com funções adaptativas. A tabela 5.8 descreve os parâmetros desse experimento.

Tabela 5.8: Baterias 10-12: Descrição dos experimentos

\begin{tabular}{ccccccc}
\hline Bateria & $k$ & $d$ & $g$ & $P(\mathrm{~m})$ & $P(\mathrm{e})$ & Estratégia \\
\hline 10 & 4 & $50 \times 50$ & 5000 & $1 \%$ & $1 \%$ & $\mathrm{U}$ \\
11 & 4 & $50 \times 50$ & 5000 & $1 \%$ & $1 \%$ & TT5 \\
12 & 4 & $50 \times 50$ & 5000 & $1 \%$ & $1 \%$ & $\mathrm{CCD}^{\star}$ \\
\hline
\end{tabular}

$\star$ Somente se aplica ao modelo B.AA.

O gráfico 5.6 exibe a utilidade média dos agentes nos experimentos realizados.

Quando a estratégia inicial U foi utilizada, o sistema não foi capaz de desenvolver uma grande quantidade de estratégias no modelo B.AF, o que impediu o crescimento da utilidade dos agentes. No entanto, no modelo B.AA foi observado um crescimento na utilidade média, que foi se acentuando com o passar das gerações. Apesar da diversidade proporcionada pelos AFAs ao sistema, notou-se que este também teve dificuldades em desenvolver novas estratégias que aumentassem a utilidade dos agentes o que gerou um comportamento diferente na curva de utilidade desse modelo, em comparação com às demais baterias.

Por outro lado, com a estratégia inicial CCD observou-se um comportamento crescente na utilidade média dos agentes, sem picos nas primeiras gerações, embora a estratégia inicial TT5 tenha garantido uma utilidade média 5,9\% maior na geração 5000 . 


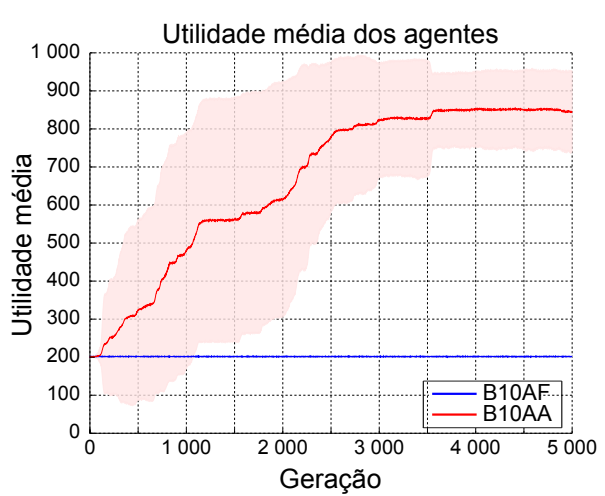

(a) Bateria 10

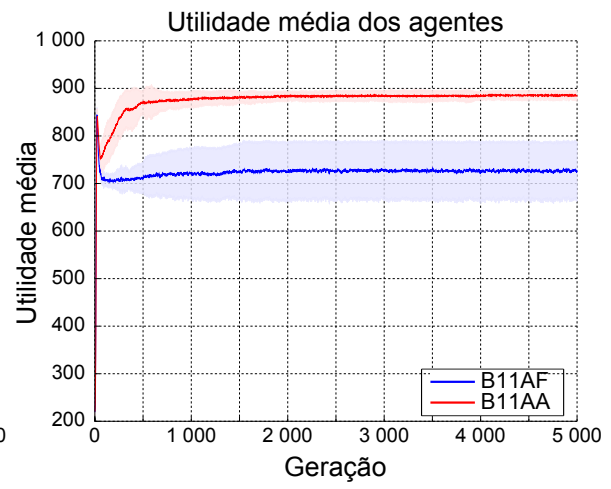

(b) Bateria 11

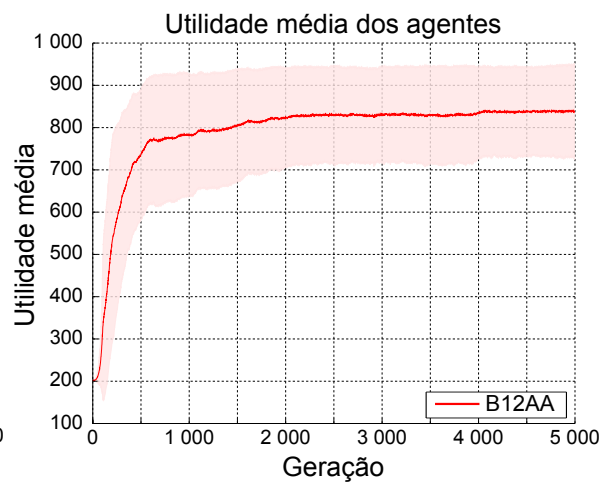

(c) Bateria 12

Gráfico 5.6: Baterias 10-12: Utilidade média do conjunto de agentes

Hipótese C: A variação da estratégia inicial aumenta a utilidade do modelo.

$$
\begin{aligned}
& H_{0}=\operatorname{Utilidade}\left(X_{1}\right) \geq \operatorname{Utilidade}\left(X_{2}\right) \\
& H_{A}=\operatorname{Utilidade}\left(X_{1}\right)<\operatorname{Utilidade}\left(X_{2}\right)
\end{aligned}
$$

Os resultados dos testes são exibidos na tabela 5.9 .

Tabela 5.9: Baterias 10-12: Resultados dos testes para a hipótese C

\begin{tabular}{ccccccc}
\hline \multirow{2}{*}{$X_{1}$} & \multirow{2}{*}{$X_{2}$} & $\alpha$ & \multicolumn{2}{c}{ B.AF } & \multicolumn{2}{c}{ B.AA } \\
\cline { 4 - 7 } & & & $p$ & $H_{0}$ & $p$ & $H_{0}$ \\
\hline B10 & B11 & 0,05 & $<0,001$ & Rejeita & $<0,001$ & Rejeita \\
B10 & B12 & 0,05 & N/A & N/A & 0,603 & Não rejeita \\
B11 & B12 & 0,05 & N/A & N/A & 0,999 & Não rejeita \\
\hline
\end{tabular}

Neste caso, nota-se que os experimentos que iniciaram utilizando a estratégia TT5 (B11) tive o melhor desempenho, pois foi rejeitada a hipótese de que o experimento B10 resultaria em uma utilidade melhor, ao mesmo tempo que não foi rejeitada a hipótese de que o experimento B11 seria maior ou igual ao experimento B12. A estratégia inicial $U$ (B10) teve o pior desempenho, pois todos os experimentos que iniciaram utilizando essa estratégia tiveram uma utilidade inferior.

\subsubsection{Efeito da probabilidade de mutação}

Com o objetivo de aumentar a diversidade da população e observar o seu efeito, algumas baterias foram inclusas variando a probabilidade de mutação. Como novas estratégias são geradas apenas através da mutação, esse se torna um parâmetro importante no estudo deste modelo, pois é ele quem garante a evolução do sistema. Os 
experimentos variando este parâmetro são descritos na tabela 5.10 .

Tabela 5.10: Baterias 13-14: Descrição dos experimentos realizados

\begin{tabular}{ccccccc}
\hline Bateria & $k$ & $d$ & $g$ & $P(\mathrm{~m})$ & $P(\mathrm{e})$ & Estratégia \\
\hline 13 & 4 & $50 \times 50$ & 5000 & $1 \%$ & $1 \%$ & TT5 \\
14 & 4 & $50 \times 50$ & 5000 & $2 \%$ & $1 \%$ & TT5 \\
15 & 4 & $50 \times 50$ & 5000 & $3 \%$ & $1 \%$ & TT5 \\
16 & 4 & $50 \times 50$ & 5000 & $5 \%$ & $1 \%$ & TT5 \\
17 & 4 & $50 \times 50$ & 5000 & $10 \%$ & $1 \%$ & TT5 \\
\hline
\end{tabular}

Tanto no modelo B.AF quanto no modelo B.AA, o aumento da taxa de mutação não influenciou positivamente a utilidade média dos agentes, pois foi observada uma utilidade menor em ambos os casos quando a taxa de mutação de $2 \%$ foi utilizada.

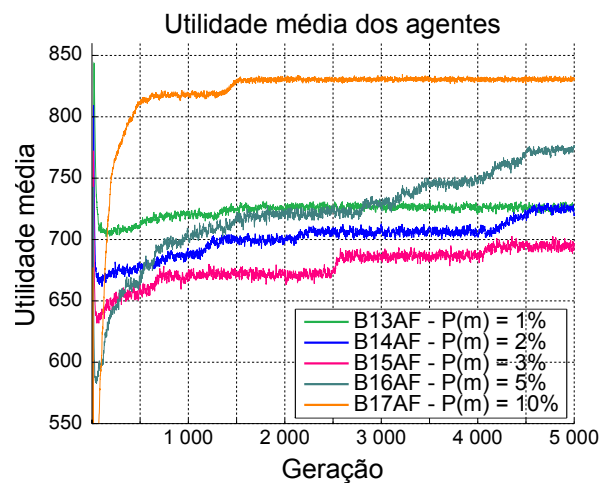

(a) B.AF

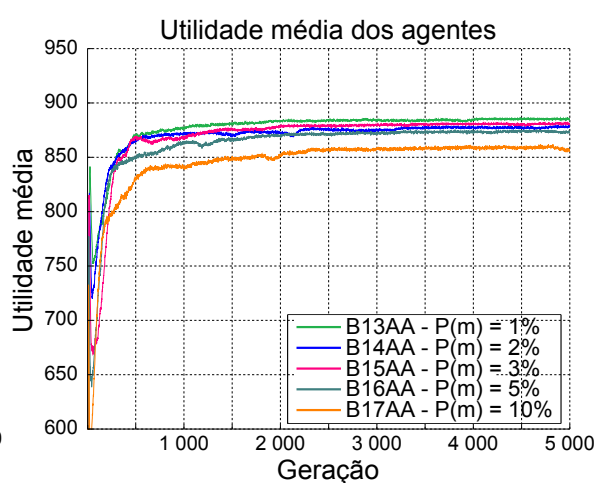

(b) B.AA

Gráfico 5.7: Bateria 13-17: Utilidade média do conjunto de agentes nos modelos B.AF e B.AA

Hipótese D: $\quad$ O aumento da probabilidade de mutação aumenta a utilidade do modelo.

$$
\begin{aligned}
& H_{0}=\operatorname{Utilidade}\left(X_{1}\right) \geq \operatorname{Utilidade}\left(X_{2}\right) \\
& H_{A}=\operatorname{Utilidade}\left(X_{1}\right)<\operatorname{Utilidade}\left(X_{2}\right)
\end{aligned}
$$

Os resultados dos testes são exibidos na tabela 5.11 .

Os dados deste experimento mostraram que o aumento na probabilidade de mutação afetou o modelo B.AA; por outro lado, o mesmo não foi constatado no modelo B.AF. Neste, o aumento da probabilidade evidentemente atuou como facilitador ao desenvolvimento de novas estratégias que garantiram o aumento na utilidade total da população. 
Tabela 5.11: Baterias 13-17: Resultados dos testes para a hipótese D

\begin{tabular}{|c|c|c|c|c|c|c|}
\hline \multirow{2}{*}{$X_{1}$} & \multirow{2}{*}{$x_{2}$} & \multirow{2}{*}{$\alpha$} & \multicolumn{2}{|c|}{ B.AF } & \multicolumn{2}{|r|}{ B. AA } \\
\hline & & & $p$ & $H_{0}$ & $p$ & $H_{0}$ \\
\hline B13 & B14 & 0,05 & 1,000 & Não rejeita & 1,000 & Não rejeita \\
\hline B13 & B15 & 0,05 & 1,000 & Não rejeita & 1,000 & Não rejeita \\
\hline B13 & B16 & 0,05 & 0,083 & Não rejeita & 1,000 & Não rejeita \\
\hline B13 & B17 & 0,05 & $<0,001$ & Rejeita & 1,000 & Não rejeita \\
\hline B14 & B15 & 0,05 & 0,999 & Não rejeita & 0,840 & Não rejeita \\
\hline B14 & B16 & 0,05 & 0,450 & Não rejeita & 0,999 & Não rejeita \\
\hline B14 & B17 & 0,05 & 0,001 & Rejeita & 1,000 & Não rejeita \\
\hline B15 & B16 & 0,05 & 0,195 & Não rejeita & 1,000 & Não rejeita \\
\hline B15 & B17 & 0,05 & $<0,001$ & Rejeita & 1,000 & Não rejeita \\
\hline B16 & B17 & 0,05 & 0,995 & Não rejeita & 1,000 & Não rejeita \\
\hline
\end{tabular}

\subsubsection{Efeito da probabilidade de erro de entendimento}

Por fim, é avaliada a variação na probabilidade de erro de entendimento. A alteração nesse parâmetro é especialmente interessante por ser o único parâmetro que exerce influencia sobre a fase de reprodução do agente. Foram feitos experimentos com $0 \%$, $1 \%, 2 \%, 5 \%$ e $10 \%$ de probabilidade de erro, sendo que $0 \%$ representa a situação em que o agente sempre joga de acordo com a sua estratégia (não erra). A tabela 5.12 detalham os parâmetros desse experimento.

Tabela 5.12: Baterias 18-22: Descrição dos experimentos realizados

\begin{tabular}{ccccccc}
\hline Bateria & $k$ & $d$ & $g$ & $P(\mathrm{~m})$ & $P(\mathrm{e})$ & Estratégia \\
\hline 18 & 4 & $50 \times 50$ & 5000 & $1 \%$ & $0 \%$ & TT5 \\
19 & 4 & $50 \times 50$ & 5000 & $1 \%$ & $1 \%$ & TT5 \\
20 & 4 & $50 \times 50$ & 5000 & $1 \%$ & $2 \%$ & TT5 \\
21 & 4 & $50 \times 50$ & 5000 & $1 \%$ & $5 \%$ & TT5 \\
22 & 4 & $50 \times 50$ & 5000 & $1 \%$ & $10 \%$ & TT5 \\
\hline
\end{tabular}

O gráfico 5.8 exibe a utilidade média obtida pelos agentes nos modelos estudados. No modelo B.AF, a probabilidade de erro de $2 \%$ foi a que gerou a maior utilidade média, que é $12,74 \%$ maior que a menor utilidade média obtida (probabilidade de erro de $10 \%)$.

Já no modelo B.AA, a utilidade média dos agentes diminuiu a medida que a probabilidade de erro foi aumentada, sendo que a maior utilidade foi obtida no experimento em que os agentes não erravam a sua jogada ( $0 \%$ de probabilidade de erro), sendo 
$21,81 \%$ maior que a menor utilidade média obtida (probabilidade de erro de $10 \%$ ).

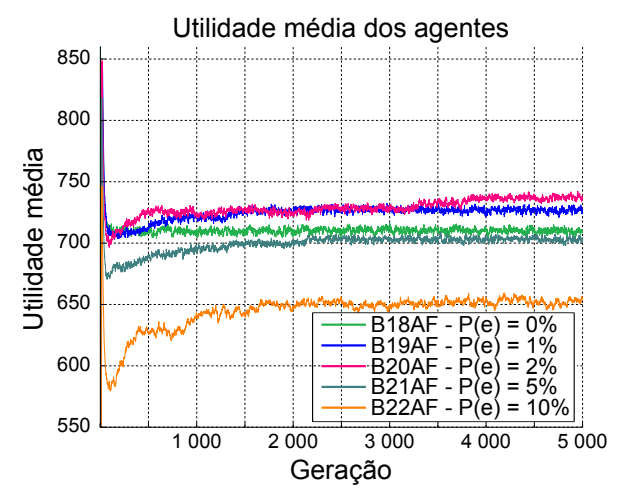

(a) B.AF

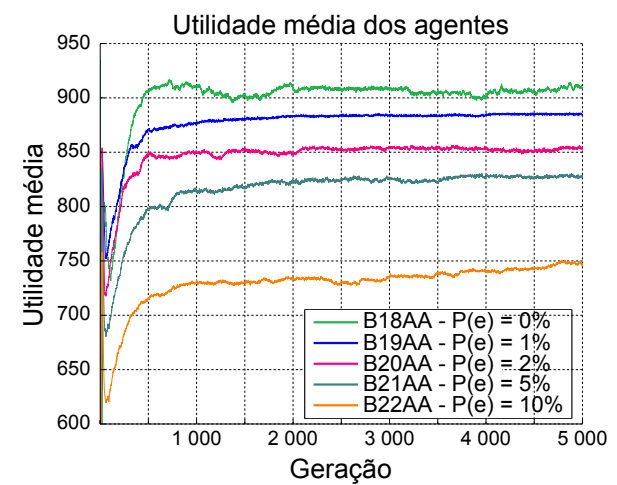

(b) B.AA

Gráfico 5.8: Baterias 18-22: Utilidade média do conjunto de agentes nos modelos B.AF e B.AA

Hipótese E: $\quad$ aumento da probabilidade de erro de entendimento aumenta a utilidade do modelo.

$$
\begin{aligned}
& H_{0}=\operatorname{Utilidade}\left(X_{1}\right) \geq \operatorname{Utilidade}\left(X_{2}\right) \\
& H_{A}=\operatorname{Utilidade}\left(X_{1}\right)<\operatorname{Utilidade}\left(X_{2}\right)
\end{aligned}
$$

Os resultados dos testes são exibidos na tabela 5.13 .

Tabela 5.13: Baterias 18-22: Resultados dos testes para a hipótese E

\begin{tabular}{lcccccc}
\hline \multirow{2}{*}{$X_{1}$} & \multirow{2}{*}{$X_{2}$} & $\alpha$ & \multicolumn{2}{c}{ B.AF } & \multicolumn{2}{c}{ B.AA } \\
\cline { 4 - 7 } & & & $p$ & $H_{0}$ & $p$ & $H_{0}$ \\
\hline B18 & B19 & 0,05 & 0,944 & Não rejeita & 1,000 & Não rejeita \\
B18 & B20 & 0,05 & 0,921 & Não rejeita & 1,000 & Não rejeita \\
B18 & B21 & 0,05 & 0,997 & Não rejeita & 1,000 & Não rejeita \\
B18 & B22 & 0,05 & 0,668 & Não rejeita & 1,000 & Não rejeita \\
B19 & B20 & 0,05 & 0,628 & Não rejeita & 1,000 & Não rejeita \\
B19 & B21 & 0,05 & 1,000 & Não rejeita & 1,000 & Não rejeita \\
B19 & B22 & 0,05 & 0,892 & Não rejeita & 1,000 & Não rejeita \\
B20 & B21 & 0,05 & 1,000 & Não rejeita & 1,000 & Não rejeita \\
B20 & B22 & 0,05 & 0,988 & Não rejeita & 1,000 & Não rejeita \\
B21 & B22 & 0,05 & 0,977 & Não rejeita & 1,000 & Não rejeita \\
\hline
\end{tabular}

Esses resultados mostram com alto nível de certeza que o aumento na probabilidade de erro de entendimento afeta negativamente a utilidade da população em ambos os modelos. 


\subsubsection{Efeito da expressividade do modelo}

Por fim, encerramos os experimentos da fase 2 verificando a influência da complexidade do formalismo de representação das estratégias. Esse experimento utiliza como referência todos os experimentos da fase 2, que compreende as baterias 07 a 22 .

Hipótese F: A utilização de AFAs para a representação das estratégias aumenta a utilidade do modelo em relação à utilização de AFs.

$$
\begin{aligned}
& H_{0}=\operatorname{Utilidade}\left(X_{1}\right) \geq \operatorname{Utilidade}\left(X_{2}\right) \\
& H_{A}=\operatorname{Utilidade}\left(X_{1}\right)<\operatorname{Utilidade}\left(X_{2}\right)
\end{aligned}
$$

Os resultados dos testes são exibidos na tabela 5.14 .

Tabela 5.14: Baterias 07-22: Resultados dos testes para a hipótese F

\begin{tabular}{cccc}
\hline Bateria & $\alpha$ & $p$ & $H_{0}$ \\
\hline 07 & 0,05 & $<0,001$ & Rejeita \\
08 & 0,05 & $<0,001$ & Rejeita \\
09 & 0,05 & $<0,001$ & Rejeita \\
10 & 0,05 & $<0,001$ & Rejeita \\
11 & 0,05 & $<0,001$ & Rejeita \\
12 & N/A & N/A & N/A \\
13 & 0,05 & $<0,001$ & Rejeita \\
14 & 0,05 & $<0,001$ & Rejeita \\
\hline
\end{tabular}

\begin{tabular}{cccc}
\hline Bateria & $\alpha$ & $p$ & $H_{0}$ \\
\hline 15 & 0,05 & $<0,001$ & Rejeita \\
16 & 0,05 & $<0,001$ & Rejeita \\
17 & 0,05 & $<0,001$ & Rejeita \\
18 & 0,05 & $<0,001$ & Rejeita \\
19 & 0,05 & $<0,001$ & Rejeita \\
20 & 0,05 & $<0,001$ & Rejeita \\
21 & 0,05 & $<0,001$ & Rejeita \\
22 & 0,05 & $<0,001$ & Rejeita \\
\hline
\end{tabular}

Aqui podemos ver claramente que a utilização dos AFAs para a representação das estratégias resultou em um aumento na utilidade total da população em todos os experimentos estudados, o que nos leva a concluir que a utilização de mecanismos mais complexos para a representação das estratégias influencia positivamente no ganho da sociedade.

No próximo capítulo, detalharemos as conclusões obtidas com a realização desse trabalho, assim como a proposta de possíveis extensões desse projeto. 


\section{CONCLUSÕES}

Neste trabalho, foi projetado e desenvolvido o Sistema Paralelo de Simulação Evolutiva Espacial $\left(\mathrm{PS}_{2} \mathrm{E}_{2}\right)$, uma reimplementação do Sistema de Simulação Evolutiva Espacial $\left(\mathrm{S}_{2} \mathrm{E}_{2}\right)$, proposto por Bó (2008), utilizando computação paralela evolutiva para o estudo da cooperação no INPPD com cinco jogadores. Para tal, foi elaborada uma nova arquitetura para o sistema, garantindo uma melhor escalabilidade com uso eficiente dos recursos computacionais.

Ainda com o intuito de dar continuidade aos estudos sobre a influência da complexidade da representação das estratégias no INPPD, experimentos foram propostos para validar as conclusões obtidas anteriormente e permitindo ainda que novas conclusões fossem elaboradas. Com base nos resultados obtidos com os experimentos, retomamos aqui as perguntas feitas no início deste trabalho.

1. Existem vantagens em realizar simulações do Dilema do Prisioneiro com $n$ jogadores em ambientes de processamento paralelo?

Nos experimentos realizados neste trabalho, houve uma redução significativa no tempo total de execução das simulações. No entanto, é preciso observar o tamanho da população que se objetiva estudar, pois simulações de populações muito pequenas podem gerar muita carga e não são capazes de extrair benefícios do sistema paralelo.

2. É possível haver cooperação no longo prazo entre diversos agentes onde há um estímulo individual para a não cooperação? Como este processo é atingido? (BÓ, 2008)

Sim, em todos os casos estudados neste trabalho, assim como nos trabalhos anteriores, notou-se que o sistema é capaz de produzir estratégias cooperativas.

3. Existem vantagens na utilização de modelos mais complexos de representação de estratégias?

Em todas os experimentos realizados com AFAs para a representação das estratégias, observou-se que o desenvolvimento e a estabilização da utilidade total dos agentes ocorreu mais rápido do que as observadas com AFs. Além disso, o teste da hipótese F mostrou, em todos os casos estudados, que o ganho do 
modelo que utilizava AFAs foi estatisticamente maior do que aquele que utilizava AFs.

4. Quais parâmetros influenciam na utilidade da sociedade? De que forma?

Muitos dos parâmetros estudados apresentaram influência significativa na utilidade obtida pelos agentes, em especial com relação ao modo como a convergência se estabiliza. Por exemplo, na simulação com AFs utilizando a estratégia inicial U, nenhuma cooperação pôde ser observada, sendo que os agentes mantiveram suas estratégias não cooperativas ao longo de todas gerações. Por outro lado, a simples alteração desta para uma estratégia mais elaborada, como o TT5, foi capaz de garantir a convergência do sistema. De um modo geral, acredita-se que são necessários mecanismos que garantam a diversificação das estratégias, como o aumento da taxa de mutação ou a inicialização do sistema com estratégias mais complexas, para atuar como facilitadores que auxiliarão na convergência do sistema para um estado estável de cooperação.

Além do desenvolvimento do protótipo computacional, este trabalho gerou as publicações Macedo e Sichman (2010) e Guerberoff, Queiroz e Sichman (2011).

Para a continuidade desse trabalho, propõe-se a melhoria da gerência dos dados produzidos pelo sistema de simulação, por exemplo utilizando identificadores únicos para nomear as simulações. Além disso, para possibilitar a reprodução dos experimentos, as sementes geradoras de números pseudoaleatórios poderiam ser armazenadas para futuras reexecuções.

Com o intuito de avaliar outros aspectos importantes do modelo que não foram explorados por este trabalho, propõe-se ainda como trabalhos futuros:

1. Analisar os tipos de estratégias produzidas pelo sistema;

2. Explorar outros métodos de paralelização, como por exemplo distribuir a população em ilhas;

3. Utilização de modelos probabilísticos para representação das estratégias, como cadeias de Markov, e eventualmente incorporando o paradigma adaptativo nestes novos modelos;

4. Investigar as características das estratégias necessárias para que o sistema garanta a manutenção da cooperação. 


\section{REFERÊNCIAS BIBLIOGRÁFICAS}

ALMASI, G.; GOTTLIEB, A. Highly Parallel Computing. Redwood City, CA: BenjaminCummings, 1989.

AXELROD, R. The Evolution of Cooperation. New York: Basic Books, 1984.

BÓ, I. G. L. Influência da complexidade da representação de estratégias em modelos evolucionários para o Dilema do Prisioneiro com $n$ jogadores. Dissertação (Mestrado) — Universidade de São Paulo, São Paulo, 2008.

BONDI, A. B. Characteristics of scalability and their impact on performance. In: Proceedings of the 2nd international workshop on Software and performance. New York, NY, USA: ACM, 2000. (WOSP '00), p. 195-203. ISBN 1-58113-195-X.

BOYD, R.; RICHERSON, P. The evolution of reciprocity in sizable groups. Journal of Thermal Biology, v. 132, n. 3, p. 337-356, 1988.

BRESLAU, K.; HERON, K. The Debriefing: Bill Clinton. San Francisco, CA: Condé Nast Publications, December 2000. Wired Magazine, 8.12. [Online; accessed on 15April-2010]. Disponível em: <http://www.wired.com/wired/archive/8.12/clinton.html $>$.

CAMPOS, G. G. de; YOSHIZAKI, H. T. Y.; BELFIORE, P. P. Algoritmos genéticos e computação paralela para problemas de roteirização de veículos com janela de tempo e entregas fracionadas. Gestão \& Produção, v. 13, n. 2, p. 271-281, mai-ago 2006.

DAWKINS, R. The Selfish Gene. [S.I.]: Oxford University Press, 1989. ISBN 0-19286092-5.

El-Rewini, H.; Abd-El-Barr, M. Advanced Computer Architecture and Parallel Processing. [S.I.]: Wiley Series on Parallel and Distributed Computing, 2005.

ERIKSSON, A.; LINDGREN, K. Cooperation driven by mutations in multi-person prisoner's dilemma. Journal of Theoretical Biology, v. 232, n. 3, p. 399-409, 2005.

GLANCE, N. S.; HUBERMAN, B. A. The dynamics of social dilemmas. Scientific American, v. 270, n. 3, p. 76-81, March 1994.

GUÉANT, O.; LASRY, J.-M.; LIONS, P.-L. Mean field games and applications. In: ParisPrinceton Lectures on Mathematical Finance 2010. [S.I.]: Springer Berlin / Heidelberg, 2011, (Lecture Notes in Mathematics, v. 2003). p. 205-266. 10.1007/978-3-642-146602_3.

GUERBEROFF, I.; QUEIROZ, D.; SICHMAN, J. S. Studies on the effect of the expressiveness of two strategy representation languages for the iterated n-players prisoner's dilemma. Revue d'intelligence artificielle, v. 25, n. 1, p. 69-82, JanvierFévrier 2011. ISSN 0992-499X. Disponível em: $<$ http://ria.revuesonline.com/article.jsp?articleld=15967>. 
HAUERT, C.; SCHUSTER, $\mathrm{H}$. Effects of increasing the number of players and memory size in the iterated prisoner's dilemma: a numerical approach. Royal Society B: Biological Sciences, v. 264, n. 1381, p. 513-519, 1997.

KUMAR, V.; GRAMA, A.; GUPTA, A.; KARYPIS, G. Introduction to Parallel Computin: Design and Analysis of Algorithms. [S.I.]: The Benjamin/Cummings Publishing Company, Inc., 1994. ISBN 0-8053-3170-0.

LASRY, J.-M.; LIONS, P.-L. Jeux à champ moyen. i - le cas stationnaire. Comptes Rendus Mathematique, v. 343, n. 9, p. 619-625, 2006. ISSN 1631-073X. Disponível em: <http://www.sciencedirect.com/science/article/pii/S1631073X06003682>.

LASRY, J.-M.; LIONS, P.-L. Jeux à champ moyen. ii - horizon fini et contrôle optimal. Comptes Rendus Mathematique, v. 343, n. 10, p. 679-684, 2006. ISSN 1631-073X. Disponível em: <http://www.sciencedirect.com/science/article/pii/S1631073X06003670>.

LASRY, J.-M.; LIONS, P.-L. Mean field games. Japanese Journal of Mathematics, Springer Japan, v. 2, p. 229-260, 2007. ISSN 0289-2316. 10.1007/s11537-007-06578.

LEWIS, H. R.; PAPADIMITRIOU, C. H. Elements of the Theory of Computation. 2nd. ed. New Jersey: Bookman, 1998. ISBN 85-7307-534-1.

LINDGREN, K.; JOHANSSON, J. Co-evolution of strategies in n-person prisoner's dilemma. In: CRUTCHFIELD, J. P.; SCHUSTER, P. (Ed.). Evolutionary Dynamics: Exploring the Interplay of Selection, Neutrality, Accident, and Function. New York: Oxford University Press, 2003. p. 341-360. ISBN 0195142659. Disponível em: <http://citeseerx.ist.psu.edu/viewdoc/summary?doi=10.1.1.123.7042>.

LINDGREN, K.; NORDAHL, M. G. Evolutionary dynamics of spatial games. Physica $D$ : Nonlinear Phenomena, v. 75, n. 1-3, p. 292-309, 1994.

MACEDO, D. Q.; SICHMAN, J. S. Analysis of von neumann neighborhoods parallel simulations. In: Joint Conference 2010: Workshops. São Bernardo do Campo: Sociedade Brasileira de Computação, 2010. p. 93-104. ISBN 978-85-76692-50-8.

MATSUSHIMA, M.; IKEGAMI, T. Evolution of strategies in the three-person iterated prisoners dilemma game. Journal of Theoretical Biology, v. 195, n. 1, p. 53-67, 1998.

NETO, J. J. Adaptive rule-driven devices - general formulation and case study. In: Implementation and Application of Automata. [S.I.]: Springer Berlin / Heidelberg, 2002. (Lecture Notes in Computer Science, v. 2494), p. 466-470. ISSN 1611-3349.

PATTERSON, D. A.; HENNESSY, J. L. Computer Organization and Design. 2nd. ed. [S.I.]: Morgan Kaufmann Publishers, 1998. ISBN 15-586-0428-6.

PISTORI, H. Tecnologia Adaptativa em Engenharia de Computação: Estado da Arte e Aplicações. Tese (Doutorado) - Escola Politécnica da Universidade de São Paulo, São Paulo, SP, 2003. Disponível em: <http://www.teses.usp.br/teses/disponiveis/3/3141/tde-02032004-145107/>. 
PIT, L. J. Parallel Genetic Algorithms. Dissertação (Mestrado) — Leiden University, August 1995.

POUNDSTONE, W. Prisoner's dilemma. 1st. ed. New York: Anchor Books, 1992.

ROCHA, R. L. A. da; NETO, J. J. Autômato adaptativo, limites e complexidade em comparação com a máquina de turing. In: FACULDADE SENAC DE CIÊNCIAS EXATAS E TECNOLOGIA. Proceedings of the second Congress of Logic Applied to Technology (LAPTEC'2000). São Paulo, 2001. v. 1, p. 33-48.

ROOSTA, S. H. Parallel processing and parallel algorithms: theory and computation. [S.I.]: Springer, 2000. ISBN 0387987169.

RUSSELL, S. J.; NORVIG, P. Artificial Intelligence: A Modern Approach. 2nd. ed. [S.I.]: Prentice Hall, 2003. ISBN 0-13-790395-2.

SHY, O. Industrial Organization: Theory and Applications. [S.I.]: MIT Press, 1995.

SIPSER, M. Introdução à Teoria da Computação: Tradução da $2^{a}$ edição norteamericana (trad. Ruy José Guerra Barreto de Queiroz). São Paulo: Thomson Learning, 2007. ISBN 85-221-0499-9.

TUROCY, T. L.; STENGEL, B. von. Game Theory. [S.I.], October 2001.

VITALII, V. Parallel Python. 2005. Software. Disponível em: <http://www.parallelpython.com $>$.

WRIGHT, R. NonZero: the logic of human destiny. [S.I.]: Vintage Books, 2001. 


\section{GLOSSÁRIO}

Eficiência - Em computação paralela, é uma métrica de avaliação de desempenho e escalabilidade de sistema paralelos (KUMAR et al., 1994, p. 120). Ver seção 2.4 na página 37

Equilíbrio de Nash - Na teoria dos jogos, representa uma situação em que nenhum jogador pode melhorar seu resultado modificando apenas a sua estratégia.

Estratégia- Na teoria dos jogos, é um plano de ação que determina o comportamento do jogador para cada situação possível.

Geração- Na teoria da evolução, representa um ciclo de vida de um indivíduo ou mais indivíduos (ver população), basicamente compreendido pela seleção, reprodução e mutação dos envolvidos.

Granularidade-É um conceito empregado na divisão de sistemas que indica o quão dividido ele se encontra.

Hierarquia de Chomsky - Na teoria das Linguagens Formais, é uma forma de classificar gramáticas de acordo com a quantidade de regras de substituição permitidas para a produção de sentenças da linguagem.

Indivíduo- De acordo com o contexto estudado, um indivíduo pode assumir diversas formas e interpretações. No entanto, de uma forma geral, pode-se considerálo como sendo uma entidade composta por um conjunto de características e atributos distintos associados a uma identidade única.

Just In Time - Em compiladores, é o termo utilizado para um tradutor que converte instruções de um formato para outro em tempo de execução.

Overhead- Na informática, é o termo utilizado para qualquer processamento ou armazenamento em excesso, seja de tempo de computação, de memória, de largura de banda ou qualquer outro recurso que seja requerido para atingir uma meta específica.

Pareto eficiente - Na teoria dos jogos, um determinado resultado é considerado Pareto eficiente (ou ótimo de Pareto) se, e somente se, não existe um meio de um jogador melhorar a sua utilidade sem piorar o resultado dos demais jogadores. No Dilema do Prisioneiro, o resultado em que todos cooperam é Pareto eficiente. 
População- Em diversos contextos, representa o conjunto de indivíduos que possuem uma determinada característica que se deseja avaliar. Ver indivíduo.

Speedup - Em computação paralela, é uma métrica de avaliação de desempenho e escalabilidade de sistema paralelos (KUMAR et al., 1994, p. 118). Ver seção 2.4 na página 37.

Vizinhança- Em autômatos celulares, a vizinhança de uma célula é o conjunto de células que se conectam a ela.

Vizinhança estendida - Em autômatos celulares, a vizinhança estendida de uma célula são todas as células conectadas a ela e às suas vizinhas. A vizinhança estendida de uma vizinhança de von Neumann de ordem $x$ é a vizinhança de von Neumann de ordem $2 x$. 


\section{APÊNDICE A - TESTE DE NORMALIDADE}

Para verificar se os dados provinham de uma amostragem normalmente distribuída foi utilizado o teste de normalidade de Shapiro-Wilk.

Este teste considera que a hipótese de que a população está normalmente distribuída e tenta rejeitá-la. Para tanto, calcula-se o valor $p$ da amostra e, caso este seja menor que um valor $\alpha$ preestabelecido, a hipótese é rejeitada. Neste caso, considerase válida a hipótese alternativa, contrária à hipótese rejeitada.

Portanto, considerando que a hipótese nula $H_{0}$ indica que a amostra é normalmente distribuída e a hipótese alternativa $H_{A}$ indica o contrário, a tabela A.1 apresenta os resultados do teste para os dados obtidos no capítulo 5 .

Tabela A.1: Baterias 07-22: Resultados do teste de normalidade

\begin{tabular}{lcccccc}
\hline \multirow{2}{*}{ Bateria } & \multirow{2}{*}{ Geração } & $\alpha$ & \multicolumn{2}{c}{ B.AF } & \multicolumn{2}{c}{ B.AA } \\
\cline { 4 - 6 } & & & $p$ & $H_{0}$ & $p$ & $H_{0}$ \\
\hline 07 & 5000 & 0,05 & $<0,001$ & Rejeita & $<0,001$ & Rejeita \\
07 & 10000 & 0,05 & $<0,001$ & Rejeita & $<0,001$ & Rejeita \\
07 & 15000 & 0,05 & $<0,001$ & Rejeita & $<0,001$ & Rejeita \\
07 & 20000 & 0,05 & $<0,001$ & Rejeita & $<0,001$ & Rejeita \\
08 & 5000 & 0,05 & $<0,001$ & Rejeita & $<0,001$ & Rejeita \\
09 & 5000 & 0,05 & $<0,001$ & Rejeita & $<0,001$ & Rejeita \\
10 & 5000 & 0,05 & $<0,001$ & Rejeita & 0,594 & Não rejeita \\
11 & 5000 & 0,05 & $<0,001$ & Rejeita & $<0,001$ & Rejeita \\
12 & 5000 & 0,05 & $<0,001$ & Rejeita & $<0,001$ & Rejeita \\
13 & 5000 & 0,05 & $<0,001$ & Rejeita & $<0,001$ & Rejeita \\
14 & 5000 & 0,05 & $<0,001$ & Rejeita & $<0,001$ & Rejeita \\
15 & 5000 & 0,05 & $<0,001$ & Rejeita & $<0,001$ & Rejeita \\
16 & 5000 & 0,05 & $<0,001$ & Rejeita & $<0,001$ & Rejeita \\
17 & 5000 & 0,05 & 0,015 & Rejeita & $<0,001$ & Rejeita \\
18 & 5000 & 0,05 & 0,020 & Rejeita & $<0,001$ & Rejeita \\
19 & 5000 & 0,05 & $<0,001$ & Rejeita & $<0,001$ & Rejeita \\
20 & 5000 & 0,05 & $<0,001$ & Rejeita & 0,002 & Rejeita \\
21 & 5000 & 0,05 & $<0,001$ & Rejeita & 0,010 & Rejeita \\
22 & 5000 & 0,05 & $<0,001$ & Rejeita & $<0,001$ & Rejeita \\
\hline
\end{tabular}

Dado que a hipótese nula $H_{0}$ foi rejeitada em todos os experimentos (excetuandose um), conclui-se que os resultados obtidos com os experimentos não são normalmente distribuídos. 